\title{
DESENVOLVIMENTO E COMPARAÇÃO DE MÉTODOS PARA AVALIAÇÃO DA QUALIDADE FÍSICA DO SOLO
}

\author{
Tairone Paiva Leão
}

Engenheiro Agrônomo

Orientador: Prof. Dr. ÁLVARO PIRES DA SILVA

Tese apresentada à Escola Superior de Agricultura

"Luiz de Queiroz", Universidade de São Paulo, para obtenção do título de Doutor em Agronomia, Área de Concentração: Solos e Nutrição de Plantas.

P IR A C I C A B A

Estado de São Paulo - Brasil

Junho -2005 
Dados Internacionais de Catalogação na Publicação (CIP) DIVISĀO DE BIBLIOTECA E DOCUMENTAÇĀO - ESALQ/USP

\author{
Leão, Tairone Paiva \\ Desenvolvimento e comparação de métodos para avaliação da qualidade física do \\ solo / Tairone Paiva Leão. - - Piracicaba, 2005. \\ 105 p. : il. \\ Tese (doutorado) - - Escola Superior de Agricultura Luiz de Queiroz, 2005. \\ Bibliografia. \\ 1. Conservação do solo 2. Crescimento vegetal 3. Estatística aplicada 4. Física \\ do solo 5 . Manejo do solo 6 . Resistência dos solos I. Título
}

$\operatorname{CDD} 631.43$ 


\section{AGRADECIMENTOS}

Ao Professor Alvaro Pires da Silva pela orientação e principalmente pelo apoio amizade e incentivo ao longo dos últimos quatro anos.

Em especial à amiga Cláudia Milene por todo o apoio, amizade e ajuda ao longo do último ano. Aos amigos Afrânio, Aline Genu, Claudia Liane, Flavia Morales, Herdjania, Karina Cavalieri, Laércio, Simão, Tiago Osório, Valdomiro pela convivência, amizade e apoio.

Ao Dr. Ed Perfect da Universidade do Tennessee pela orientação e colaboração cientifica. Silvia Imhoff pelo apoio, amizade e colaboração científica. Cássio Tormena da Universidade de Maringá pela colaboração científica e amizade. Ao professor Paulo Libardi pelos ensinamentos em dinâmica de água e solutos no solo e pela amizade. Ao pesquisador Manuel Macedo da Embrapa Gado de Corte pela colaboração científica, amizade e incentivo ao longo dos últimos anos.

A minha mãe Tânia e minha irmã Tatiana pelo apoio e compreensão apesar de todas as dificuldades.

E finalmente a todos que direta ou indiretamente colaboraram na realização deste trabalho. 


\section{SUMÁRIO}

Página

RESUMO.................................................................................... vii

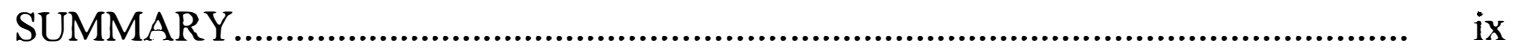

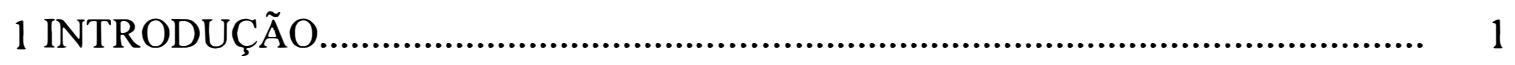

2 REVISÃO DE LITERATURA................................................................ 4

2.1 Qualidade do solo, sustentabilidade e seus indicadores.................................... 4

2.2 A curva de compressão como indicador da qualidade físico-estrutural do solo.... 9

2.3 Indicadores integrais da qualidade física do solo: intervalo hídrico ótimo.......... 18

2.4 Regressão não-linear como técnica auxiliar na quantificação de indicadores da qualidade física do solo................................................................................. 24

2.5 Parâmetros da curva de resistência à penetração do solo como indicadores de alterações na qualidade física do solo............................................................... 25

3 UM ALGORITMO SIMPLIFICADO, DESENVOLVIDO EM EXCEL ${ }^{\circledR}$, PARA ESTIMATIVA DO INTERVALO HÍDRICO ÓTIMO DOS SOLOS..................... 27

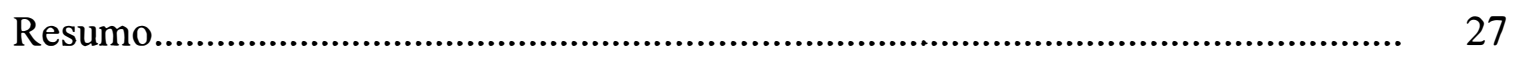

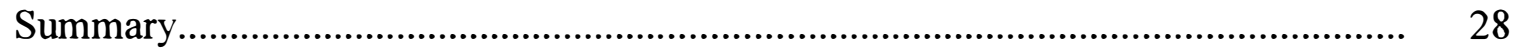

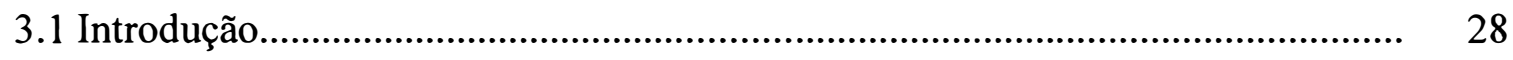

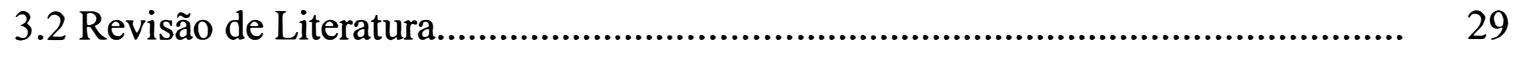

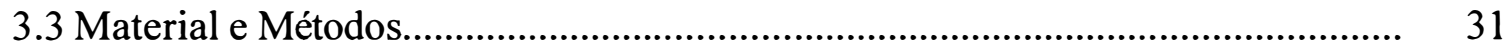

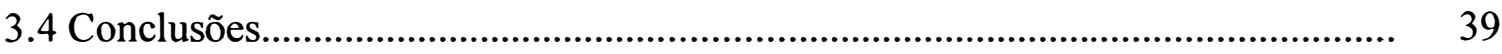

4 CÓDIGO SAS PARA QUANTIFICAÇÃO DO INTERVALO HÍDRICO ÓTIMO

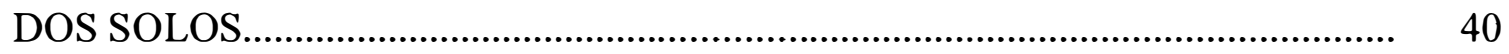

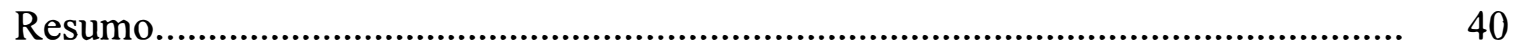

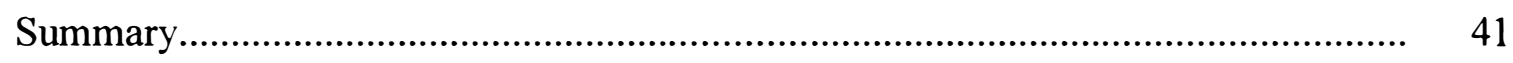




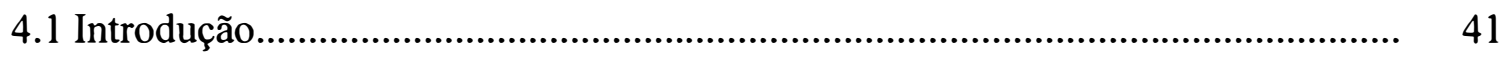

4.2 Revisão de Literatura.................................................................................. 43

4.3 Material e Métodos.................................................................................... 46

4.3.1 Dados de entrada...................................................................................... 46

4.3.2 Estimativa de parâmetros por regressão não-linear e cálculo do IHO............... 47

4.3.3 Estimativa da densidade crítica do solo............................................................ 50

4.3.4 Construção do gráfico................................................................................... 50

4.3.5 Exemplo de aplicação................................................................................... 51

4.4 Conclusão.............................................................................................. 53

5 MÉTODO ESTATÍSTICO-MATEMÁTICO PARA DETERMINAÇÃO DA PRESSÃO DE PRÉ-CONSOLIDAÇÃO DO SOLO.............................................. 55

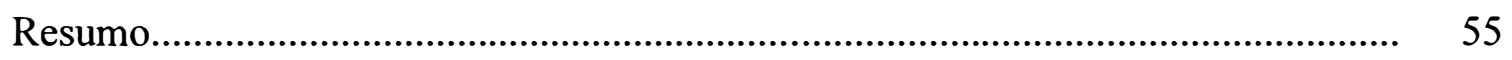

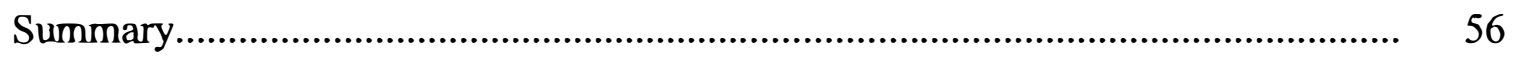

5.1 Introdução........................................................................................ 57

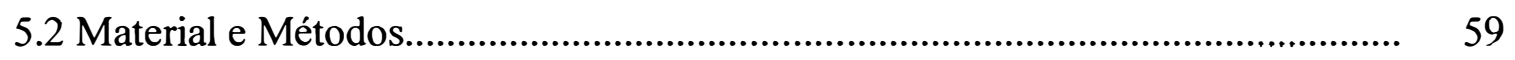

5.2.1 Descrição do algoritmo ................................................................................... 59

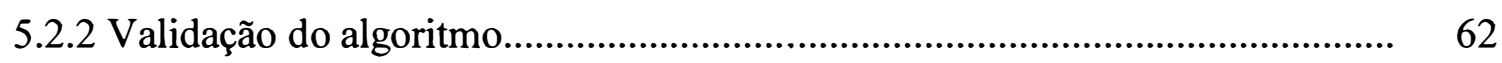

5.3 Resultados e Discussão.................................................................................. 63

5.3.1 Comparações quantitativas entre os métodos........................................................ 63

5.3.2 Avaliações qualitativas entre os métodos.......................................................... 66

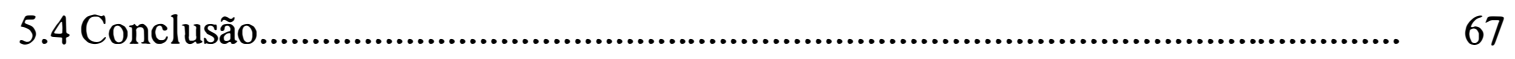

6 CRITÉRIOS ESTATÍSTICOS PARA A SELEÇÃO DE PARÂMETROS

UTILIZADOS NA AVALIAÇÃO DA RESISTÊNCIA DO SOLO À PENETRAÇÃO68

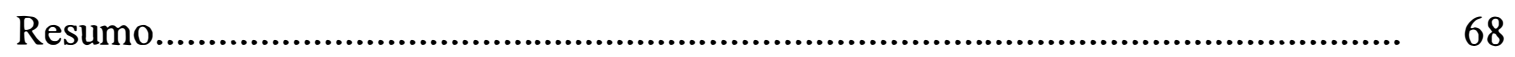

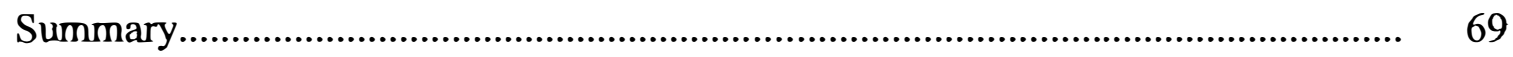

6.1 Introdução........................................................................................ $\quad 70$

6.2 Material e Métodos................................................................................. 72

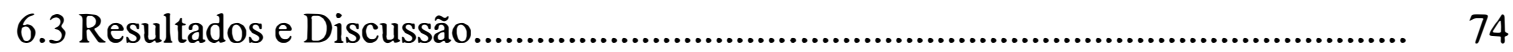

6.4 Conclusões........................................................................................... 81

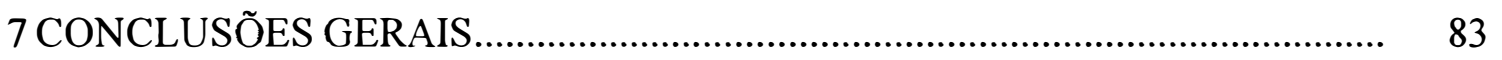




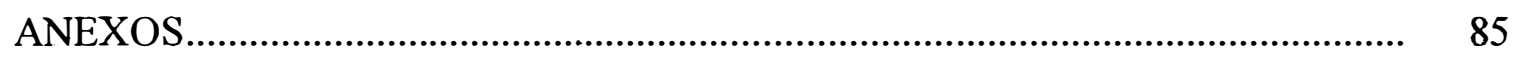

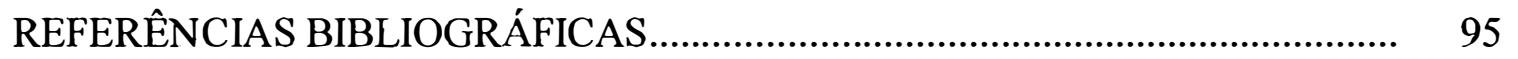




\title{
DESENVOLVIMENTO E COMPARAÇÃO DE MÉTODOS PARA AVALIAÇÃO DA QUALIDADE FÍSICA DO SOLO
}

\author{
Autor: TAIRONE PAIVA LEÃO \\ Orientador: Prof. Dr. ÁLVARO PIRES DA SILVA
}

\section{RESUMO}

A avaliação da qualidade física do solo tem sido usualmente baseada na quantificação de propriedades nem sempre relacionadas diretamente ao crescimento de plantas. Grande parte dos estudos desenvolvidos no Brasil são baseados na quantificação de propriedades físico-hidráulicas do solo, como a curva de retenção de água e condutividade hidráulica, e em indicadores de agregação. Apesar da inegável contribuição de tais estudos, há uma necessidade de quantificação de indicadores que representem mais adequadamente o solo como um meio para o crescimento de plantas. Dentre estes indicadores, o intervalo hídrico ótimo é uma alternativa útil, uma vez que integra propriedades físicas do solo que afetam diretamente o crescimento de plantas. Parâmetros de resistência a penetração também são úteis na avaliação da resistência mecânica do solo ao crescimento de raízes. Dentre os diversos parâmetros de resistência a penetração do solo, a média aritmética tem sido tida como um parâmetro estatístico adequado para representar resistência do solo a penetração. No que se refere a quantificação de características de trafegabilidade e trabalhabilidade do solo, os parâmetros da curva de compressão do solo tem sido bastante utilizados. Assim, o objetivo geral deste trabalho foi desenvolver e avaliar novas metodologias para a 
quantificação e análise de dados dos indicadores da qualidade física do solo obtidos através da curva de compressão dos solos, intervalo hídrico ótimo e curva de resistência à penetração do solo. A tese foi desenvolvida em capítulos, de modo que cada um dos objetivos específicos da tese correspondeu a um dos capítulos, conforme os itens à seguir: i) Propor e descrever um algoritmo simplificado, desenvolvido em planilha eletrônica, para quantificação do intervalo hídrico ótimo (IHO) incluindo o cálculo da densidade do solo crítica, na qual o IHO é nulo, ii) Propor um algoritmo para quantificação do intervalo hídrico ótimo utilizando a linguagem de programação $\mathrm{SAS}^{\circledR} \mathrm{e}$ discutir aspectos técnicos referentes aos procedimentos de regressão não linear empregados para este fim, iii) Propor uma metodologia estatística e computacional para determinação da pressão de pré-consolidação dos solos, desenvolvida na forma de um algoritmo no software $\mathrm{SAS}^{\circledR}$, melhorando a qualidade e reduzindo o tempo para obtenção dos resultados, e iv) Avaliar comparativamente a qualidade estatística dos parâmetros do perfil de resistência à penetração do solo: média, mediana, máximo, $m, n$, e porcentagem linear de penetrabilidade a $2 \mathrm{MPa}\left(\mathrm{PLP}_{2 \mathrm{MPa}}\right)$. Como resultado, foram desenvolvidos algoritmos em Excel $^{\circledR}$ e $\mathrm{SAS}^{\circledR}$ os quais simplificaram sensivelmente e reduziram o tempo necessário para quantificação do intervalo hídrico ótimo, sem quaisquer perdas em termos de precisão nos resultados. No que se refere a determinação da pressão de pré-consolidação do solo, foi desenvolvida uma modificação do método de Casagrande, onde a pressão de pré-consolidação é calculada de forma rápida e precisa. Quanto à determinação de parâmetros estatísticos de resistência a penetração do solo, os resultados da razão $F, \mathrm{p}>F$ e do teste da Diferença Mínima Significativa confirmaram a hipótese de que a média é o parâmetro com melhores propriedades estatísticas como critério para avaliar as alterações na resistência à penetração do solo. 


\title{
DEVELOPMENT AND COMPARATIVE EVALUATION OF METHODS FOR SOIL PHYSICAL QUALITY EVALUATION
}

\author{
Author: TAIRONE PAIVA LEÃO \\ Adviser: Prof. Dr. ALVARO PIRES DA SILVA
}

\section{SUMMARY}

The evaluation of soil physical quality has been based on the quantification of properties not always directly related to plant growth. The majority of the studies developed in Brazil are based in the quantification of soil physico-hydraulic properties, such as the water retention curve and hydraulic conductivity, as well as soil aggregation indicators. Despite the contribution of these studies to soil science, there is a demand for indicators that represent more adequately the soil as a physical media for plant growth. Among these indicators, the least limiting water range (LLWR) is a useful alternative since it integrates soil physical properties that directly affect plant growth, such as: aeration, soil water retention characteristics, and soil penetration resistance. Soil penetration resistance parameters are also useful in the evaluation of the soil mechanical resistance to root growth. The arithmetic mean has been recognized as the more adequate statistical parameter to represent a set of soil penetration resistance values for a given soil sample or layer. In respect to the trafegability and workability characteristics of a soil the parameters from the soil compression curve has been employed, specially the preconsolidation pressure. Thus, the general objective of this thesis was to develop and evaluate methodologies for quantification of soil physical quality indicators derived 
from the soil compression curve, least limiting water range and soil penetration resistance curve. The thesis was developed in chapters so that each one of the specific objectives corresponds to one of the chapters, as follows: i) Present and describe a simplified algorithm, developed as an electronic spreadsheet, for quantification of the LLWR, including the calculation of critical bulk density where the LLWR equals zero, ii) Present an algorithm for determination of the LLWR using the SAS ${ }^{\circledR}$ programming language and discuss technical aspects related to the nonlinear regression procedures employed, iii) Present a statistical and computational methodology for determination of the soil preconsolidation pressure, developed as a $S A S^{\circledR}$ algorithm, improving the quality and reducing the time for obtention of the results, and iv) Evaluate comparatively the statistical quality of the parameters of soil penetration resistance profiles: mean, median, maximum, $m, n$, and percentage linear penetrability at the critical resistance value of $2 \mathrm{MPa}\left(\mathrm{PLP}_{2 \mathrm{MPa}}\right)$. As a result, Excel ${ }^{\circledR}$ and $\mathrm{SAS}^{\circledR}$ algorithms were developed, which simplified and also reduced the time necessary for quantification of the least limiting water range without reducing the precision and quality of the results. In respect to the determination of soil preconsolidation pressure, it was developed a modification of Casagrande's method in the form of an algorithm where the preconsolidation pressure is calculated in a fast and precise way as compared to a method described in literature. In regard to the penetration resistance study, results from the $F$ ratio, $p>F$ values and Least Significant Difference test confirmed the hypothesis that the average is the statistical parameter with best statistical properties as a criteria to evaluate alterations in soil penetration resistance as a response to use and management. 


\section{INTRODUÇÃO}

A qualidade física do solo está relacionada às características de resistência do solo e capacidade de transmissão e armazenamento de fluidos na zona radicular das culturas. Um solo fisicamente degradado pode oferecer limitações severas, ou mesmo impedir o crescimento de plantas cultivadas. Apesar disso, no Brasil, pouca atenção tem sido dada ao efeito das propriedades físicas do solo sobre o crescimento de plantas. Isso se reflete na comunidade científica da grande área de Solos e Nutrição de Plantas no Brasil, onde o número de pesquisadores que se dedicam à subárea da Física do Solo é ainda pequeno com relação às demais subáreas.

Como conseqüência disso, grande parte dos estudos incluídos nas seções de Física, Conservação e Manejo do solo publicados em periódicos nacionais nos últimos anos empregam metodologias pouco eficientes para avaliação quantitativa do efeito do uso e manejo do solo sobre suas propriedades físicas. Exemplo disso é o constante emprego da curva de retenção de água no solo, densidade do solo, índice de cone no campo, água disponível, estabilidade de agregados e argila dispersa como indicadores da qualidade estrutural do solo ou como parâmetros para avaliação do efeito de práticas de manejo sobre a estrutura do solo. Apesar da indiscutível contribuição de tais metodologias nos estudos em solos e manejo de irrigação ao longo dos anos, eles não têm se mostrado eficientes para refletir adequadamente as alterações na qualidade fĩsica do solo.

Ao longo da última década, algumas metodologias têm sido propostas para melhor representação da qualidade física do solo em termos quantitativos. $\mathrm{O}$ uso de penetrômetros e consolidômetros eletrônicos acoplados a sistemas de aquisição automática de dados, o emprego de curvas de resistência e compressão dos solos obtidas 
através destes métodos e a quantificação do intervalo hídrico ótimo são alguns exemplos dessas metodologias. Entretanto, o emprego de tais metodologias no Brasil ainda é limitado, em parte devido à ausência de laboratórios providos de equipamentos necessários ao emprego de tais tecnologias, mas também devido à ausência de aprofundamento teórico, matemático e/ou estatístico para análise e interpretação dos resultados.

São levantadas quatro hipóteses neste trabalho sendo que cada uma delas se refere a um dos capítulos da tese. A hipótese do terceiro capítulo é que o intervalo hídrico ótimo pode ser calculado de forma simplificada e mais rápida através de uma planilha eletrônica desenvolvida no software Microsoft Excel ${ }^{\circledR}$. O quarto capítulo é baseado na hipótese de que o intervalo hídrico ótimo pode ser calculado de forma rápida e precisa através de um algoritmo desenvolvido na forma de um arquivo SAS. A hipótese do quinto capítulo é de que a pressão de pré-consolidação pode ser calculada de forma mais rápida e estatisticamente precisa modificando-se o método de ajuste estatístico da curva de compressão do solo. E finalmente, a hipótese do sexto capítulo é de que o parâmetro estatístico média possui melhores propriedades estatísticas como critério para avaliar alterações na resistência à penetração do solo em resposta ao uso e manejo com relação aos parâmetros: mediana, máximo, $m, n$ e porcentagem linear de penetrabilidade no valor crítico de $2 \mathrm{MPa}\left(\mathrm{PLP}_{2 \mathrm{MPa}}\right)$.

O objetivo geral deste trabalho foi avaliar novas metodologias para a quantificação e análise de dados dos indicadores da qualidade física do solo obtidos através da curva de compressão dos solos, intervalo hídrico ótimo e curva de resistência à penetração do solo. A tese será desenvolvida em capítulos, de modo que cada um dos objetivos específicos da tese corresponde a um dos capítulos, conforme os ítens à seguir: i) Propor e descrever um algoritmo simplificado, desenvolvido em planilha eletrônica, para quantificação do IHO, incluindo o cálculo da densidade do solo crítica, na qual o IHO é nulo, ii) Propor um algoritmo para quantificação do intervalo hídrico ótimo utilizando a linguagem de programação do programa SAS e discutir aspectos técnicos referentes aos procedimentos de regressão não linear empregados para este fim. iii) Propor uma metodologia estatística e computacional para determinação da pressão de 
pré-consolidação dos solos, desenvolvida na forma de um algoritmo no software $\mathrm{SAS}^{\circledR}$, melhorando a qualidade e reduzindo o tempo de obtenção dos resultados, e iv) Avaliar comparativamente a qualidade estatística dos parâmetros do perfil de resistência à penetração do solo: média, mediana, máximo, $m, n$, e percentagem linear de penetrabilidade para o valor crítico de $2 \mathrm{MPa}\left(\mathrm{PLP}_{2 \mathrm{MPa}}\right)$. 


\section{REVISÃO DE LITERATURA}

\subsection{Qualidade do solo, sustentabilidade e seus indicadores}

A partir da segunda metade do século XX, houve uma mudança na percepção da importância do solo como componente ambiental e um reconhecimento da necessidade de manter ou melhorar a capacidade do solo de desempenhar suas funções no ecossistema. Ao mesmo tempo, tem havido uma conscientização, ainda que lenta, de que o solo não é um recurso inesgotável e que o uso ou o manejo inadequados podem degradar o solo em um período relativamente curto de tempo, com poucas possibilidades de recuperação ou reposição (Nortcliff, 2002). Assim, tem-se procurado termos e definições que se apliquem à capacidade que o solo tem de desempenhar suas funções no ecossistema terrestre e ao mesmo tempo fornecer um meio para produção de alimentos, bens, matérias-primas bem como, fundação para edificações, e ambiente para deposição (proposital ou não) de despojos.

A qualidade, ou saúde do solo, como preferem alguns autores, pode ser definida como "a capacidade de um solo funcionar, dentro dos limites de um ecossistema natural ou manejado, de sustentar a produtividade animal e vegetal, manter ou melhorar a qualidade do ar e da água, e promover a saúde humana e animal" (Karlen et al. 1997; Doran, 2002). Qualquer discussão sobre a interação entre qualidade do solo e desenvolvimento humano não é completa sem a abordagem da sustentabilidade do manejo agrícola do solo. Doran (2002) define a sustentabilidade como um equilíbrio entre três fatores: a) responsabilidade social; b) viabilidade econômica; e c) a estabilidade ambiental. Entretanto, como a qualidade do solo é encarada de forma diferente por pesquisadores, produtores e sociedade (Andrews et al., 2003; Karlen et al., 
2003; Sparovek \& de Maria, 2003) estes fatores podem muitas vezes ser antagônicos, pondo em cheque a sustentabilidade da produção agropecuária.

No universo da qualidade do solo, a qualidade física do solo tem um papel muitas vezes subestimado ou ignorado, principalmente nas atividades agrícola e pastoril. A qualidade física de solos agrícolas refere-se às características de resistência do solo $\mathrm{e}$ capacidade de transmissão e armazenamento de fluidos na zona radicular das culturas (Topp et al., 1997). As propriedades físicas, químicas e biológicas do solo estão intimamente relacionadas, e as propriedades físicas têm um efeito pronunciado sobre as duas últimas (Schoenholtz et al., 2000; Dexter, 2004).

Os indicadores físicos da qualidade do solo estão associados ao arranjo físico das partículas sólidas e poros e incluem textura, densidade do solo, porosidade, estabilidade de agregados, encrostamento superficial, compactação e profundidade do solo (Nortcliff, 2002). No entanto, para Letey (1985), estes indicadores podem ser divididos em duas classes, aqueles que influenciam diretamente o crescimento de plantas, através de sua influência sobre os processos fisiológicos do vegetal, como aeração do solo, temperatura, resistência à penetração e retenção de água, e aqueles que influenciam indiretamente o crescimento, através de sua ação sobre os primeiros, como textura, densidade, porosidade, estabilidade de agregados, encrostamento, etc. Para Nortcliff (2002), a seleção de indicadores da qualidade do solo deve ser baseada nos seguintes critérios:

i) Uso do solo.

ii) Relação entre o uso do solo e o indicador.

iii) Facilidade e confiabilidade das medidas.

iv) Variações espaciais e temporais e a importância destas variações.

v) Sensibilidade das medidas à mudanças no manejo do solo.

vi) Possibilidade de comparação com amostragens de rotina e programas de monitoramento.

vii) Nível de habilidade necessária para o uso e interpretação do indicador. 
Um dos primeiros indicadores da qualidade física do solo utilizado foi provavelmente a densidade do solo. A densidade do solo preenche grande parte dos requisitos propostos por Nortcliff (2002), sendo facilmente medida e sensível a variações no uso e manejo do solo. Entretanto, em solos diferentes, a densidade do solo não é um parâmetro adequado para a caracterização do grau de compactação do solo. A densidade do solo ideal e os limites críticos de densidade variam consideravelmente entre solos com composições granulométricas e mineralógicas distintas, e mesmo em solos com mesma composição granulométrica, mas com processos genéticos diferenciados (Håkansson \& Voorheess, 1998). Um exemplo disso pode ser encontrado no estudo de Jones (1983) no qual foram avaliados o limite inferior de densidade do solo onde o crescimento radicular não é limitado, e o limite superior de densidade do solo, acima do qual o crescimento radicular é severamente limitado. $O$ limite inferior variou de 1,2 a $1,6 \mathrm{~g} \mathrm{~cm}^{-3}$ para solos com conteúdo de argila + silte variando de 10 a $90 \%$, respectivamente, e o limite superior variou de 1,4 a $1,8 \mathrm{~g} \mathrm{~cm}^{-3}$, para estes mesmos conteúdos de argila + silte. Apesar de alguns autores terem proposto o uso da densidade do solo relativa como um critério para a comparação do grau de compactação entre solos com características e propriedades distintas (Silva et al., 1997; Håkansson \& Lipiec, 2000) a utilização deste parâmetro ainda não se popularizou em estudos sobre compactação do solo.

Outro indicador muito utilizado é a resistência mecânica, ou resistência à penetração do solo (Bradford, 1980). A resistência à penetração do solo avaliada por meio de penetrômetros fornece um parâmetro que indica o grau de limitação (ou resistência) que o solo oferece ao crescimento de raízes (Bradford, 1986; Herrick \& Jones, 2002). Um dos principais problemas do uso da resistência à penetração como um indicador da qualidade física do solo, principalmente quando em condições de campo, é que ela tem uma relação acentuadamente exponencial com a umidade do solo, sendo também influenciada pela densidade do solo e outros fatores (Busscher, 1990). Assim, para que a resistência do solo à penetração seja utilizada como indicador da qualidade fĩsica do solo, é necessário conhecer a umidade do solo e a densidade na ocasião da amostragem (Busscher, 1990), ou mesmo trabalhar com ensaios de laboratório, através 
da construção da curva de resistência do solo à penetração (Imhoff et al., 2000a), o que tem restringido a utilidade deste parâmetro.

A compactação não seria propriamente um indicador da qualidade física do solo, conforme propõe Nortcliff (2002), e sim um processo, que ocorre em um sistema solo tridimensional induzido por um estresse mecânico, normalmente causado pelo tráfego de maquinário ou pisoteio de animais, e caracterizado por um decréscimo de volume (e aumento de densidade), principalmente devido à extrusão de ar (Håkansson \& Voorhees, 1998). Neste contexto, indicadores como densidade e resistência mecânica são utilizados como índices do grau de compactação de um determinado solo. Um dos principais enganos, por parte de produtores e mesmo de alguns técnicos e pesquisadores é a idéia de que a compactação é um processo facilmente reversível, por meio de cultivo superficial ou subsolagem. O cultivo sempre resulta em um declínio acentuado da resistência interna do solo, o que posteriormente leva a uma maior susceptibilidade à compactação (Gabriels et al., 1998). A compactação subsuperficial é diretamente relacionada ao peso aplicado sobre o solo e ao conteúdo de água e argila do mesmo, e em muitos casos sua correção pode ser quase impossível ou impraticável (Håkansson \& Voorhees, 1998).

A aeração, ou o status de aeração do solo, também tem sido utilizado como um indicador da qualidade física do solo para o crescimento de plantas (Singh \& Sainju, 1998). Devido à complexidade do tratamento teórico e experimental para determinação do status de aeração do solo (Cook \& Knight, 2003) este parâmetro é freqüentemente determinado a partir de medidas de densidade e umidade do solo, sendo caracterizado pela porosidade de aeração do solo. Uma porosidade de aeração menor que $10 \%$ do volume de poros do solo tem sido assumida como limitante para as trocas gasosas entre as raízes e a atmosfera do solo, sendo portanto limitante ao crescimento de plantas (Grable \& Siemer, 1968). No entanto a caracterização apenas da aeração não é suficiente para a avaliação da qualidade física do solo.

Atributos do solo como porosidade, estabilidade de agregados e argila dispersa não têm sido reconhecidos como índices adequados para a avaliação da qualidade física do solo. Isto ocorre devido às incertezas metodológicas nas determinações destes 
parâmetros e ao fato de serem medidas indiretas da limitação física de um solo ao crescimento de plantas (Letey, 1985).

Indicadores tradicionalmente utilizados na avaliação da qualidade física do solo, como infiltração, retenção e disponibilidade de água são universalmente importantes para o monitoramento das funções do solo. Destes indicadores, a água disponível (conteúdo de água retido entre a capacidade de campo e o ponto de murcha permanente) e condutividade hidráulica saturada são os mais freqüentemente encontrados em conjuntos de indicadores para a avaliação da qualidade do solo. A água disponível quantifica a capacidade relativa de um solo de fornecer água, e a condutividade hidráulica saturada é um indicador da taxa de drenagem dos solos (Schoenholtz et al., 2000). No entanto, a significância de indicadores fĩsico-hidráulicos tradicionais em termos de limitação estrutural do solo ao crescimento de plantas é questionável. Apesar da limitação por aeração poder ser estimada conhecendo-se o conteúdo volumétrico de água disponível e a densidade do solo, o grau de resistência mecânica da matriz do solo não pode ser estimado através da água disponível (Phene \& Beale, 1976).

O principal problema da condutividade hidráulica saturada como índice da qualidade física do solo é a extrema variabilidade deste parâmetro em condições de campo, sendo influenciada por diversos fatores como temperatura, textura, porosidade e estrutura (Reichardt, 1996, p.187), além das incertezas metodológicas e experimentais em sua determinação. Iwata et al. (1995) relatam coeficientes de variação acima de $40 \%$ para tabuleiros cultivados com arroz, e ainda maiores para culturas de terras altas. Os autores afirmam ainda que seria necessário um número de amostras superior a 100 para uma acurácia de $\pm 10 \%$ nas medidas de condutividade hidráulica.

Dentre os indicadores estruturais da qualidade física do solo, os indicadores de trafegabilidade e trabalhabilidade têm tido uma atenção crescente nos últimos anos (Godwin \& Spoor, 1977; Earl, 1997; Imhoff, 2002). A resposta de um solo estruturado a uma força mecânica externa é dependente das características da estrutura do solo e da força aplicada. Por definição, o solo se deformará quando a força aplicada exceder a resistência mecânica do solo à deformação. Dentre os indicadores estruturais de trafegabilidade do solo, aqueles obtidos a partir da curva de compressão do solo, como a 
pressão de pré-consolidação e o índice de compressão têm sido freqüentemente utilizados na avaliação da qualidade física do solo (Larson et al., 1980; Etana et al., 1997; Imhoff et al., 2001). Imhoff (2002) apresenta uma revisão detalhada sobre a utilização da curva de compressão na avaliação da qualidade estrutural do solo. Aspectos teóricos e fỉsico-matemáticos da curva de compressão serão abordados com detalhe no próximo item.

\subsection{A curva de compressão como indicador da qualidade físico-estrutural do solo}

Antes de se definir aspectos teóricos da curva de compressão, é preciso diferenciar três termos de uso corrente em física do solo e que têm causado muitas controvérsias na avaliação da qualidade física do solo, sendo eles compressão, compactação e consolidação, os quais têm sido denominados genericamente de compactação. Mediante um apanhado de diferentes glossários nas áreas de ciência do solo, geotecnia e geologia serão utilizadas neste trabalho as seguintes definições:

Compressão: Redução do volume de um solo mediante a uma pressão ou estresse aplicado.

Compactação: Aumento da densidade de um solo pela expulsão de ar.

Consolidação: Redução do volume de um solo pela expulsão de água.

Os ensaios de adensamento, ou compressão, dos solos tiveram origem na engenharia civil, para determinação do adensamento de argilas para construção de fundações e suportes. No início do século XX não havia grandes exigências no que se refere a fundações para obras de engenharia, uma vez que os níveis de solicitação das obras e a disponibilidade de espaço não eram limitantes. Com o desenvolvimento urbano e industrial, tornou-se necessário edificar sobre fundações argilosas de alta compressibilidade e de baixa capacidade de suporte. Nestas condições, o uso de técnicas de construção por etapas ou por pré-carregamento tornou-se freqüente e para tanto, a previsão das velocidades de adensamento de fundações tornou-se, um elemento determinante em projetos, seja para avaliação da estabilidade durante as diversas fases 
de construção, seja para a determinação do calendário de construção ou a viabilidade da obra (UFV, 2003).

Os ensaios de adensamento foram adaptados para a agricultura com o surgimento dos problemas de compactação severa causados pela introdução de maquinário pesado na agricultura, principalmente após a segunda metade do século XX (Soane \& Ouwerkerk, 1994).

Um modelo teórico ideal da curva de compressão uniaxial dos solos é ilustrado na Figura 1. Em mecânica de solos aplicada à engenharia civil, o comportamento compressivo de solos e fundações compostas de materiais diversos é associada à hipótese de uma ligação rígida entre as partículas pelo filme de água adsorvida, e solidificada em torno das mesmas (Vargas, 1977). Ainda segundo este autor, durante a sedimentação natural, como esta é muito lenta e por acréscimos de carga extremamente pequenos, tal ligação seria mantida. Retirada a amostra do solo, a ligação se manteria, com pequena expansão. Entretanto, ao se aplicar uma pressão muito superior que àquela encontrada em condições naturais, a ligação entre as partículas só poderia suportar pressões até o limite já suportado, ou seja a recompressão na Figura la. Pressões superiores às pressões suportadas no passado quebrariam as ligações intergranulares e o solo se deformaria plástica e irreversivelmente segundo a reta de compressão virgem (Figura 1c). O valor limite, ou intervalo de valores, que divide os dois ramos da curva é chamado de pressão de pré-consolidação (Figura 1b). A pré-consolidação foi definida por Terzaghi (1959) como o processo de manter-se uma amostra temporariamente sob uma pressão maior que a pressão aplicada anteriormente. Logo, a pressão de préconsolidação divide os limites entre a recompressão e deformações adicionais e irreversíveis nos solos segundo a reta de compressão virgem. 


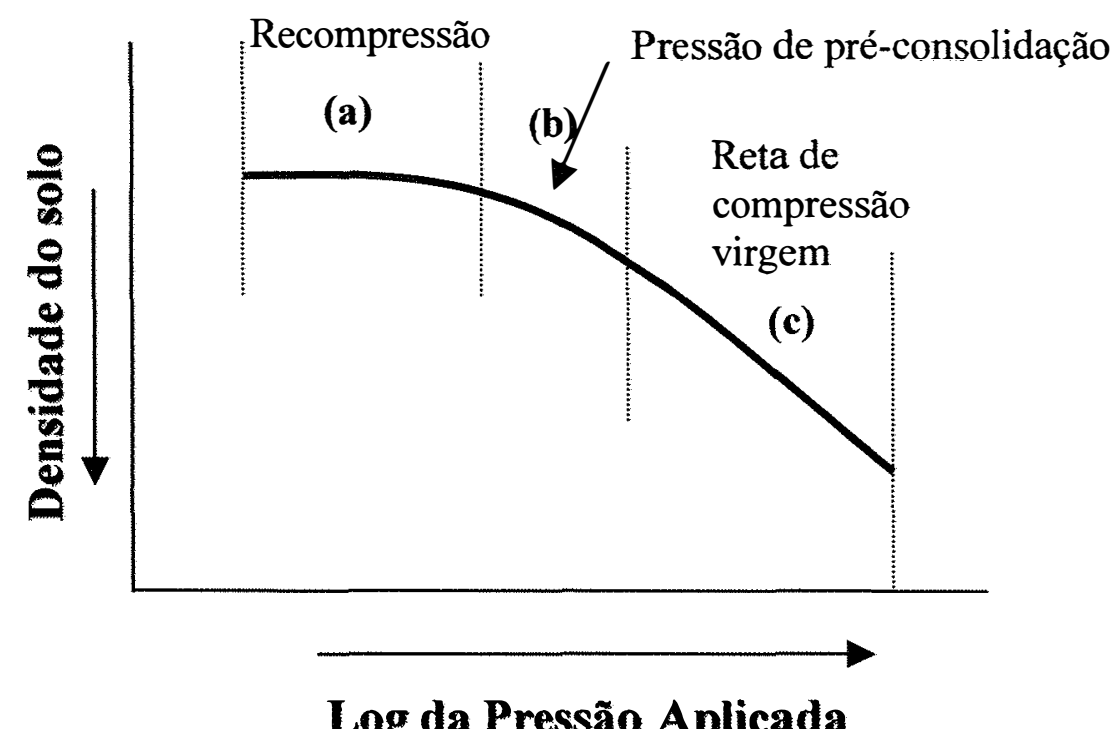

Figura 1 - Variação da densidade do solo em função do logaritmo da pressão aplicada

Em solos agrícolas, um processo similar àquele observado em fundações é observado. A aplicação de pressões no solo, normalmente causadas por maquinário agrícola ou pisoteio de animais causará compactação adicional somente se a pressão de pré-consolidação do solo for excedida. $\mathrm{Na}$ ausência de processos de endurecimento por envelhecimento (age-hardening), a pressão de pré-consolidação é igual à máxima força de compactação aplicada ao solo no passado (Dexter, 1988). Em horizontes superficiais, o processo de secagem pode causar compactação através da ação do potencial da água no solo causando estresses efetivos ${ }^{I}$ (Childs, 1969; Chancellor, 1994). A pressão de préconsolidação é ainda função da umidade do solo. Solos mais úmidos possuem menor resistência interna que solos mais secos, e deste modo, a pressão de pré-consolidação diminui com o aumento do conteúdo de água (Dexter, 1988; Mosaddeghi, 2003).

Como o solo é um sistema multifase de grande complexidade, seu processo de deformação mediante a aplicação de pressão não é perfeitamente elástico nem linear (Figura 1). Existem dois tipos de adensamentos ou recalques $^{2}$ normais. Os provenientes

\footnotetext{
${ }^{1}$ Segundo o glossário da Sociedade Americana de Ciência do Solo "O estresse transmitido através do solo por pressões intergranulares".

${ }^{2}$ Em jargão de Engenharia civil: deformação vertical positiva de uma superfície qualquer delimitada de um terreno (Vargas, 1977).
} 
das deformações a volume constante do solo, isto é, deformações que se dão a índices de vazios constantes - as quais são, impropriamente, muitas vezes chamadas de deformações plásticas - e os recalques por adensamento - os quais se dão com variação do índice de vazios. Os primeiros são típicos das areias e dos carregamentos rápidos das argilas (quando não há drenagem da água intersticial); e os segundos são os das camadas argilosas quando sofrem carregamentos permanentes (Vargas, 1977).

O gráfico da Figura 1 é obtido por meio de ensaios de compressão uniaxial (Vargas, 1977). Uma limitação da caracterização do comportamento compressivo dos solos por estes ensaios é que, em condições de campo, há possibilidade de drenagem da água pelas laterais das áreas carregadas. Isto ocorrendo, a dissipação da pressão neutra se faz mais rapidamente que o previsto pela teoria e mais rapidamente nos lados que no centro. $\mathrm{O}$ afastamento das condições previstas na teoria é tanto maior quanto mais espessa a camada de solo e quanto menor a largura da área carregada na superfície (Pinto, 2000) características essas normalmente observadas na compressão de solos agrícolas por tráfego ou pisoteio.

Em solos agrícolas, o conhecimento da pressão de pré-consolidação é importante para determinar a capacidade de suporte de carga de um solo, e assim, a trafegabilidade do mesmo para máquinas e implementos com diferentes combinações de peso $\mathrm{x}$ área de contato do rodado. A primeira metodologia para cálculo da pressão de pré-consolidação a partir da curva de compressão foi a de Casagrande (1936). A determinação da pressão de pré-consolidação pode ser feita através da curva de índice de vazios ou densidade do solo como função da pressão aplicada, em escala logarítmica (Figura 2). Sobre essa curva, estima-se o ponto de máxima curvatura, e desse ponto traça-se uma horizontal (Figura 2b), e uma tangente à curva (Figura 2c). Marca-se a bissetriz do ângulo formado entre a horizontal e a tangente (Figura 2d). A abscissa do ponto de interseç̧ão da bissetriz com o prolongamento da reta virgem representa a pressão de pré-consolidação (Casagrande, 1936; Taylor, 1958). 


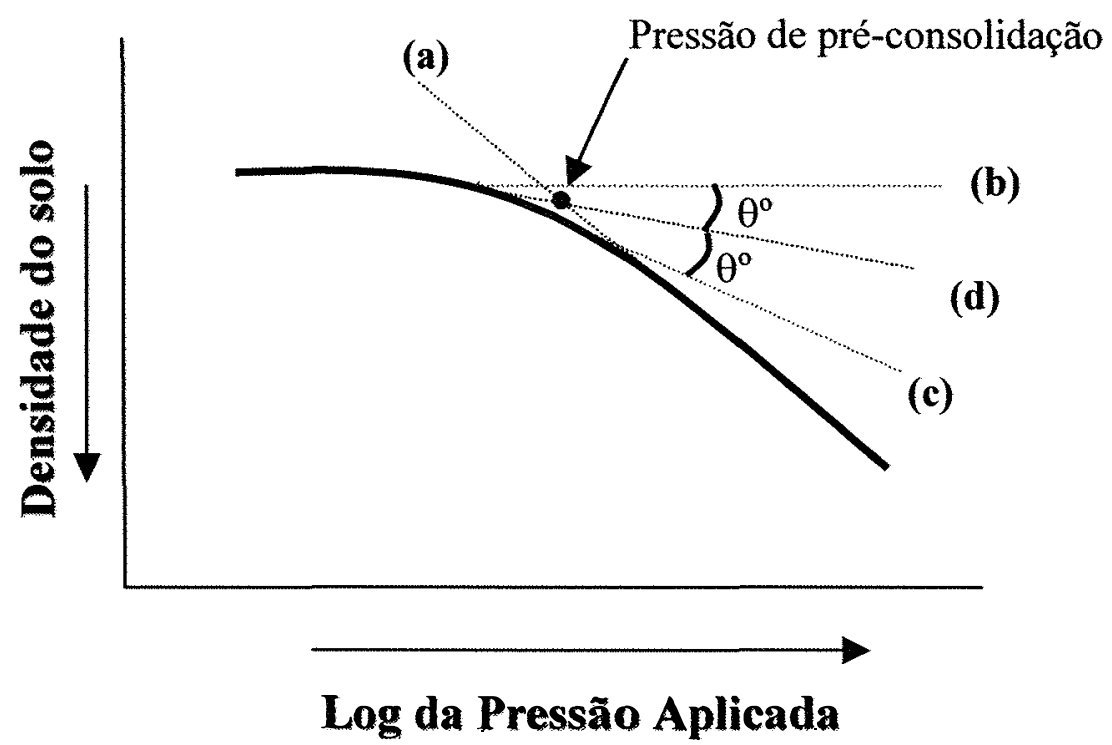

Figura 2 - Estimativa da pressão de pré-consolidação através do método de Casagrande. (a) Reta de compressão virgem, (b) Reta no ponto de máxima curvatura, (c) Tangente no ponto de máxima curvatura, e (d) Bissetriz às retas $b$ e $c$

Apesar do método de Casagrande (1936) ter tido seu uso consagrado em engenharia civil, Terzaghi \& Peck (1955) argumentam que o método deixa muito a desejar, visto que o processo de compressão de fundações no campo é sujeito a condições muito distintas daquelas encontradas em laboratório, e que os resultados obtidos em pesquisas por este método deixa muita margem para interpretação pessoal.

Em solos agrícolas, o processo de compressão foi primeiramente descrito por uma equação log-linear (Bailey \& Vandenberg, 1968; Larson et al., 1980). Essa equação é um modelo estatístico para ajuste da reta de compressão virgem, tendo sido utilizado para o ajuste de curvas de compressão realizadas em amostras de diferentes tipos de solos.

$$
\rho=\rho_{\mathrm{k}}+\mathrm{C} \log \left(\sigma_{\mathrm{a}} / \sigma_{\mathrm{k}}\right)
$$

Em que:

$\rho=$ Densidade do solo estimada $\left[\mathrm{M} \mathrm{L}^{-3}\right]$.

$\rho_{\mathrm{k}}=$ Densidade do solo a uma pressão conhecida $\sigma_{\mathrm{k}}\left[\mathrm{ML}^{-3}\right]$.

$\sigma_{\mathrm{a}}=$ Pressão uniaxial aplicada $\left[\mathrm{M} \mathrm{L}^{-1} \mathrm{~T}^{-2}\right]$. 
$\mathrm{C}=$ Coeficiente angular da reta de compressão virgem.

A limitação óbvia do modelo linear (eq. 1) é não estimar o ramo não-linear da curva, referente a recompressão, impossibilitando assim a determinação da pressão de pré-consolidação. Para contornar essa limitação esses autores optaram pelo ajuste segmentado de equações lineares e ajuste de polinômios de segundo grau. Culley \& Larson (1987) empregaram uma equação semelhante à eq. (1) para avaliar a susceptibilidade à compactação de um solo franco-argiloso. Eles concluíram que a compressão segundo a reta de compressão virgem é fortemente afetada pelo histórico de pressões sofrido pelo solo. E ainda, que em solos agrícolas, onde as pressões aplicadas raramente excedem 300 a $400 \mathrm{kPa}$, a maior parte da compressão de áreas previamente trafegadas ou sujeitas ao ressecamento ocorre abaixo da pressão de pré-consolidação (recompactação).

O efeito do secamento sobre o comportamento compressivo de um solo argiloso ilítico em condições não saturadas foi avaliado por Nearing et al. (1988) através da incorporação do potencial da água do solo, e estresse efetivo na eq. (1). Nearing et al. (1988) concluíram que o potencial da água no solo e a duração da aplicação da pressão aumentaram a resistência compressiva e a densidade do solo avaliado, o que foi associado ao aumento da energia de ligação entre as partículas causado pelo envelhecimento (age-hardening) e por pressões causadas por ciclos de secamento pretéritos.

Bailey et al. (1986) propuseram uma equação não-linear multiplicativa, com três parâmetros empíricos, capaz de ajustar todo intervalo de valores da curva de compressão do solo.

$$
\ln (\rho)=\ln \left(\rho_{0}\right)-(A+B \sigma)[1-\exp (-C \sigma)]
$$

Em que:

$\rho=$ Densidade do solo $\left[\mathrm{M} \mathrm{L}^{-3}\right]$.

$\rho_{0}=$ Densidade do solo estimada a pressão zero $\left[\mathrm{M} \mathrm{L}^{-3}\right]$.

$\sigma=$ Pressão uniaxial aplicada $\left[\mathrm{M} \mathrm{L}^{-1} \mathrm{~T}^{-2}\right]$.

$A, B, C=$ Parâmetros empíricos provenientes do ajuste estatístico do modelo. 
Mais tarde, McNabb \& Boersma (1993) modificaram a eq. (2) incorporando ajustes para a variação da densidade do solo de amostras indeformadas.

$$
\ln (\rho)=\ln \left(\rho_{0} \delta_{\mathrm{i}}\right)-\left(A+B \sigma+D \delta_{\mathrm{c}}\right)[1-\exp (-C \sigma)]
$$

Em que:

$\rho_{0}=$ Densidade do solo estimada a pressão zero $\left[\mathrm{M} \mathrm{L}^{-3}\right]$.

$\sigma=$ Pressão uniaxial aplicada $\left[\mathrm{M} \mathrm{L}^{-1} \mathrm{~T}^{-2}\right]$.

$A, B, C$ e $D=$ Parâmetros empíricos provenientes do ajuste estatístico do modelo.

$\delta_{\mathrm{i}}=\rho_{\mathrm{i}} / \rho_{\mathrm{i} \text { (média) }}=$ Densidade do solo inicial normalizada.

$\delta_{\mathrm{c}}=\left(\delta_{\mathrm{i}}-1\right) \rho_{0}=$ Ajusta a curva de compressão para diferenças na densidade do solo inicial para cada amostra.

Os autores concluíram que o modelo descreveu adequadamente a compressão dos Andissolos avaliados no intervalo de pressões a que normalmente estão sujeitos os solos agrícolas, o que não ocorre em equações lineares como a eq. (1) (McNabb \& Boersma, 1993). Entretanto, apesar dos elevados coeficientes de determinação dos ajustes $\left(r^{2}>0,90\right)$ a eq. (3) não foi utilizada para estimar a pressão de pré-consolidação dos solos.

McNabb \& Boersma (1996) modificaram a eq. (3) de modo que se pudesse incorporar a variação do conteúdo de água no solo durante o ensaio de compressão na modelagem do processo de compressão dos solos. O conteúdo de água foi inserido no modelo na forma do grau de saturação, de modo que quando o solo estivesse saturado a equação se reduzisse à forma da eq. (3).

$\ln (\rho)=\ln \left(\rho_{0} \delta_{\mathrm{i}}\right)-\left(A+B \sigma+D \delta_{\mathrm{c}}+E \theta_{\mathrm{m}}{ }^{G}+F \sigma \theta_{\mathrm{m}}{ }^{G}\right)\left\{\left[1-\exp \left[-\mathrm{C} \sigma\left(1-\theta_{\mathrm{m}}{ }^{G}\right)\right]\right\}\right.$

Em que:

$\theta_{\mathrm{m}}=1-\theta_{\mathrm{s}}$.

$\theta_{\mathrm{s}}=$ Grau de saturação.

$E, F$ e $G=$ Parâmetros empíricos adicionados ao modelo.

E os demais termos são os mesmos descritos na eq. (3).

O excesso de parâmetros empíricos (overparameterization) na eq. (4) toma difícil seu ajuste por técnicas de regressão não-linear, uma vez que a convergência é 
dificultada (Ratkowsky, 1990). E deste modo, para que o modelo pudesse se ajustar a diferentes solos, foi necessária uma reestruturação dos parâmetros, tornando possível a avaliação da compressibilidade dos Andissolos estudados (McNabb \& Boersma, 1996).

Assouline et al. (1997) propuseram um modelo semi-empírico dinâmico para ajuste da curva de compressão do solo, levando em consideração as variações de umidade do solo e pressão aplicada.

$$
\rho\left(\sigma, \theta_{\mathrm{i}}\right)=\rho_{\mathrm{i}}\left(\theta_{\mathrm{i}}\right)+\left[\left(\rho_{\max }\left(\theta_{\mathrm{i}}\right)-\rho_{\mathrm{i}}\left(\theta_{\mathrm{i}}\right)\right]\left\{1-\exp \left[-\xi\left(\theta_{\mathrm{i}}\right) \sigma\right]\right\}\right.
$$

Em que:

$\rho=$ Densidade do solo $\left[\mathrm{M} \mathrm{L}^{-3}\right]$.

$\rho_{\mathrm{i}}=$ Densidade do solo inicial $\left[\mathrm{M} \mathrm{L}^{-3}\right]$.

$\theta_{\mathrm{i}}=$ Umidade atual do solo $\left[\mathrm{L}^{3} \mathrm{~L}^{-3}\right]$.

$\xi=$ Parâmetro empírico proveniente do ajuste estatístico do modelo.

$\sigma=$ Pressão uniaxial aplicada $\left[\mathrm{M} \mathrm{L}^{-1} \mathrm{~T}^{-2}\right]$.

Para valores específicos de $\rho_{\max }\left(\theta_{\mathrm{i}}\right)$ e $\xi\left(\theta_{\mathrm{i}}\right)$ denotados por $\rho_{\max }{ }^{*}$ e $\xi *$ a eq. (5) se simplifica para:

$$
\rho(\sigma)=\rho_{1}+\left(\rho_{\max }^{*}-\rho_{1}\right)\left[1-\exp \left(-\xi^{*} \sigma\right)\right]
$$

A principal vantagem deste modelo é que a densidade do solo não tende a um comportamento assintótico com o aumento da pressão aplicada, se restringindo a um valor máximo de densidade, dependente do conteúdo inicial de água do solo na compressão (Assouline et al., 1997). Apesar de não serem apresentados valores de coeficientes de determinação, os autores afirmam que o modelo se ajustou bem aos dados dos Oxissolos brasileiros avaliados, com a vantagem de possuir apenas dois parâmetros empíricos para ajuste e portanto melhores propriedades estatísticas (Assouline et al., 1997).

Fritton (2001) modificou a equação semi-empírica, proposta por van Genuchten (1980) para ajuste de curvas de retenção de água no solo, para uso na caracterização do processo de compressão dos solos. Isso foi obtido substituindo-se o conteúdo volumétrico de água pela densidade do solo e o potencial mátrico pela pressão uniaxial aplicada. 


$$
\rho=\rho_{\mathrm{m}}-\left(\rho_{\mathrm{m}}-\rho_{0}\right)\left\{1+[\alpha(\sigma+1)]^{\mathrm{n}}\right\}^{-\mathrm{m}}
$$

Em que:

$\rho=$ Densidade do solo $\left[\mathrm{M} \mathrm{L}^{-3}\right]$.

$\rho_{\mathrm{m}}=$ Densidade do solo máxima $\left[\mathrm{ML}^{-3}\right]$.

$\rho_{0}=$ Densidade do solo inicial $\left[\mathrm{ML}^{-3}\right]$.

$\sigma=$ Pressão uniaxial aplicada $\left[\mathrm{M} \mathrm{L}^{-1} \mathrm{~T}^{-2}\right]$.

$\alpha, \mathrm{m}, \mathrm{n}=$ Parâmetros empíricos provenientes do ajuste estatístico do modelo.

Uma possível vantagem do modelo é que o autor propõe que a pressão de préconsolidação pode ser estimada através do parâmetro empírico $\alpha$ :

$$
p_{\mathrm{c}}=1 / \alpha
$$

$\mathrm{Na}$ qual $p_{\mathrm{c}}$ é a pressão de pré-consolidação do solo. Apesar dos elevados coeficientes de determinação obtidos por Fritton (2001) $\left(\mathrm{r}^{2}>0,9\right)$ mais estudos correlacionando a pressão de pré-consolidação estimada pelo parâmetro $\alpha$ à estimativas pelos métodos convencionas são necessárias para validar esse procedimento. Em uma análise crítica do modelo apresentado na eq. (7), Assouline (2002) argumenta que não existe razão física para que a densidade do solo seja apresentada como função da pressão aplicada mais o número um $(\sigma+1)$, apresentando uma versão simplificada do modelo, corrigida para condições de contorno reais, o qual estimou valores de densidade de partícula irreais. Neste mesmo estudo, Assouline (2002) propôs uma modificação ao modelo apresentado na eq. (5) (Assouline et al., 1997), adicionando um parâmetro empírico ao mesmo, de modo a permitir a presença de um ponto de inflexão na curva ajustada.

$$
\rho=\rho_{0}+\left(\rho_{\max }-\rho_{0}\right)\left\{1-\exp \left[-(\kappa \sigma)^{\omega}\right]\right\}
$$

Em que:

к e $\omega=$ Parâmetros empíricos empíricos provenientes do ajuste estatístico do modelo. $\omega>0$.

Assouline (2002) afirma que a eq. (9) têm condições de contorno fisicamente definidas, ao contrário do modelo de Fritton (2001), e ainda, que deve ser usada em casos onde uma maior flexibilidade de ajuste é necessária, pois em modelos empíricos, 
as chances de desenvolvimento de funções de pedotransferência, relacionando parâmetros do modelo e propriedades do solo diminui à medida que se aumenta o número de parâmetros no modelo.

Imhoff et al. (2004) desenvolveram um algoritmo no software MathCad ${ }^{\circledR}$ (Mathsoft, 2000) para quantificação da pressão de pré-consolidação pelo método de Casagrande (1936). Resumidamente, o programa usa a derivada segunda de um ajuste por "splines cúbicas" para encontrar o ponto de máxima curvatura. Em seguida, através de procedimentos matemáticos, o programa ajusta os demais passos do método, chegando à pressão de pré-consolidação (ver a descrição da Figura 2). Imhoff et al. (2004) usaram também um modelo análogo à eq. (3) para ajustar a curva de compressão e desenvolver funções de pedotransferência entre os parâmetros de ajuste e propriedades físicas do solo. Os autores (Imhoff et al., 2004) observaram que o índice de compressão correlacionou-se com o conteúdo de argila (até 29,42\%), e com a densidade do solo, enquanto que a pressão de pré-consolidação correlacionou-se com a densidade do solo, o conteúdo de argila e o conteúdo de água do solo.

\subsection{Indicadores integrais da qualidade física do solo: intervalo hídrico ótimo}

Nas últimas décadas, tem havido uma busca por indicadores da qualidade física do solo capazes de integrar parâmetros físicos do solo em um único índice que possa ser facilmente medido e correlacionado com fatores produtivos das culturas (Letey, 1985; Silva et al., 1994; Schoenholtz et al., 2000). Dexter (2004) propõe que a qualidade física do solo pode ser avaliada pela inclinação da curva de retenção determinada no ponto de inflexão da curva, no entanto, por ser uma metodologia recente, não foi ainda validada por outras pesquisas.

Um índice da qualidade física do solo que tem sido utilizado e validado em diferentes condições é o intervalo hídrico ótimo (Silva et al., 1994; Zou et al., 2000; Wu et al., 2003). O intervalo hídrico ótimo (Least Limiting Water Range ou Nonlimiting Water Range) foi idealizado por Letey (1995) e quantificado por Silva et al. (1994). Um histórico do desenvolvimento do intervalo hídrico ótimo (IHO) e descrição da 
metodologia para cálculo são apresentados por Leão (2002). O IHO é sensível ao efeito de alterações físicas do solo sobre a porosidade de aeração e resistência à penetração, além de integrar o índice tradicional da qualidade física do solo descrito pelo conteúdo da água disponível (conteúdo de água retido entre a capacidade de campo e o ponto de murcha permanente). Na metodologia de Silva et al. (1994) porosidade de aeração, resistência à penetração, ponto de murcha permanente e capacidade de campo são integrados em função da densidade do solo, criando um índice da qualidade do solo que, uma vez determinado, pode ser utilizado para monitorar a qualidade física de solos cultivados.

Desde sua quantificação (Silva et al., 1994), o IHO tem sido utilizado como uma abordagem metodológica para avaliação da qualidade física do solo em uma gama de solos e condições de manejo (Tormena et al., 1999; Sharma \& Bhusan, 2001; Wu et al., 2003), incluindo em sua relação com propriedades químicas do solo (Drury et al., 2003).

O IHO também foi citado como uma abordagem metodológica para avaliação da qualidade física do solo em revisões de literatura (Lal, 2000; Schoenholtz et al., 2000) e livros (Brady \& Weil, 1999; Silva et al., 2002a; Silva et al., 2002b).

Apesar dos avanços na caracterização e uso do IHO, sua popularização entre a comunidade científica tem sido restrita por dois fatores. Primeiro, a impossibilidade de caracterização da relação entre resistência à penetração e densidade do solo e umidade do solo no campo (Reynolds et al., 2002) tornando a sua aplicação impossível sem análises laboratoriais prévias e em segundo, a inexistência de uma metodologia de análise de dados simplificada tem limitado o uso do procedimento a pesquisadores familiarizados com técnicas de regressão linear ou não-linear.

A quantificação do IHO é baseada no ajuste de uma função de retenção de água e uma função de resistência do solo à penetração. A função de retenção de água neste caso específico deve incorporar a variabilidade estrutural do solo, o que pode ser obtido incorporando-se a densidade do solo na função. Silva et al. (1994) incorporaram a variabilidade da densidade do solo em uma função potência empregada por Ross et al. (1991) para ajuste da curva de retenção de água no solo.

$$
\theta=a \Psi^{b}
$$


Em que:

$\theta=$ Umidade volumétrica do solo $\left[\mathrm{L}^{3} \mathrm{~L}^{-3}\right]$.

$\Psi=$ Potencial mátrico da água no solo $\left[\mathrm{M} \mathrm{L}^{-1} \mathrm{~T}^{-2}\right]$.

$a, b=$ Parâmetros empíricos.

Os procedimentos de seleção de variáveis por técnicas de análise multivariada (regressão "stepwise") empregados por Silva et al. (1994) resultaram em uma equação de três parâmetros com boas propriedades estatísticas para caracterização da influência estrutural no fenômeno de retenção de água no solo (Tormena et al., 1998; Betz et al., 1998).

$$
\theta=\exp \left(a+b \mathrm{D}_{\mathrm{s}}\right) \Psi^{c}
$$

Em que:

$\theta=$ Umidade volumétrica do solo $\left[\mathrm{L}^{3} \mathrm{~L}^{-3}\right]$.

$\mathrm{D}_{\mathrm{s}}=$ Densidade do solo $\left[\mathrm{M} \mathrm{L}^{-3}\right]$.

$\Psi=$ Potencial mátrico $\left[\mathrm{M} \mathrm{L}^{-1} \mathrm{~T}^{-2}\right]$.

$a, b$, e $c=$ Parâmetros empíricos.

Tormena et al. (1999) incorporaram a densidade do solo no modelo proposto por van Genuchten (1980) para ajuste da curva de retenção de água. A densidade foi incorporada no parâmetro $\gamma$ através de um polinômio de segundo grau.

$$
\theta=\theta_{\mathrm{r}}+\left(\theta_{\mathrm{s}}-\theta_{\mathrm{r}}\right)\left[1+(\beta \Psi)^{\gamma}\right]^{(1-1 / \gamma)}
$$

Em que:

$\gamma=a+b \mathrm{D}_{\mathrm{s}}+c \mathrm{D}_{\mathrm{s}}^{2}$

$\theta=$ Umidade volumétrica do solo $\left[\mathrm{L}^{3} \mathrm{~L}^{-3}\right]$.

$\theta_{\mathrm{r}}=$ Umidade residual do solo $\left[\mathrm{L}^{3} \mathrm{~L}^{-3}\right]$.

$\theta_{\mathrm{s}}=$ Umidade de saturação do solo $\left[\mathrm{L}^{3} \mathrm{~L}^{-3}\right]$.

$\beta=$ Inverso do valor de entrada de ar do solo $\left[\mathrm{L} \mathrm{T}^{2} \mathrm{M}^{-1}\right]$.

$a, b$, e $c=$ Parâmetros empíricos.

$\Psi=$ Potencial mátrico $\left[\mathrm{M} \mathrm{L}^{-1} \mathrm{~T}^{-2}\right]$.

Recentemente, Leão (2002) incorporou a variabilidade estrutural do solo na eq. (10) através do parâmetro $a$, obtendo elevado coeficiente de determinação $\left(r^{2}=0,87\right)$ no 
ajuste das curvas de retenção com amostras de áreas sob diferentes condições de manejo em pastagens.

$$
\theta=a_{0} \mathrm{D}_{\mathrm{s}}^{a l} \Psi^{b}
$$

Em que:

$a_{0}, a_{l}$ e $b=$ Parâmetros empíricos.

A função de resistência mecânica do solo à penetração tem sido adequadamente descrita utilizando a equação não-linear proposta por Busscher \& Sojka (1987) (Silva et al., 1994; Imhoff et al., 2000a; Imhoff et al., 2000b; Leão, 2002).

$$
\mathrm{RP}=d \theta^{e} \mathrm{D}_{\mathrm{s}}^{f}
$$

Em que:

$\mathrm{RP}=$ Resistência do solo à penetração $\left[\mathrm{M} \mathrm{L}^{-1} \mathrm{~T}^{-2}\right]$.

$\theta=$ Umidade volumétrica do solo $\left[\mathrm{L}^{3} \mathrm{~L}^{-3}\right]$.

$\mathrm{D}_{\mathrm{s}}=$ Densidade do solo $\left[\mathrm{M} \mathrm{L}^{-3}\right]$.

$d, e, \mathrm{e} f=$ Parâmetros empíricos.

Busscher (1990) avaliou oito equações para ajuste da função de resistência à penetração do solo, e dentre elas a eq. (14) foi a que apresentou os maiores valores de coeficiente de determinação $\left(\mathrm{r}^{2}\right.$ médio $\left.=0,91\right)$ e uma boa relação entre coeficiente de determinação e número de parâmetros empíricos, sendo matematicamente simples de ser aplicada em softwares estatísticos.

Apesar do uso freqüente da eq. (14) nos estudos para caracterização do intervalo hídrico ótimo do solo e outros parâmetros, existe um grande número de equações adequadas para o ajuste da curva de resistência do solo, incluindo outras variáveis independentes, como fatores granulométricos, quantidade de água retida em um determinado potencial, conteúdo de matéria orgânica, dentre outros. Perumpral (1987), Busscher (1990) e Caranache (1987) citam quase duas dezenas de equações referentes ao ajuste de funções de resistência à penetração do solo. Serão citadas a seguir algumas destas equações, as quais podem ser relevantes em aplicações para cálculo do intervalo hídrico ótimo, cabendo ao pesquisador que deseja trabalhar com este tipo de função 
testar cada tipo de equação selecionando aquela que melhor se adequar aos seus dados e condições.

Ayres \& Perumpral (1982) estudaram uma equação não-linear empírica que fosse pouco complexa, porém com boas propriedades de ajuste para dados de resistência à penetração como função da umidade do solo e densidade do solo seco, chegando à eq. (15).

$$
\mathrm{RP}=\left(C 1 \mathrm{D}_{\mathrm{s}}^{C 4}\right) /\left[C 2+\left(\theta_{\mathrm{g}}-C 3\right)^{2}\right]
$$

Em que:

$\theta_{\mathrm{g}}=$ Umidade gravimétrica do solo $\left[\mathrm{M} \mathrm{M}^{-1}\right]$

$C 1, C 2, C 3$ e $C 4$ = Parâmetros empíricos.

Ayres \& Perumpral (1982) obtiveram elevados coeficientes de determinação $\left(\mathrm{r}^{2}\right.$ $>0,9)$ para solos com conteúdos de argila variando de 0 a $1000 \mathrm{~g} \mathrm{~kg}^{-1}$. No entanto, conforme discutido anteriormente para os modelos de compressão dos solos, o excesso de parâmetros em equações não-lineares pode prejudicar suas propriedades estatísticas, apesar de proporcionar elevados valores para o coeficiente de determinação (Ratkowsky, 1990).

Busscher (1990) desenvolveu uma equação empírica a partir de condições de contorno previamente estabelecidas. Em solo úmido, foi assumido não haver resistência à penetração e o solo seco foi assumido como sendo impenetrável. Na umidade de saturação $\left(\theta=\theta_{\text {sat }}\right)$, a resistência à penetração foi assumida como sendo igual a zero (RP $=0)$. Teoricamente, com o solo completamente seco $(\theta=0)$, a resistência à penetração é infinita $(\mathrm{RP}=\infty)$. Busscher (1990) justifica esta propriedade pelo fato de, apesar da RP não chegar ao infinito, ela pode ser grande o suficiente para ir além da escala de medida. À densidade do solo também foram atribuídas condições de contorno, onde para $\mathrm{D}_{\mathrm{s}}=0$ $\rightarrow R P=0$ e para $D_{s}=$ Densidade de partículas $\left(D_{p}\right) \rightarrow R P=\infty$.

$$
\mathrm{RP}=A \mathrm{D}_{\mathrm{s}}^{B}\left\{\sec \left[\pi / 2\left(\theta_{\mathrm{g}} / \theta_{\mathrm{sat}}-1\right)-1\right]-1\right\}^{C}
$$

Em que:

$A, B$, e $C=$ Parâmetros empíricos. 
No estudo de Busscher (1990) a eq. (16), com o parâmetro $C$ fixado para um, apresentou elevados valores de coeficiente de determinação, com a vantagem de possuir apenas dois parâmetros empíricos, sendo relatada por ele como a melhor alternativa para caracterização da função de resistência à penetração do solo.

Mais recentemente, Vaz et al. (2001) utilizaram uma equação não-linear com três parâmetros empíricos para ajuste de medidas de umidade do solo e resistência à penetração realizadas simultaneamente por um penetrômetro provido de uma agulha com sensor TDR.

$$
\mathrm{RP}=a\left(\rho^{n} / \rho_{\mathrm{s}}\right) \exp (-b \theta)
$$

Em que:

$a, b$, e $n=$ Parâmetros empíricos.

$\rho=$ Densidade do solo $\left[\mathrm{M} \mathrm{L}^{-3}\right]$.

$\rho_{\mathrm{s}}=$ Densidade de partículas $\left[\mathrm{M} \mathrm{L}^{-3}\right]$.

Grande parte das equações para ajuste das curvas de resistência à penetração e retenção de água do solo citadas anteriormente são passíveis de linearização, uma vez que podem ser modificadas por transformação logarítmica. Devido à simplicidade de trabalhar com modelos lineares, muitos pesquisadores utilizaram estas equações na forma linearizada (Silva et al., 1994; Betz et al., 1998; Zou et al., 2000). Entretanto, em muitos casos, a transformação envolve também uma transformação do termo estocástico (erro), afetando as hipóteses assumidas sobre o modelo (Bates \& Watts, 1988). Outro ponto é que atualmente as técnicas e algoritmos de regressão não-linear se encontram bastante desenvolvidos, eficientes e mais acessíveis a um maior número de pesquisadores que no passado, facilitando o seu emprego (Seber \& Wild, 1989). O uso de regressão não-linear é útil não somente na determinação do IHO mas também no ajuste das equações utilizadas na descrição do fenômeno de compressibilidade dos solos, citadas no item anterior. No item a seguir será feita uma breve discussão sobre técnicas de regressão não-linear. 


\subsection{Regressão não-linear como técnica auxiliar na quantificação de indicadores da qualidade física do solo}

Um modelo de regressão não-linear pode ser escrito da seguinte forma (Bates \& Watts, 1988; Seber \& Wild, 1989; Souza, 1998):

$$
y_{\mathrm{i}}=f\left(\mathbf{x}_{\mathbf{i}} ; \boldsymbol{q}\right)+\varepsilon_{\mathrm{i}}(i=1,2, \ldots, n)
$$

Em que $\mathrm{E}\left[\varepsilon_{\mathbf{i}}\right]=0$ é o termo estocástico, $f$ é a função resposta e $\mathbf{x}_{\mathbf{i}}$ é um vetor de regressores associados ou variáveis independentes de enésima ordem. Este modelo é exatamente o mesmo caso de um modelo linear, exceto que as respostas esperadas são funções não-lineares de um parâmetro $m$-dimensional, descrito aqui como $q$. Isto significa que, em modelos não-lineares, pelo menos uma das derivadas dos parâmetros é função de pelo menos um dos parâmetros (Bates \& Watts, 1988).

Existe um grande número de técnicas de ajuste especializadas para modelos nãolineares, e dentre elas, a melhor e mais conhecida é a dos modelos não-lineares de mínimos quadrados.

$$
\mathrm{F}(\boldsymbol{q})=\sum_{i=1}^{N}\left\{y_{\mathrm{i}}-f_{\mathrm{i}}(\boldsymbol{q})\right\}^{2}
$$

Nesta técnica, valores adequados de ajuste dos parâmetros são aqueles em que a função objetiva $F(q)$ assume valores mínimos. As ferramentas computacionais básicas para mínimos quadrados não-lineares são as mesmas que no caso de mínimos quadrados lineares. Para alcançar isto, todos os métodos atualmente utilizados começam com uma aproximação linear a $f_{\mathrm{i}}(\boldsymbol{q})$.

$$
f(q+\delta) \cong h_{\mathrm{i}}+a_{\mathrm{i}} \cdot \delta
$$

Em que $h_{\mathrm{i}}$ e $a_{\mathrm{i}}$ dependem dos cálculos conduzidos em $\boldsymbol{q}$, e possivelmente em outros pontos prévios. O método mais antigo para realizar este cálculo, conhecido como método de Gauss usa uma série de Taylor simples para aproximar $f_{\mathrm{i}}$.

$$
h_{\mathrm{i}}=f_{\mathrm{i}}(\boldsymbol{q}), \quad a_{\mathrm{i}}=\partial f_{\mathrm{i}} / \partial \boldsymbol{q}
$$

O procedimento escolhe $\delta$ de modo a minimizar a soma dos quadrados linear. 


$$
\sum_{i=1}^{N}\left(z_{\mathrm{i}}-a_{\mathrm{i}} \cdot \delta\right)^{2}
$$

Em que $z_{\mathrm{i}}=y_{\mathrm{i}}-h_{\mathrm{i}}$.

Como a seqüência produzida por aplicações diretas da eq. (22) pode não obter convergência, vários métodos computacionais para mínimos quadrados não-lineares têm sido desenvolvidos (Seber \& Wild, 1989). Dentre eles, um método bastante eficiente, conhecido como método de Levenberg-Marquardt se tornou padrão em modelos nãolineares de mínimos quadrados empregados em estudos de ciência do solo e hidrologia (Šimůnek \& Hopmans, 2002). Em alguns casos, métodos mais genéricos, presentes em planilhas eletrônicas, como o gradiente conjugado e o de Newton podem ser usados sem grandes perdas na qualidade dos resultados da otimização de modelos não-lineares em relação àqueles obtidos pelo método de Levenberg-Marquardt (Wrait \& Or, 1998).

\subsection{Parâmetros da curva de resistência à penetração do solo como indicadores de alterações na qualidade física do solo}

Diversos estudos empregaram a quantificação da resistência à penetração do solo na avaliação da qualidade estrutural do solo para o crescimento de plantas (Busscher \& Sojka, 1987; Silva et al., 1994; Betz et al., 1998). No entanto, diferentes abordagens para análise dos resultados têm sido utilizadas sem que houvesse, na maioria dos casos, uma análise crítica destes procedimentos e avaliação de sua qualidade estatística como diferenciadores do impacto do uso e manejo do solo sobre a qualidade física do solo. A maior parte dos estudos, realizados quer seja utilizando penetrômetros estáticos ou dinâmicos (Herrick \& Jones, 2002) emprega a média dos valores de resistência ao longo de uma dada camada de solo, ou o valor máximo da resistência registrado em um ensaio de penetração ao longo desta camada (Corrêa \& Reichardt, 1995; Sojka et al., 2001; Villamil et al., 2001).

Metodologias para caracterização da resistência da matriz do solo à deformação causada por uma raiz em crescimento deveriam levar em consideração o maior número possível de peculiaridades do desenvolvimento das raízes (Groenevelt et al., 1984). 
Dentre elas pode-se citar: o tamanho da raiz, o sistema de lubrificação, a capacidade de desenvolver pressões axiais e radiais, a velocidade do crescimento radicular, e principalmente, a capacidade da raiz de buscar poros de tamanho e resistência à deformação apropriados.

Informações como a média ou a resistência máxima à penetração ao longo de uma camada de solo dão apenas uma idéia aproximada do grau de limitação oferecido pela matriz do solo ao crescimento das raízes. Valores médios, por outro lado, podem não representar adequadamente a heterogeneidade estrutural do solo, como a presença de fissuras ou poros, onde o crescimento radicular seria facilitado. Ainda mais complexo é o emprego do valor máximo de resistência à penetração do solo ao longo de uma camada. A máxima resistência à penetração do solo é altamente sujeita a erros uma vez que uma única medida seria representativa de toda uma camada de solo.

Com o objetivo de minimizar a influência da heterogeneidade estrutural na avaliação da qualidade estrutural do solo Groenevelt et al. (1984) definiram a porcentagem linear de penetrabilidade (PLP) como a porcentagem da trajetória linear através do solo, na qual a resistência à penetração do solo é menor do que um determinado valor crítico. Assim, a um valor crítico de, digamos $2 \mathrm{MPa}$, uma determinada porcentagem linear da trajetória do penetrômetro através do solo seria penetrável com valores de resistência inferiores a $2 \mathrm{MPa}$ (Groenevelt et al., 1984). Perfect et al. (1990) aprimoraram a aplicação do PLP, utilizando análise de regressão linear em dados linearizados por transformação Probit (Finney, 1952; Tietjen, 1986). Através da análise de regressão linear nos dados transformados, foram obtidos dois parâmetros empíricos, a inclinação $(m)$ e o intercepto $(n)$ das curvas. A inclinação, $m$, reflete a dispersão na distribuição das resistências dos agregados, enquanto o intercepto n, descreve a macroporosidade do solo (Perfect et al., 1990). Apesar destes parâmetros serem potencialmente úteis na descrição da qualidade estrutural dos solos, eles não foram utilizados em estudos posteriores de avaliação da qualidade física do solo. 


\section{UM ALGORITMO SIMPLIFICADO, DESENVOLVIDO EM EXCEL ${ }^{\circledR}$, PARA ESTIMATIVA DO INTERVALO HÍDRICO ÓTIMO DOS SOLOS}

\section{Resumo}

O intervalo hídrico ótimo (IHO) dos solos tem sido empregado como uma metodologia para a avaliação da qualidade física do solo em diferentes sistemas agrícolas, incluindo áreas florestais, pastagens e grandes culturas. Entretanto, a inexistência de uma metodologia simplificada para a quantificação do IHO tem dificultado a popularização do uso desta técnica entre pesquisadores e técnicos. Levando isto em consideração, este trabalho teve como objetivo propor e descrever um algoritmo simplificado, desenvolvido em planilha eletrônica Excel ${ }^{\circledR}$, para quantificação do IHO, incluindo o cálculo da densidade do solo crítica, na qual o IHO é nulo. Apesar da simplicidade dos procedimentos e técnicas numéricas de otimização utilizadas, a regressão não-linear produziu resultados confiáveis quando comparados com aqueles encontrados em literatura.

Termos para indexação: regressão não-linear, planilha eletrônica, otimização, física do solo, qualidade do solo. 


\section{A SIMPLIFIED EXCEL ${ }^{\circledR}$ ALGORITHM FOR ESTIMATING THE LEAST LIMITING WATER RANGE OF SOILS}

\section{Summary}

The least limiting water range (LLWR) of soils has been employed as a methodological approach for evaluation of soil physical quality in different agricultural systems, including forestry, grasslands and major crops. However, the absence of a simplified methodology for the quantification of LLWR has hampered the popularization of its use among researchers and soil managers. Taking this into account this work has the objective of proposing and describing a simplified algorithm developed in Excel $^{\circledR}$ software for quantification of LLWR, including the calculation of the critical bulk density, at which the LLWR becomes zero. Despite the simplicity of the procedures and numerical techniques of optimization used, the nonlinear regression produced reliable results when compared to those found in the literature.

Index terms: nonlinear regression, spreadsheet software, optimization, soil physics, soil quality.

\subsection{Introdução}

O conceito de um índice do conteúdo ótimo de água no solo para o crescimento de plantas, com relação às propriedades físicas do solo foi introduzido por Letey (1985) e identificado como "non-limiting water range" (NLWR). Mais tarde, Silva et al. (1994) desenvolveram o conceito do NLWR quantitativamente, renomeando-o como "least limiting water range" ou intervalo hídrico ótimo (IHO), segundo a tradução de Tormena (1998). Para um determinado tipo de solo, o IHO incorpora as limitações de aeração do solo, retenção de água, e resistência à penetração do solo como função de uma única variável (i.e. a densidade do solo).

Desde sua quantificação (Silva et al., 1994), o IHO tem sido empregado como uma metodologia para a avaliação da qualidade física do solo em diferentes solos e 
práticas de manejo (Tormena et al., 1999; Sharma \& Bhusan, 2001; Wu et al., 2003), incluindo em sua relação com propriedades químicas do solo (Drury et al., 2003). O IHO também foi citado como um método para avaliação da qualidade física do solo em revisões de literatura (Lal, 2000; Schoenholtz et al., 2000) e livros (Brady \& Weil, 1999; Silva et al., 2002). Apesar dos avanços na caracterização e quantificação do IHO, uma descrição detalhada da metodologia computacional para cálculo do IHO a partir de propriedades físicas do solo, incluindo a manipulação dos dados, procedimentos de ajuste de curvas e confecção de gráficos ainda não existe.

O objetivo deste trabalho foi propor um algoritmo simplificado para estimativa do intervalo hídrico ótimo do solo usando a planilha eletrônica Microsoft Excel ${ }^{\circledR 3} \mathrm{e}$ discutir aspectos técnicos referentes ao procedimento de ajuste de curvas por regressão

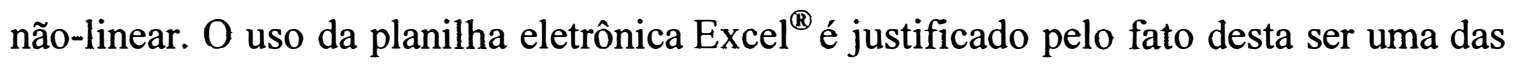
planilhas eletrônicas mais utilizadas no Brasil e em muitos outros países. Entretanto, a metodologia descrita neste trabalho pode ser adaptada a outros softwares providos de planilhas eletrônicas, de acordo com os recursos e conhecimentos do usuário.

\subsection{Revisão de Literatura}

A quantificação do intervalo hídrico ótimo (IHO) é baseada no ajuste de uma função de retenção de água e uma função de resistência à penetração do solo. A função de retenção de água neste caso específico deve levar em consideração a variabilidade estrutural do solo, o que pode ser realizado incorporando a densidade do solo na equação. Silva et al. (1994) incorporaram a variabilidade da densidade do solo em uma função potência simples, empregada por Ross et al. (1991) para o ajuste da curva de retenção de água:

$$
\theta=a \Psi^{b}
$$

Em que:

$\theta=$ Umidade volumétrica $\left[\mathrm{L}^{3} \mathrm{~L}^{-3}\right]$.

\footnotetext{
${ }^{3}$ A menção do nome de companhias e produtos comercias não implica na aprovação dos mesmos pelo autor ou instituição de ensino, servindo meramente para fins didáticos.
} 
$\Psi=$ Potencial mátrico $\left[\mathrm{M} \mathrm{L}^{-1} \mathrm{~T}^{-2}\right]$.

$a, b=$ Parâmetros empíricos.

Os procedimentos de regressão stepwise de Silva et al. (1994) resultaram em uma equação não-linear de três parâmetros com boas propriedades para caracterizar a influência estrutural no processo de retenção de água no solo (Tormena et al., 1998; Betz et al., 1998):

$$
\theta=\exp \left(a+b \mathrm{D}_{s}\right) \Psi^{c}
$$

Em que:

$\theta=$ Umidade volumétrica $\left[\mathrm{L}^{3} \mathrm{~L}^{-3}\right]$.

$\mathrm{D}_{\mathrm{s}}=$ Densidade do solo $\left[\mathrm{M} \mathrm{L}^{-3}\right]$.

$\Psi=$ Potencial mátrico $\left[\mathrm{M} \mathrm{L}^{-1} \mathrm{~T}^{-2}\right]$.

$a, b$, e $c=$ Parâmetros empíricos.

A função de resistência à penetração do solo tem sido adequadamente descrita usando a equação não-linear proposta por Busscher \& Sojka (1987) (Silva et al., 1994; Betz et al., 1998; Leão, 2002).

$$
\mathrm{RP}=d \theta^{e} \mathrm{D}_{\mathrm{s}}^{f}
$$

Em que:

$\mathrm{RP}=$ Resistência do solo à penetração $\left[\mathrm{M} \mathrm{L}^{-1} \mathrm{~T}^{-2}\right]$.

$\theta=$ Umidade volumétrica $\left[\mathrm{L}^{3} \mathrm{~L}^{-3}\right]$.

$\mathrm{D}_{\mathrm{s}}=$ Densidade do solo $\left[\mathrm{M} \mathrm{L}^{-3}\right]$.

$d, e$, e $f=$ Parâmetros empíricos.

As eqs. (2) e (3) são passíveis de linearização, através de transformação logarítmica. Devido à simplicidade de se utilizar métodos de regressão linear, alguns pesquisadores preferem trabalhar com elas na forma linearizada (Silva et al., 1994; Betz et al., 1998; Zou et al., 2000). Entretanto, este procedimento não foi adotado neste trabalho pelas seguintes razões: i) Dada a disponibilidade de algoritmos eficientes para regressão não-linear, a utilidade da linearização é discutível (Seber \& Wild, 1989); e ii) 
A transformação dos dados normalmente envolve uma transformação do termo estocástico, o que afeta as suposições estatísticas sobre o modelo (Bates \& Watts, 1988).

\subsection{Material e Métodos}

Procedimentos de amostragem e coleta dos dados para a quantificação do IHO são descritos em artigos científicos e livros (Silva et al., 1994; Leão, 2002; Silva et al., 2002a). Resumidamente, é necessário coletar um conjunto de amostras indeformadas na área a ser avaliada. As amostras indeformadas são levadas para o laboratório e saturadas com água. No laboratório, os anéis são equilibrados em potenciais mátricos diferentes e crescentes (Klute, 1986). A resistência à penetração, conteúdo volumétrico de água e densidade do solo são determinados em cada amostra. O resultado é um conjunto de pontos de resistência à penetração do solo $(\mathrm{RP})$, umidade volumétrica $(\theta)$, densidade do solo $\left(D_{s}\right)$, e potencial mátrico $(\Psi)$ para cada um dos anéis. Os dados são ajustados às eqs. (2) e (3), resultando em um conjunto de parâmetros empíricos $a, b, c, d, e$ e $f$ utilizados na quantificação do IHO.

Na planilha $\operatorname{Excel}^{\circledR}$ descrita aqui, as primeiras quatro colunas são os dados do solo franco-siltoso de Silva et al. (1994) (Figura 1). O solo é classificado segundo o Sistema Americano de Classificação de Solos como Aquic Eutrochrept, com $180 \mathrm{~g} \mathrm{~kg}^{-1}$ de argila, $520 \mathrm{~g} \mathrm{~kg}^{-1}$ de silte, $300 \mathrm{~g} \mathrm{~kg}^{-1}$ de areia e $38 \mathrm{~g} \mathrm{~kg}^{-1}$ de matéria orgânica, e densidade do solo média de $1,47 \mathrm{~g} \mathrm{~cm}^{-3}$. Para os procedimentos de otimização, é necessário criar duas outras colunas, com o valor estimado para o conteúdo volumétrico de água e resistência à penetração do solo. Isto pode ser conseguido criando-se colunas com as eqs. (2) e (3), e utilizando estimativas iniciais para os parâmetros empíricos. É recomendável que as estimativas sejam determinadas com base em literatura, uma vez que estimativas iniciais adequadas são críticas para a convergência de algoritmos de otimização em regressão não-linear (Wraith \& Or, 1998). Além das estimativas para as funções de $\theta$ e RP é necessário criar colunas com os quadrados dos desvios (erros) para estas variáveis (Figura 2). Isto é necessário para a quantificação da estimativa da soma dos quadrados dos desvios. O quadrado do desvio é calculado pela seguinte equação: 


$$
\text { Erro }=\left[(\theta \text { ou RP })_{\text {medido }}-(\theta \text { ou RP })_{\text {estimado pelo modelo }}\right]^{2}
$$

Com os quadrados dos desvios para $\theta$ e RP, é possível estabelecer células contendo a soma dos quadrados dos desvios (SQD) para o ajuste das eqs. (2) e (3). A SQD é a função a ser minimizada no problema de otimização não-linear apresentado aqui. O procedimento de minimização é executado pelo comando "solver". Uma vez que a "célula de destino" é definida, que neste caso é a célula contendo a soma dos quadrados dos desvios; a opção mínimo deve ser selecionada (Figura 3). As células variáveis são as estimativas dos parâmetros utilizadas previamente para calcular as somas dos quadrados dos desvios para as variáveis (Figura 2). Vale ressaltar que, ao procedimento de otimização podem ser facilmente determinadas restrições. Em geral, não é necessário aplicar nenhuma restrição para ajustar as equações utilizadas nos cálculos do IHO, desde que valores iniciais adequados para os parâmetros sejam adotados. Entretanto, para conjuntos de dados em que o usuário suspeite que haja baixa correlação entre as variáveis no ajuste, é recomendável adotar restrições para a otimização. $\mathrm{O}$ intervalo de valores para as restrições deve ser assumido de acordo com a literatura e a prática do usuário.

O procedimento de minimização deve ser executado independentemente para variáveis e parâmetros das eqs. (2) e (3). A qualidade do ajuste pode ser facilmente computada à partir da variância dos valores medidos (uma função interna das planilhas eletrônicas) pelo coeficiente de determinação $\left(\mathrm{r}^{2}\right)$ do ajuste (Figura 4):

$$
\mathrm{r}^{2}=1-\mathrm{SQD} / \mathrm{N} \sigma_{\text {variável }}^{2}
$$

Em que:

$\mathrm{N}=$ Número de pontos.

$\sigma_{\text {variavel }}^{2}=$ Variância das medidas da variável independente.

$\mathrm{SQD}=$ Soma dos quadrados dos desvios. 


\begin{tabular}{|c|c|c|c|c|}
\hline & A. & 8. & & D) \\
\hline 1 & D. & 18 & wh & 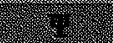 \\
\hline$\frac{20 s}{2}$ & $\mathrm{~g} \mathrm{~cm}^{-3}$ & $\mathrm{~cm}^{3} \mathrm{~cm}^{-3}$ & $\mathrm{MPa}$ & $\mathrm{MPa}$ \\
\hline Se. & 1.35 & 0.4305 & 0.23 & 0.002 \\
\hline 34 & 1.43 & 0.4209 & 0.85 & 0.005 \\
\hline 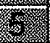 & 1.51 & 0.363 & 0.5 & 0.008 \\
\hline 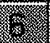 & 1.6 & 0.367 & 1.34 & 0.01 \\
\hline 12 & 1.54 & 0.3097 & 2.13 & 0.0333 \\
\hline 8 & 1.43 & 0.3217 & 0.61 & 0.1 \\
\hline 9 & 1.53 & 0.2516 & 2.27 & 0.5 \\
\hline 10 & 1.6 & 0.249 & 3.93 & 1.5 \\
\hline 14. & & . & . & 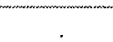 \\
\hline 12 & & & & \\
\hline 13 & & & & \\
\hline
\end{tabular}

Figura 1 - Exemplo dos dados de entrada para o solo franco-siltoso (Silva et al., 1994) utilizado na quantificação do Intervalo Hídrico Ótimo

\begin{tabular}{|c|c|c|c|c|c|c|}
\hline $12 \mathrm{E}$ & tef & 200 & 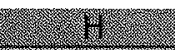 & X & 2 & ME: \\
\hline$m p(a y s)$ & $\theta(A /$ as) & Pr nesvol & (t) $(3+v 0)$ & & & \\
\hline $\mathrm{MPa}$ & $\mathrm{cm}^{3} \mathrm{~cm}^{-3}$ & $(\mathrm{MPa})^{2}$ & $\left(\mathrm{~cm}^{3} \mathrm{~cm}^{-3}\right)^{2}$ & & & \\
\hline 0.8034 & 0.4460 & 0.3287 & 0.00024 & \multicolumn{3}{|c|}{ Resistência à penetraçăo } \\
\hline 0.9933 & 0.4033 & 0.0205 & 0.00031 & \multirow{3}{*}{$\underset{\substack{0 \\
0}}{\dot{0}}$} & d & 0.08 \\
\hline 1.4885 & 0.3785 & 0.9772 & 0.00024 & & e & -1.61 \\
\hline 1.7457 & 0.3615 & 0.1646 & 0.00003 & & $t$ & 3.06 \\
\hline 2.0409 & 0.3330 & 0.0079 & 0.00054 & & & \\
\hline 1.5307 & 0.3140 & 0.8476 & 0.00006 & & & \\
\hline 2.7947 & 0.2664 & 0.2753 & 0.00022 & & & \\
\hline 3.2583 & 0.2379 & 0.4512 & 0.00012 & \multicolumn{3}{|c|}{ Conteúdo de águr } \\
\hline \multirow{3}{*}{-} & & 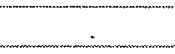 & & \multirow{3}{*}{ 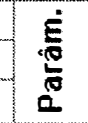 } & a & -0.92 \\
\hline & & . & . & & $b$ & -0.30 \\
\hline & & & & & c & -0.08 \\
\hline
\end{tabular}

Figura 2 - Colunas com os valores estimados e os quadrados dos desvios para as variáveis resistência à penetração e conteúdo volumétrico de água. As estimativas dos parâmetros para as eqs. (2) e (3) são mostradas à direita

Com as estimativas dos parâmetros, o IHO para cada valor de $D_{s}$ pode ser estimado a partir de transformações algébricas simples das eqs. (2) e (3). Também é necessário estabelecer limites críticos para as variáveis físicas utilizadas nas análises. Neste trabalho foram utilizados os valores críticos normalmente encontrados em literatura. A capacidade de campo foi estabelecida no potencial de 0,01 $\mathrm{MPa}$ (Haise et al., 1955), e o ponto de murcha foi estabelecido em 1,5 MPa (Richards \& Weaver, 
1944). A resistência à penetração limitante para o crescimento de plantas foi estabelecida em 2,0 MPa (Taylor et al., 1966) e a porosidade de aeração limitante foi estabelecida em 10\% (Grable \& Siemer, 1968). Entretanto, o usuário é encorajado a mudar estes valores críticos de acordo com suas condições experimentais e o conhecimento dos processos físicos envolvidos nestes limites críticos.

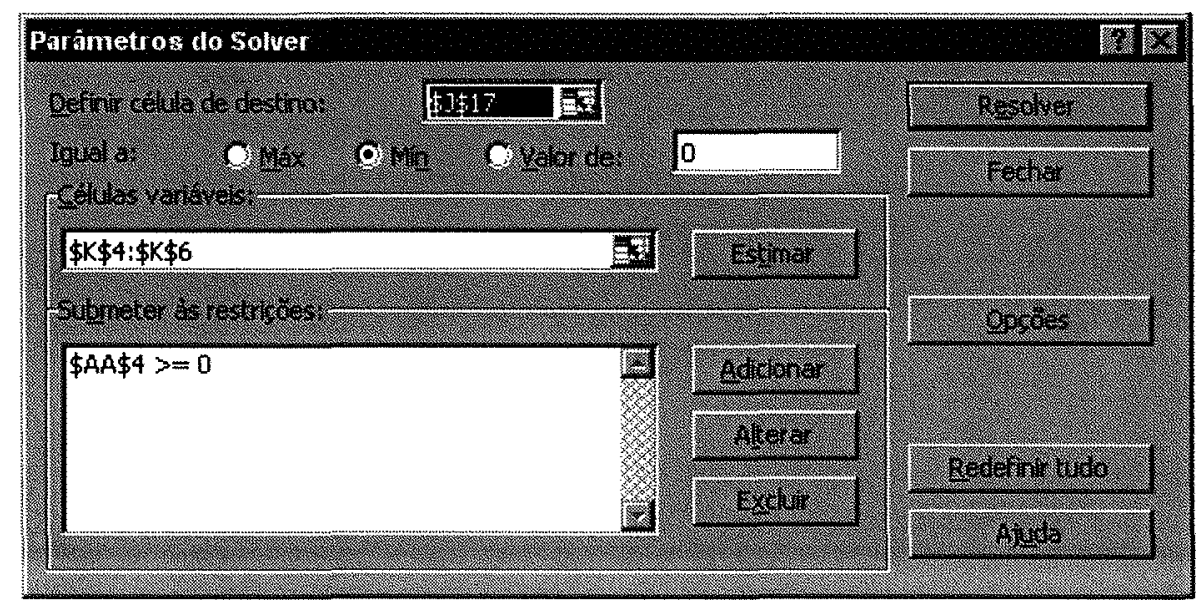

Figura 3 - Menu do otimizador para definição da "célula de destino", "célula variável" e restrições

A variação do conteúdo de água na capacidade de campo $\left(\theta_{\mathrm{cc}}\right)$ e ponto de murcha permanente $\left(\theta_{\mathrm{pmp}}\right)$ com a $\mathrm{D}_{\mathrm{s}}$ pode ser encontrada aplicando-se os valores críticos de potencial mátrico à eq. (2).

$$
\begin{aligned}
& \theta_{\mathrm{cc}}=\exp \left(a+b \mathrm{D}_{\mathrm{s}}\right) 0,01^{c} \\
& \theta_{\mathrm{pmp}}=\exp \left(a+b \mathrm{D}_{\mathrm{s}}\right) 1,5^{c}
\end{aligned}
$$

A variação do conteúdo de água em que a resistência do solo à penetração é igual a 2,0 MPa com a umidade do solo $\left(\theta_{\mathrm{rp}}\right)$ pode ser calculada isolando-se o conteúdo de água na Equação 3.

$$
\theta_{\mathrm{sr}}=\left(2,0 / d \mathrm{D}_{\mathrm{s}}^{\zeta}\right)^{(1 / e)} \text {. }
$$

A variação do conteúdo de água em que a porosidade de aeração é igual a $10 \%$ com a densidade do solo $\left(\theta_{\mathrm{pa}}\right)$ pode ser calculada conhecendo-se a densidade do solo e a densidade de partículas $\left(D_{\mathrm{p}}\right)$, aqui assumida como $2,65 \mathrm{~g} \mathrm{~cm}^{-3}$. 


$$
\theta_{\mathrm{pa}}=\left[\left(1-\mathrm{D}_{\mathrm{s}} / \mathrm{D}_{\mathrm{p}}\right)\right]-0,1
$$

Em que os parâmetros e variáveis nas eqs. (6), (7), (8) e (9) são os mesmos descritos anteriormente.

O limite superior (LS) do IHO pode ser determinado pelo menor valor dentre $\theta_{\mathrm{cc}}$ ou $\theta_{\mathrm{pa}}$. O limite inferior (LI) do IHO pode ser determinado pelo maior valor dentre $\theta_{\mathrm{rp}}$ ou $\theta_{\text {pmp. }}$ O IHO é determinado por IHO $=$ LS - LI e, como valores negativos não tem significado físico é necessário determinar que valores negativos sejam iguais a zero. Isso pode ser facilmente estabelecido no Excel $^{\circledR}$ usando a função "SE" incluída no programa. A Figura 5 ilustra as colunas com os valores preditos de $\theta_{\mathrm{cc}}, \theta_{\mathrm{pmp}}, \theta_{\mathrm{pa}}$ e $\theta_{\mathrm{rp}}$, juntamente com os resultados para os valores de LS, LI e IHO calculados utilizando blocos "SE".

$\mathrm{O}$ cálculo da densidade crítica do solo $\left(\mathrm{D}_{\mathrm{sc}}\right)$ pelo $\mathrm{IHO}$ é o último passo e muitas vezes o mais importante (do ponto de vista do manejo do solo) na avaliação do IHO. Para calcular a $D_{\mathrm{sc}}$ é necessário conhecer as equações para as variáveis $\theta_{\mathrm{cc}}, \theta_{\mathrm{pmp}}, \theta_{\mathrm{pa}}$, e $\theta_{\text {тр }}$ (eqs. 6, 7, 8 e 9) e então determinar quando LS e LI convergem de modo que IHO = 0 . Isto pode ser realizado analisando-se quais variáveis no conjunto de dados definem o primeiro ponto em que o IHO é igual a zero, ou por uma análise do gráfico das variáveis $\theta_{\mathrm{cc}}, \theta_{\mathrm{pmp}}, \theta_{\mathrm{pa}}$, e $\theta_{\mathrm{rp}}$ como função da $\mathrm{D}_{\mathrm{s}}$. Uma vez que as equações das variáveis que interceptam quando o IHO é igual a zero são identificadas, duas células devem ser estabelecidas com estas equações. Entretanto, as equações devem ser escritas como função de um valor simulado de densidade do solo que será otimizado para gerar o valor de $\mathrm{D}_{\text {sc. }}$. Outra célula com um valor simulado para a equação $\mathrm{LS}_{\text {equação }}-\mathrm{LI}_{\text {equação }}$ também deve ser criada (Figura 6). 


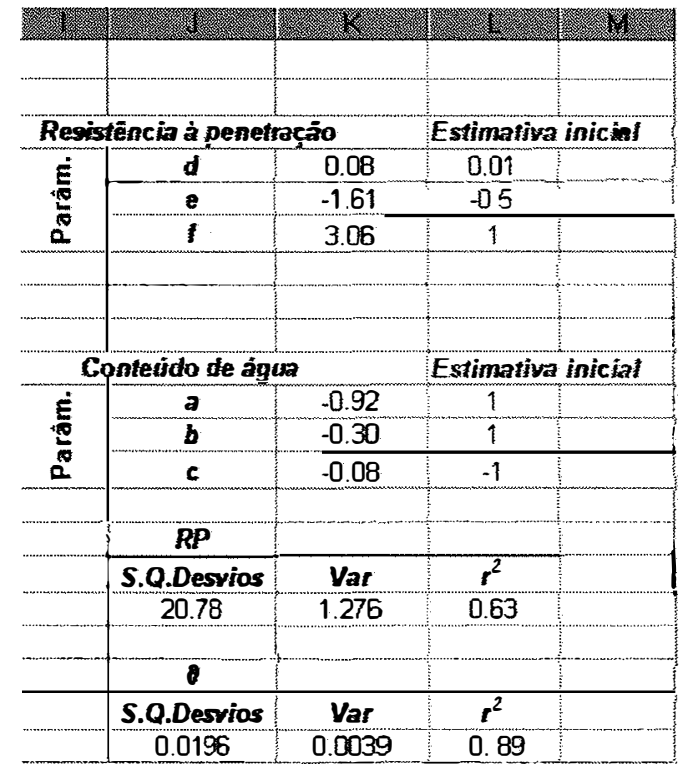

Figura 4 - Resultados após os procedimentos de otimização do solver

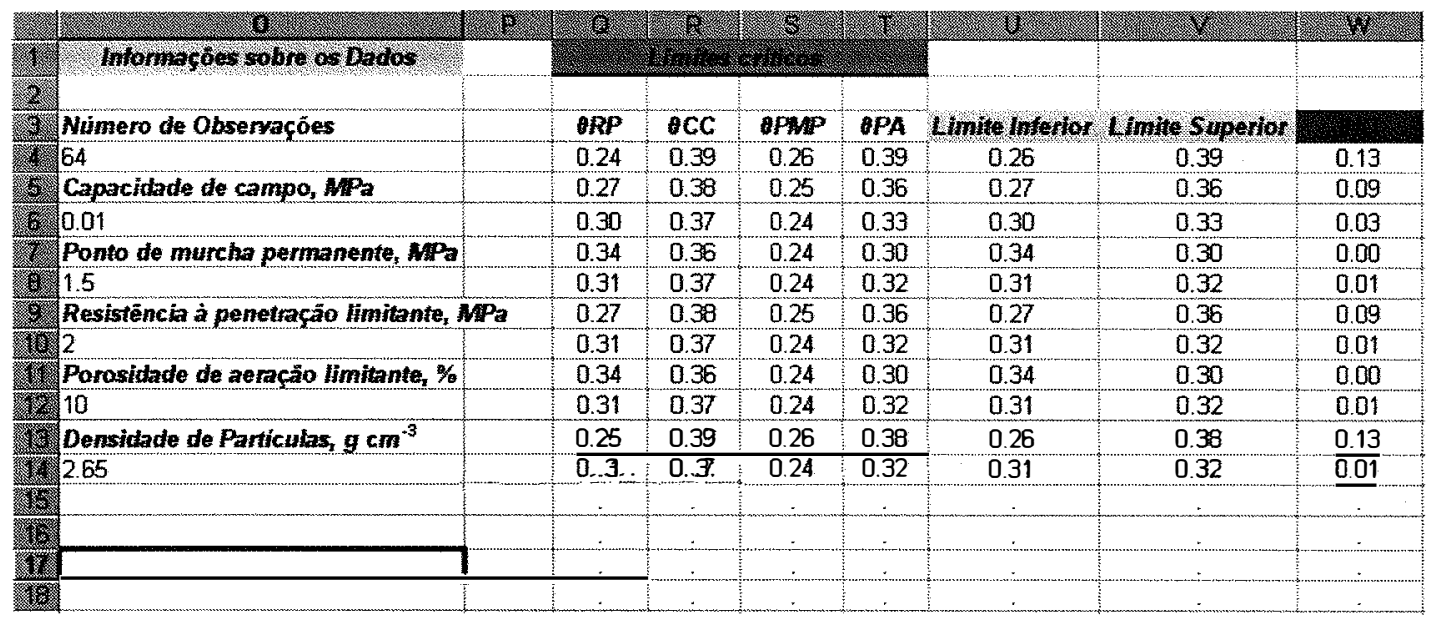

Figura 5 - Valores fixados para os limites críticos da capacidade de campo, ponto de murcha permanente, resistência à penetração do solo, porosidade de aeração e densidade de partículas (esquerda); e valores estimados para o intervalo hídrico ótimo (direita)

Neste ponto o comando "solver" é utilizado novamente. A "célula de destino" será o valor simulado de $\mathrm{LS}_{\text {equação }}-\mathrm{LI}_{\text {equação. }}$ A opção "min" deve ser selecionada e a "célula variável" será a célula contendo o valor simulado de $D_{\mathrm{s}}$ (Figura 6). É necessário 
estabelecer condições de contomo relativas à célula com valor simulado $\left(\mathrm{LS}_{\text {equação }}\right.$ $\mathrm{LI}_{\text {equação }}$ o qual não pode ser menor que zero na otimização. Após a otimização, a $\mathrm{D}_{\text {sc }}$ será determinada pelo "valor simulado" de $\mathrm{D}_{\mathrm{s}}$, como mostrado na Figura 6.

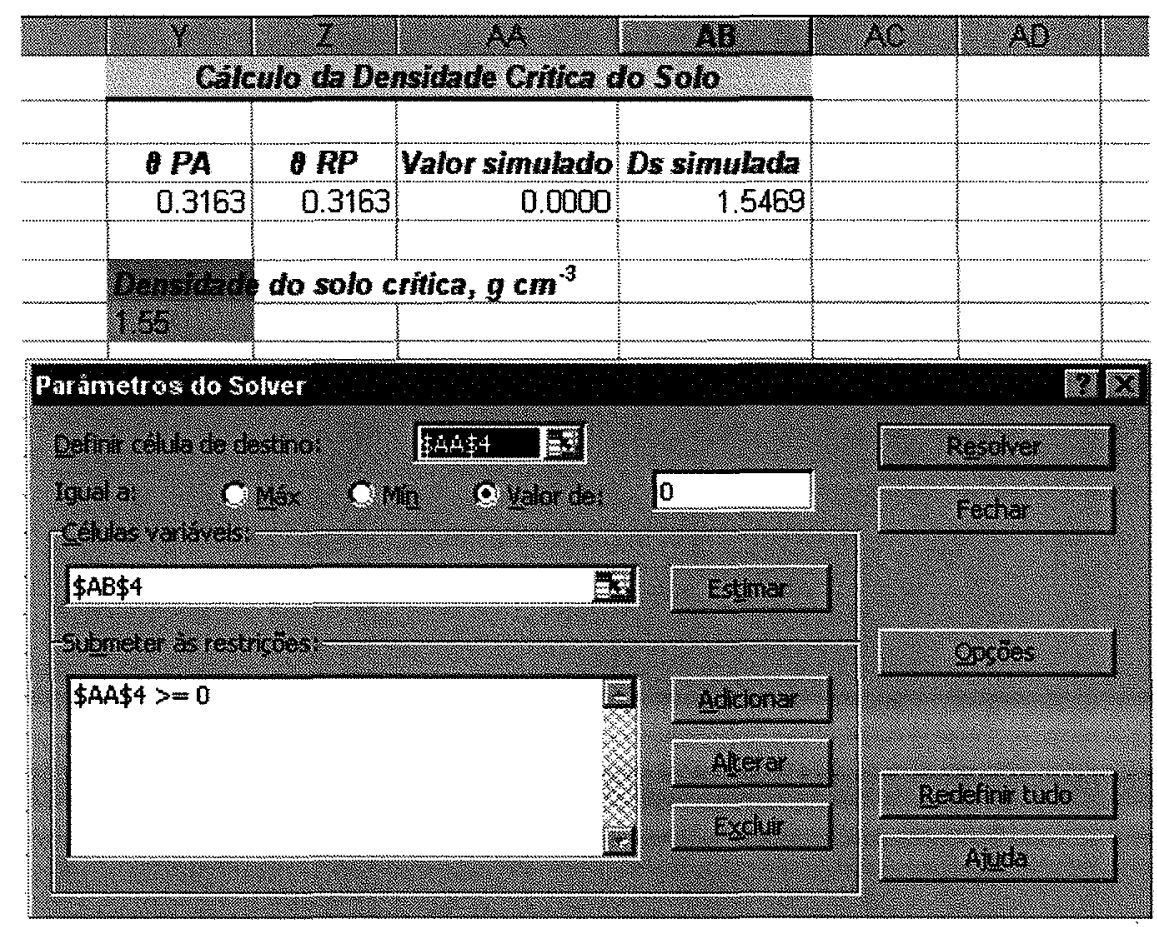

Figura 6 - Menu do otimizador "solver" para cálculo do intervalo hídrico ótimo

Os gráficos típicos do $\mathrm{IHO}$ resultantes dos procedimentos descritos acima são ilustrados nas Figuras 7 e 8 . Apesar do uso de procedimentos estatísticos simplificados, os resultados foram similares àqueles encontrados por Silva et al. (1994). A densidade do solo crítica encontrada pelo "Solver" do Excel $\left(D_{\mathrm{sc}}\right)$ foi de $1,55 \mathrm{~g} \mathrm{~cm}^{-3}$, enquanto Silva et al. (1994) encontraram $1,56 \mathrm{~g} \mathrm{~cm}^{-3}$. Esta pequena diferença nos valores pode ser atribuída aos métodos estatísticos utilizados em cada um dos casos. Silva et al. (1994) utilizaram regressão linear, enquanto que neste trabalho foram utilizadas técnicas de regressão não-linear, pela simplicidade de uso neste caso específico, e para evitar a necessidade de linearização dos modelos, conforme discutido anteriormente. Na planilha Excel $^{\circledR}$ apresentada aqui, as Figuras 7 e 8 são automaticamente plotadas utilizando os coeficientes ajustados para os modelos, evitando a necessidade de procedimentos de 
confecção de gráficos após as análises estatísticas. A Figura 7 apresenta os limites críticos do IHO por aeração $\left(\theta_{\mathrm{pa}}\right)$, capacidade de campo $\left(\theta_{\mathrm{cc}}\right)$, ponto de murcha permanente $\left(\theta_{\mathrm{pmp}}\right)$ e resistência à penetração do solo $\left(\theta_{\mathrm{rp}}\right)$ plotados como função da densidade do solo $\left(D_{s}\right)$. Uma estimativa do valor simulado para $D_{s}$ e as equações que interceptam onde o IHO é igual a zero podem ser facilmente visualizados na Figura 7. Esta informação pode ser utilizada para facilitar o procedimento de cálculo da densidade do solo crítica descrito anteriormente.

\section{Limites críticos do IHO}

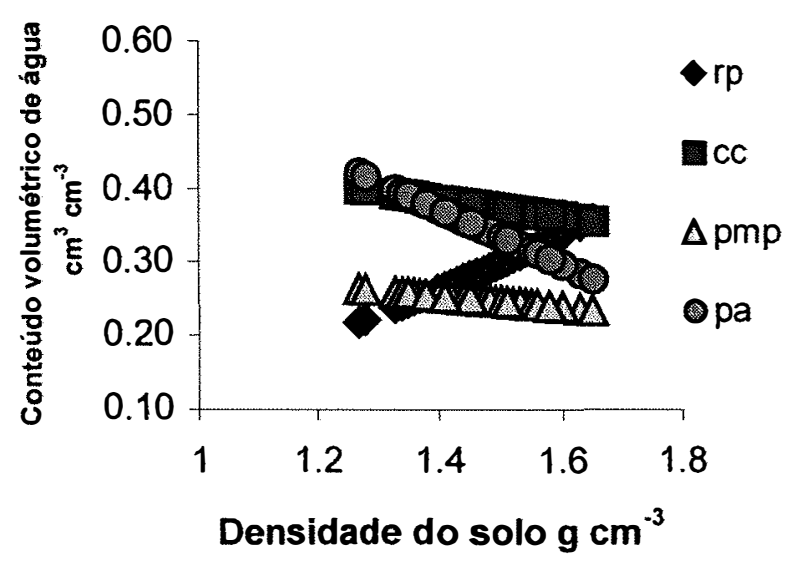

Figura 7 - Variação do conteúdo de água com a densidade do solo nos níveis críticos da capacidade de campo (cc) em 0,01 MPa, ponto de murcha permanente (pmp) em 1,5 MPa, porosidade de aeração (pa) de $10 \%$, e resistência à penetração de (rp) de $2 \mathrm{MPa}$

Apesar de não estimados na planilha descrita aqui, existem outros valores relevantes de $D_{s}$ para a avaliação do $\mathrm{IHO}$, os quais podem ser facilmente quantificados utilizando os procedimentos descritos acima. Estes valores são: (i) a $D_{s}$ em que a $\theta_{p a}$ substitui a $\theta_{\mathrm{cc}}$ como limite superior do IHO, e (ii) a $\mathrm{D}_{\mathrm{s}}$ em que $\theta_{\mathrm{rp}}$ substitui $\theta_{\mathrm{pmp}}$ como limite inferior do IHO (Silva \& Kay, 1997). Outras combinações relevantes também podem ser encontradas de acordo com as características dos dados do usuário. 
Outro gráfico que tem sido muito utilizado na caracterização e interpretação do IHO é ilustrado na Figura 8. A variação do IHO é apresentada como função da $\mathrm{D}_{\mathrm{s}}$. A partir de gráficos similares a este, Tormena et al. (1999) foram capazes de identificar importantes tendências na análise do IHO, como intervalos de valores onde o IHO é positivamente correlacionado com a $\mathrm{D}_{\mathrm{s}}$, e o valor de $\mathrm{D}_{\mathrm{s}}$ onde o IHO começa a decrescer acentuadamente.

IHO

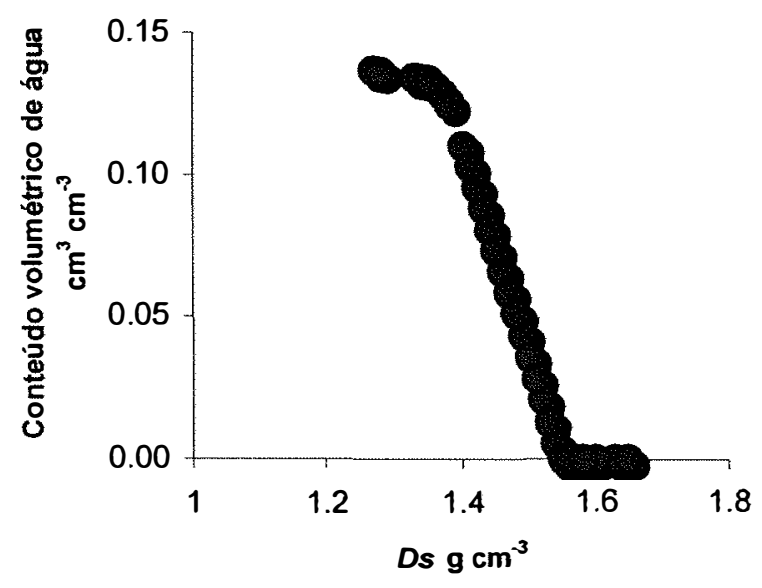

Figura 8 - Variação do intervalo hídrico ótimo (IHO) com a densidade do solo

\subsection{Conclusões}

O algoritmo simplificado apresentado aqui é uma alternativa na redução do tempo para realização das análises estatísticas e confeç̧ão dos gráficos utilizados na quantificação e avaliação do intervalo hídrico ótimo como um índice da qualidade física do solo. Apesar da simplicidade dos procedimentos e técnicas numéricas de otimização utilizadas, o procedimento de regressão não-linear produziu resultados confiáveis quando comparados àqueles encontrados em literatura. $\mathrm{O}$ valor de densidade crítica do solo e os gráficos do IHO são também produzidos pelo algoritmo, facilitando a interpretação dos resultados. 


\section{CÓDIGO SAS PARA QUANTIFICAÇÃO DO INTERVALO HÍDRICO ÓTIMO DOS SOLOS}

\section{Resumo}

O intervalo hídrico ótimo (IHO) é uma metodologia utilizada para estimar o conteúdo ótimo de água no solo para crescimento de plantas baseado na quantificação dos valores de densidade do solo para um determinado solo. Entretanto, o uso desta metodologia pela comunidade científica tem sido restrito pela ausência de uma descrição detalhada dos procedimentos estatísticos e matemáticos usados na quantificação do IHO. Neste capítulo é descrito um algoritmo em linguagem SAS para cálculo do IHO à partir de dados de densidade do solo, conteúdo volumétrico de água, potencial mátrico e resistência do solo à penetração. Como são utilizadas técnicas de regressão não-linear, uma descrição sucinta da teoria envolvida neste tipo de análise estatística é apresentada. Para melhorar a visualização e interpretação dos resultados do IHO, uma sub-rotina para confecção de gráficos é também descrita. O código SAS apresentado aqui produziu resultados confiáveis quando comparados com aqueles encontrados em literatura e deste modo é uma ferramenta útil para simplificar a análise e interpretação do IHO.

Termos de indexação: regressao não-linear, SAS, otimização. 


\section{A SAS CODE FOR QUANTIFICATION OF THE LEAST LIMITING WATER RANGE OF SOILS}

\section{Summary}

The least limiting water range (LLWR) approach is used to estimate the optimum soil water content for plant growth based on the quantification of the bulk density values for a given soil type under evaluation. However, the use of this methodological approach by soil science scientific community has been restricted by the lack of a detailed description of the statistical and mathematical procedures used for the quantification of the LLWR. This paper describes a SAS algorithm for calculation of the LLWR from bulk density, volumetric water content, water potential and soil penetration resistance data. Since nonlinear regression techniques are used, a brief description of the theory involved in this type of statistical analysis is presented. In order to improve the visualization and interpretation of the LLWR results, a plotting subroutine is also described. The SAS code present here produced reliable results when compared to those found in literature and is therefore a valuable tool for simplifying the analysis and interpretation of the LLWR.

Index terms: nonlinear regression, SAS, optimization.

\subsection{Introdução}

O intervalo hídrico ótimo (IHO) é uma função de pedotransferência usada para estimar o conteúdo ótimo de água no solo para o crescimento de plantas baseado na quantificação dos valores da densidade do solo para um determinado tipo de solo em avaliação. Entretanto, antes da sua aplicação, é necessário quantificar os parâmetros de uma função de retenção de água $\theta(\psi)$ e uma função de resistência à penetração $\operatorname{RP}(\theta$, $D_{s}$ ) (Silva et al., 1994; Leão \& Silva, 2004).

O IHO tem sido empregado por diversos grupos de pesquisa no mundo, para a avaliação da qualidade física do solo em diferentes culturas em condições de manejo 
(e.g. Zou et al. 1998; Tormena et al., 1999; McKenzie \& McBratney, 2001; Sharma \& Bhusan, 2001; Drury et al., 2003; Wu et al., 2003). Entretanto, a popularização do uso do IHO entre pesquisadores tem sido restrita pela ausência de uma descrição detalhada dos procedimentos estatísticos não-lineares de estimativa dos parâmetros para as funções $\theta(\psi)$ e $\mathrm{RP}\left(\theta, D_{b}\right)$ e também dos procedimentos matemáticos para cálculo dos valores do IHO e da densidade do solo crítica (Dsc) onde o IHO é igual a zero.

Nas primeiras descrições do procedimento de quantificação do IHO, transformações lineares das funções $\theta(\psi)$ e $\operatorname{RP}\left(\theta, D_{b}\right)$ eram normalmente empregadas (Silva et al., 1994; Betz et al., 1998). Este procedimento era utilizado para evitar a necessidade de trabalhar com procedimentos de ajuste não-linear. Na época, os algoritmos de regressão linear eram mais confiáveis estatísticamente e simples de se utilizar que a grande maioria dos procedimentos de regressão não-linear implementados em softwares estatísticos ou matemáticos.

O uso de técnicas de regressão não-linear para ajuste de curvas cresceu enormemente nas últimas décadas (Chambers, 1973; Gallant, 1987; Ratkowsky, 1991) e aplicações em ciência do solo são agora comuns (Wrait and Or, 1998; Šimůnek and Hopmans, 2002). As razões para o aumento no uso de regressão não-linear estão associadas a: i) Popularização de softwares estatísticos ou matemáticos contendo algoritmos para regressão não-linear (e.g. SAS ${ }^{\circledR}, \operatorname{Origin}^{\circledR}, \operatorname{MathCad}^{\circledR}, \operatorname{Excel}^{\circledR}$ ); ii) Desenvolvimento de técnicas numéricas mais robustas para o ajuste de equações nãolineares, a dados observados, com propriedades de convergência melhoradas, tais como o algoritmo de Levenberg-Marquardt (Šimůnek \& Hopmans, 2002); e iii) Desenvolvimento de metodologias para avaliação da qualidade do ajuste e análise residual (Souza, 1998).

Deste modo, o objetivo deste trabalho foi propor um algoritmo para estimativa do intervalo hídrico ótimo do solo usando a linguagem de programação do software SAS e discutir aspectos técnicos à respeito dos procedimentos de ajuste não-linear. $\mathrm{O}$ algoritmo foi desenvolvido em SAS devido à sua grande aceitação entre a comunidade científica e à sua grande flexibilidade de módulos e procedimentos. Entretanto, a sequência de operações descritas aqui pode ser facilmente adaptada para outros softwares ou 
linguagens de programação de acordo com a experiência e recursos computacionais do usuário.

\subsection{Revisão de Literatura}

Um modelo de regressão não-linear pode ser escrito da seguinte forma (Bates \& Watts, 1988; Seber \& Wild, 1989; Souza, 1998):

$$
y_{\mathrm{i}}=f\left(\mathbf{x}_{\mathrm{i}} ; \boldsymbol{q}\right)+\varepsilon_{\mathrm{i}}(i=1,2, \ldots, n)
$$

Em que $\mathrm{E}\left[\varepsilon_{\mathrm{i}}\right]=0$ é o termo estocástico, $f$ é a função resposta $\mathrm{e} \mathbf{x}_{\mathbf{i}}$ é um vetor de regressores associados ou variáveis independentes de enésima ordem. Este modelo é exatamente o mesmo caso de um modelo linear, exceto que as respostas esperadas são funções não-lineares de um parâmetro $m$-dimensional, descrito aqui como $\boldsymbol{q}$. Isto significa que, em modelos não-lineares, pelo menos uma das derivadas dos parâmetros é função de pelo menos um dos parâmetros (Bates \& Watts, 1988).

Existe um grande número de técnicas de ajuste especializadas para modelos nãolineares, e dentre elas, a melhor e mais conhecida é a dos modelos não-lineares de mínimos quadrados.

$$
\mathrm{F}(\boldsymbol{q})=\sum_{i=1}^{N}\left\{y_{\mathrm{i}}-f_{\mathrm{i}}(\boldsymbol{q})\right\}^{2}
$$

Nesta técnica, valores adequados de ajuste dos parâmetros são aqueles em que a função objetiva $F(\boldsymbol{q})$ assume valores mínimos. As ferramentas computacionais básicas para mínimos quadrados não-lineares são as mesmas que no caso de mínimos quadrados lineares. Para alcançar isto, todos os métodos atualmente utilizados começam com uma aproximação linear a $f_{\mathrm{i}}(\boldsymbol{q})$.

$$
f(\boldsymbol{q}+\delta) \cong h_{\mathrm{i}}+\boldsymbol{a}_{\mathrm{i}} . \delta
$$

Em que $h_{\mathrm{i}}$ e $\boldsymbol{a}_{\mathbf{i}}$ dependem dos cálculos conduzidos em $\boldsymbol{q}$, e possivelmente em outros pontos prévios. O método mais antigo para realizar este cálculo, conhecido como método de Gauss usa uma série de Taylor simples para aproximar $f_{\mathrm{i}}$

$$
h_{\mathrm{i}}=f_{\mathrm{i}}(\boldsymbol{q}), \quad \boldsymbol{a}_{\mathrm{i}}=\partial f_{\mathrm{i}} / \partial \boldsymbol{q}
$$

O procedimento escolhe $\delta$ de modo a minimizar a soma dos quadrados linear. 


$$
\sum_{i=1}^{N}\left(z_{\mathrm{i}}-a_{\mathrm{i}} . \delta\right)^{2}
$$

Em que $z_{\mathrm{i}}=y_{\mathrm{i}}-h_{\mathrm{i}}$.

Como a seqüência produzida por aplicações diretas da eq. 5 pode não obter convergência, vários métodos computacionais para mínimos quadrados não-lineares têm sido desenvolvidos (Seber \& Wild, 1989). Dentre eles, um método bastante eficiente, conhecido como método de Levenberg-Marquardt se tornou padrão em modelos nãolineares de mínimos quadrados empregados em estudos de ciência do solo e hidrologia (Šimůnek \& Hopmans, 2002). Em alguns casos, métodos mais genéricos, presentes em planilhas eletrônicas, como o gradiente conjugado e o de Newton podem ser usados sem grandes perdas na qualidade dos resultados da otimização de modelos não-lineares em relação àqueles obtidos pelo método de Levenberg-Marquardt (Wraith \& Or, 1998). Seber and Wild (1989) argumentam que o algoritmo de Levenberg-Marquardt provou ser um bom algoritmo para problemas de mínimos quadrados, exceto no caso de problemas com resíduos excessivos, onde a convergência linear pode ser muito lenta ou falhar.

A quantificação do intervalo hídrico ótimo (IHO) é baseada no ajuste de uma função de retenção de água e uma função de resistência à penetração do solo. A função de retenção de água neste caso específico deve levar em consideração a variabilidade estrutural do solo, o que pode ser obtido incorporando-se a densidade do solo na equação. Silva et al. (1994) incorporaram a variabilidade da densidade do solo em uma função potência simples, empregada por Ross et al. (1991) para o ajuste da curva de retenção de água:

$$
\theta=a \Psi^{b}
$$

Em que:

$\theta=$ Umidade volumétrica $\left[\mathrm{L}^{3} \mathrm{~L}^{-3}\right]$.

$\Psi=$ Potencial mátrico $\left[\mathrm{M} \mathrm{L}^{-1} \mathrm{~T}^{-2}\right]$.

$a, b=$ Parâmetros empíricos.

Os procedimentos de regressão stepwise de Silva et al. (1994) resultaram em uma equação não-linear de três parâmetros com boas propriedades para caracterizar a 
influência estrutural no processo de retenção de água no solo (Tormena et al., 1998; Betz et al., 1998):

$$
\theta=\exp \left(a+b \mathrm{D}_{\mathrm{s}}\right) \Psi^{c}
$$

Em que:

$\theta=$ Umidade volumétrica $\left[\mathrm{L}^{3} \mathrm{~L}^{-3}\right]$.

$\mathrm{D}_{\mathrm{s}}=$ Densidade do solo $\left[\mathrm{M} \mathrm{L}^{-3}\right]$.

$\Psi=$ Potencial mátrico $\left[\mathrm{ML}^{-1} \mathrm{~T}^{-2}\right]$.

$a, b$, e $c=$ Parâmetros empíricos.

A função de resistência à penetração do solo tem sido adequadamente descrita usando a equação não-linear proposta por Busscher \& Sojka (1987) (Silva et al., 1994; Betz et al., 1998; Leão, 2002).

$$
\mathrm{RP}=d \theta^{e} \mathrm{D}_{\mathrm{s}}^{f}
$$

Em que:

$\mathrm{RP}=$ Resistência do solo à penetração $\left[\mathrm{M} \mathrm{L}^{-1} \mathrm{~T}^{-2}\right]$.

$\theta=$ Umidade volumétrica $\left[\mathrm{L}^{3} \mathrm{~L}^{-3}\right]$.

$\mathrm{D}_{\mathrm{s}}=$ Densidade do solo $\left[\mathrm{M} \mathrm{L}^{-3}\right]$.

$d, e$, e $f=$ Parâmetros empíricos.

As eqs. 7 e 8 são passíveis de linearização, através de transformação logarítmica. Devido à simplicidade de se utilizar métodos de regressão linear, alguns pesquisadores preferem trabalhar com elas na forma linearizada (Silva et al., 1994; Betz et al., 1998; Zou et al., 2000). Entretanto, este procedimento não foi adotado neste trabalho pelas seguintes razões: i) Dada a disponibilidade de algoritmos eficientes para regressão nãolinear, a utilidade da linearização é discutível (Seber \& Wild, 1989); e ii) A transformação dos dados normalmente envolve uma transformação do termo estocástico, o que afeta as suposições estatísticas sobre o modelo (Bates \& Watts, 1988). 


\subsection{Material e Métodos}

As ferramentas computacionais necessárias para avaliar o intervalo hídrico ótimo são os módulos SAS/STAT (SAS Institute, 1999a), SAS/GRAPH (SAS Institute, 2000) e SAS/OR (SAS Institute, 1999b) inclusos no software SAS, versão 9. Os dados de entrada necessários para o cálculo do IHO incluem a s variáveis densidade do solo $(\mathrm{Db})$, umidade volumétrica (ThetaV), resistência à penetração (PR) e potencial da água (|Psi|).

O conjunto de dados utilizados no desenvolvimento do programa foi coletado e descrito por Silva et al. (1994). Como existem diversas publicações tratando de aspectos teóricos do conceito do IHO (Letey, 1985; Brady \& Weil, 1999; Silva et al., 2002a) e também dos procedimentos de coleta de amostras e análises laboratoriais necessárias para a quantificação das variáveis Db, ThetaV, PR e Psi (Klute, 1986; Silva et al., 1994; Betz et al., 1998; Tormena et al., 1999) este trabalho foi focado principalmente nos procedimentos de análise de dados.

\subsubsection{Dados de entrada}

Um exemplo de dados de entrada, de um solo franco siltoso descrito por Silva et al. (1994) é apresentado a seguir. O conjunto de dados utilizado no software SAS é apresentado no arquivo SKP1994.dat, parte do qual é ilustrado a seguir.
$\begin{array}{llll}1.35 & 0.4305 & 0.23 & 0.0020\end{array}$
$\begin{array}{llll}1.43 & 0.4209 & 0.85 & 0.0050\end{array}$
$\begin{array}{lllll}1.51 & 0.3630 & 0.50 & 0.0080\end{array}$
$\begin{array}{llll}1.60 & 0.3670 & 1.34 & 0.0100\end{array}$
$\begin{array}{llll}1.54 & 0.3097 & 2.13 & 0.0333\end{array}$
$\begin{array}{llll}1.43 & 0.3217 & 0.61 & 0.1\end{array}$
$\begin{array}{llll}1.53 & 0.2516 & 2.27 & 0.5\end{array}$
$\begin{array}{llll}1.58 & 0.2324 & 3.94 & 1.5\end{array}$ 


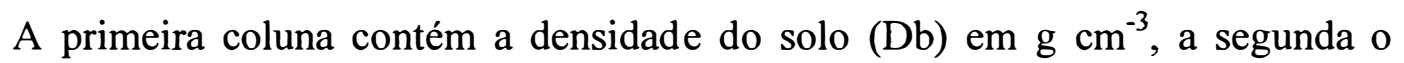
conteúdo volumétrico de água (ThetaV) $\mathrm{em}^{3} \mathrm{~cm}^{-3}$, e a terceira e quarta colunas a resistência a penetração (PR) e o potencial mátrico (|Psi|), respectivamente, ambos em $\mathrm{MPa}$. O comando SAS para leitura de arquivos externos é apresentado a seguir:

data LLWR;

infile 'c:\SKP1994.dat';

input Db ThetaV PR Psi;

\subsubsection{Estimativa de parâmetros por regressão não-linear e cálculo do IHO}

Uma vez que o arquivo externo é lido pelo código, o próximo passo é o ajuste das funções de resistência à penetração e retenção de água descritas pelas eqs. (7) e (8). Este passo também é realizado através dos comandos do software SAS/STAT. O procedimento PROC NLIN (SAS Institute 1999a) utilizado para análise de regressão não-linear é utilizado para a estimativa dos parametros empíricos $a, b, c, d, e$, e $f$ das eqs. (7) e (8). O fragmento de código utilizado para ajustar as duas equações é apresentado a seguir:

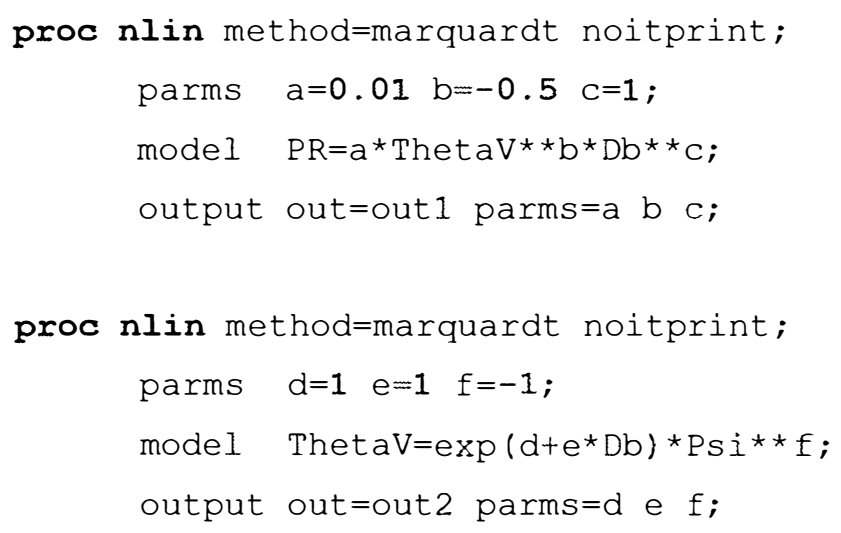

A opção METHOD = MARQUARDT seleciona o algoritmo de LevenbergMarquardt para tratamento do problema de quadrados mínimos não lineares apresentado. O método de Levenberg-Marquardt é atualmente um dos mais eficientes algoritmos para a solução de quadrados mínimos não lineares e tem sido amplamente utilizado em estudos em hidrologia e ciência do solo (Šimůnek and Hopmans, 2002). A opção 
NOITPRINT impede que as iterações do procedimento de otimização sejam impressas no 'output' do programa, entretanto, o usuário deve sempre checar o 'output' para verificar a convergência do algoritmo. Estimativas inicias para os parâmetros são dadas no comando PARMS e podem ser alteradas ou restritas de acordo com as propriedades de convergência do procedimento. Como resultado do PROC NLIN, os arquivos de saída OUT1 e OUT2 contêm as estimativas dos parâmetros utilizadas nos cálculos do IHO.

Com as estimativas dos parâmetros obtidas pelo PROC NLIN as eqs. (7) e (8) são manipuladas algebricamente para fornecer os limites críticos do IHO como função da Db apenas:

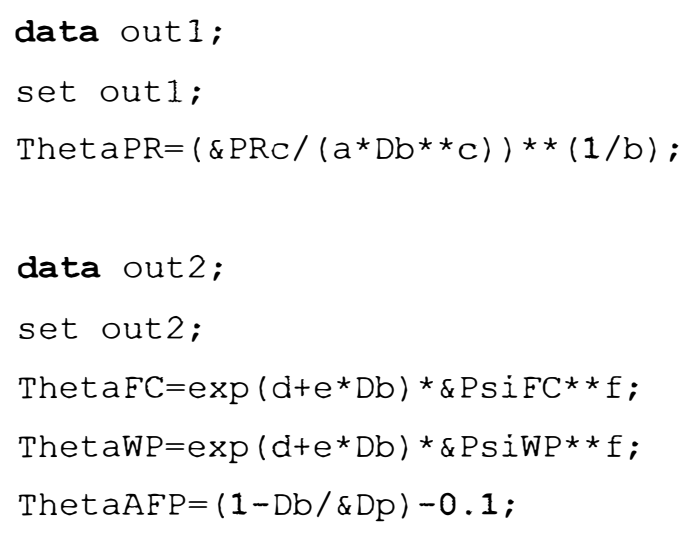

Aqui, ThetaPR é a variação do conteúdo de água em que a resistência à penetração é igual a um determinado valor crítico, com a densidade do solo, ThetaFC é a variação do conteúdo de água no solo na capacidade de campo com a densidade do solo, ThetaWP a variação do conteúdo de água no ponto de murcha permanente com a densidade do solo, e ThetaAFP é a variação do conteúdo de água em que a porosidade de aeração é igual a 10\% com a densidade do solo. A função ThetaAFP é estimada a partir da porosidade total do solo $[(1-\mathrm{Db} / \mathrm{Dp})-0,1]$, onde $\mathrm{Dp}=$ densidade de partículas do solo.

Neste ponto, é válido assinalar que os limites críticos para densidade de partículas (Dp), potencial mátrico na capacidade de campo (PsiFC), ponto de murcha permanente (PsiWP), resistência à penetração ( $\mathrm{PRc}$ ), e porosidade de aeração (AFPc) são definidos no início do código através de comandos de macro do SAS: 
ㄴLET Dp $=2.65$;

LET PSIFC $=0.01$;

LET PRC $=2.0$;

○LET PSIWP = 1.5;

OLET AFPC = 10;

Onde os valores críticos foram obtidos da literatura (e.g. Silva et al., 1994). Para o exemplo apresentado aqui, a densidade de partículas foi assumida como $2,65 \mathrm{~g} \mathrm{~cm}^{-3}$ (Brady and Weil, 1999), a capacidade de campo em $|-0,01| \mathrm{MPa}$, o ponto de murcha em $|-1,5| \mathrm{MPa}$, a resistência à penetração restritiva ao crescimento de plantas em 2,0 $\mathrm{MPa}$, e a porosidade de aeração limitante em $10 \%$. Entretanto, o usuário deve mudar estes limites críticos de acordo com seu conhecimento dos fenômenos envolvidos nestes limites críticos, e condições experimentais.

Como descrito por Wu et al. (2003) existem quatro possibilidades para o cálculo do IHO, dependendo dos valores das funções ThetaPR, ThetaFC, ThetaWP e ThetaAFC:

(a) Se (ThetaAFP $\geq$ ThetaFC) e (ThetaPR $\leq$ ThetaWP):

$$
\mathrm{IHO}=\text { ThetaFC }- \text { ThetaWP; }
$$

(b) Se (ThetaAFP $\geq$ ThetaFC) e (ThetaPR $\geq$ ThetaWP):

$$
\mathrm{IHO}=\text { ThetaFC }- \text { ThetaPR; }
$$

(c) Se (ThetaAFP $\leq$ ThetaFC) e (ThetaPR $\leq$ ThetaWP):

$$
\mathrm{IHO}=\text { ThetaAFP }- \text { ThetaWP; }
$$

(d) Se (ThetaAFP $\leq$ ThetaFC) e (ThetaPR $\geq$ ThetaWP):

$$
\mathrm{IHO}=\text { ThetaFC }- \text { ThetaPR. }
$$

Estas possibilidades podem ser facilmente implementadas no software SAS, bem como, na maioria das linguagens de programação utilizando blocos "IF" "THEN" (Ver Anexo A1 para detalhes). 


\subsubsection{Estimativa da densidade crítica do solo}

Uma subrotina para cálculo da densidade crítica (Dbc), em que o IHO é igual a zero é apresentada aqui. Caso o cálculo da Dbc não seja necessário, o usuário deve simplesmente remover a subrotina para cálculo da Dbc do código (Ver Anexo A1). A densidade crítica é calculada através de procedimentos de otimização, utilizando o módulo de Pesquisa Operacional do software SAS: SAS/OR (SAS Institute, 1999b).

O procedimento de programação não linear PROC NLP (SAS Institute, 1999b) é utilizado para cálculo do valor de densidade crítica, onde o IHO é igual a zero. O algoritmo de Levenberg-Marquardt é também empregado neste módulo, sendo selecionado através do commando $\mathrm{TECH}=\mathrm{LM}$. As equações que interceptam onde o IHO é igual a zero são automaticamente selecionadas dentre as equações ThetaFC, ThetaWP, ThetaPR e ThetaAFP e inseridas como MODEL1 (Para o limite inferior do IHO) e MODEL2 (Para o limite superior do IHO). A variável simulada, z, é otimizada por quadrados mínimos como $\mathrm{z}=$ MODEL1 - MODEL2, dentro dos valores de contorno $0<\mathrm{X}<2,0 \mathrm{~g} \mathrm{~cm}^{-3}$. O resultado é o valor de $\mathrm{X}$, ou de densidade do solo onde $\mathrm{z}=0$, também conhecido como densidade crítica do solo (Dbc). Os limites críticos dentre PR, WP, FC e AFP que interceptam onde o IHO é igual a zero são também indicados qualitativamente como a variável Intercept no 'output' do software SAS.

\subsubsection{Construção do gráfico}

Uma subrotina para construção do gráfico apresentando o IHO também é apresentada, com o objetivo de melhorar qualitativamente a avaliação do IHO. O procedimento PROC GPLOT incluído no módulo SAS/GRAPH (SAS Institute 1999a) é utilizado para a produção de gráficos com qualidade para publicação. Um código SAS descrito no manual do programa foi adaptado de modo que a área entre os limites superior e inferior do IHO fosse preenchida (SAS Institute, 1990) (Ver Anexo Al para detalhes). 


\subsubsection{Exemplo de aplicação}

O código apresentado foi utilizado para o cálculo do IHO para o conjunto de dados SKP1994.dat (Silva et al., 1994). Os resultados da análise de regressão não linear para as eqs. (7) e (8) são apresentados nas Tabelas 1 e 2 . A razão $F$ e o intervalo de confiança mostraram que o ajuste foi altamente significativo para as duas funções avaliadas (Tabelas 1 e 2) (Glantz and Slinker, 1990). O gráfico produzido pelo código SAS é apresentado na Figura 1. A densidade crítica calculada pelo algoritmo, onde os limites críticos superior e inferior do IHO se interceptam, é representada no gráfico por uma linha vertical. A Figura 1 é muito similar a figura produzida por Silva et al. (1994) em seu desenvolvimento do conceito do IHO. A densidade crítica calculada pelo método proposto aqui $\left(\mathrm{Dbc}=1.55 \mathrm{~g} \mathrm{~cm}^{-3}\right)$ foi muito similar aquela encontrada por Silva et al. (1994) $\left(\mathrm{Dbc}=1.56 \mathrm{~g} \mathrm{~cm}^{-3}\right)$. O gráfico 1:1 do IHO estimado pelo método de regressão não-linear proposto aqui versus o IHO estimado por técnicas convencionais de regressão linear é apresentado na Figura 2. O elevado coeficiente de determinação para o ajuste $1: 1\left(r^{2}=0,99\right)$ mostra que os valores estimados pelos dois métodos foram muito equivalentes, confirmando a eficiência do novo método.

$\mathrm{O}$ código resulta em um arquivo SAS que pode ser facilmente exportado para planilhas eletrônicas ou utilizado em análises estatísticas posteriores. Aqui, o arquivo de saída é denominado Final e contêm as variáveis Db, ThetaV, PR, Psi, ThetaPR, ThetaFC, ThetaWP, ThetaAFP, UL (limite superior do IHO), LL (limite inferior do IHO) e LLWR (IHO). 


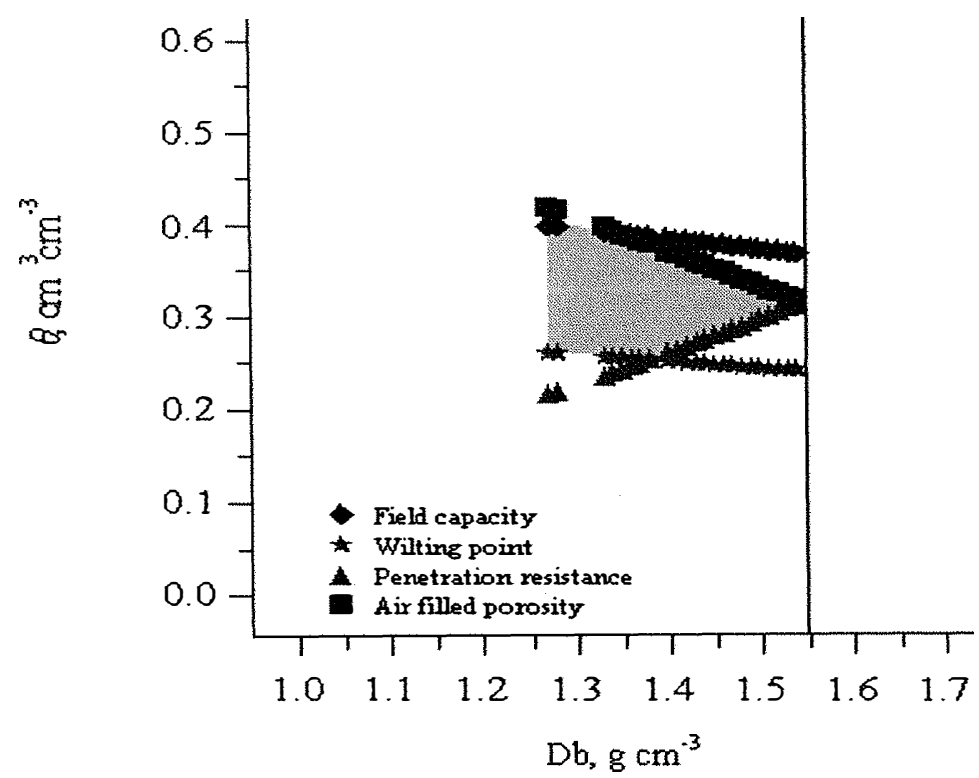

Figura 1 - Variação do conteúdo de água $(\theta)$ com a densidade do solo $(\mathrm{Db})$ nos limites críticos da capacidade de campo em $0,01 \mathrm{MPa}$, ponto de murcha permanente, em 1,5 MPa, porosidade de aeração de $10 \%$, e resistência à penetração de 2 MPa. A linha vertical representa a densidade crítica do solo, onde o $\mathrm{IHO}=0$

Tabela 1. Ajuste por quadrados mínimos da função de retenção de água: $\theta=\exp (a+b$ $\left.D_{b}\right) \Psi^{\mathrm{c}}$

\begin{tabular}{ccccc}
\hline Parâmetro & Estimativa & Erro Padrão & \multicolumn{2}{c}{$\begin{array}{c}\text { 95\% Intervalo de } \\
\text { Confiança }\end{array}$} \\
\hline $\boldsymbol{a}$ & $-0,9175$ & 0,1471 & $-1,2117$ & $-0,6234$ \\
$b$ & $-0,3027$ & 0,0997 & $-0,5021$ & $-0,1034$ \\
$c$ & $-0,0835$ & 0,00416 & $-0,0918$ & $-0,0752$ \\
\hline$F=5184,11 ; p<0,0001$ & & & \\
$\theta:$ Conteúdo volumétrico de água $\left(\mathrm{cm}^{3} \mathrm{~cm}^{-3}\right), D_{b}$ : Densidade do solo \\
$\left(\mathrm{Mg} \mathrm{m}^{-3}\right),|\psi|:$ Potencial mátrico $(\mathrm{MPa})$
\end{tabular}


Tabela 2. Ajuste por quadrados mínimos da função de resistancia a penetração: $R P=d$ $\theta^{\mathrm{e}} D_{b}^{\mathrm{f}}$

\begin{tabular}{ccccc}
\hline Parâmetro & Estimativa & Erro Padrão & \multicolumn{2}{c}{$\begin{array}{c}\text { C5\% Intervalo de } \\
\text { Confiança }\end{array}$} \\
\hline$d$ & 0,0827 & 0,0273 & 0,0281 & 0,1373 \\
$e$ & $-1,6087$ & 0,1762 & $-1,9611$ & $-1,2564$ \\
$f$ & 3,057 & 0,787 & 1,4833 & 4,6308 \\
\hline$F=176,67 ; p<0,0001$ & & &
\end{tabular}

PR: Resistência do solo à penetração $(\mathrm{MPa}), \theta$ : Conteúdo volumétrico de água $\left(\mathrm{cm}^{3} \mathrm{~cm}^{-3}\right), D_{b}$ : Densidade do solo $\left(\mathrm{g} \mathrm{cm}^{-3}\right)$

\subsection{Conclusão}

O algoritmo apresentado neste trabalho é uma ferramenta estatística confiável e eficiente para a quantificação do intervalo hidrico ótimo dos solos. É uma alternativa que reduz o tempo das análises estatísticas e procedimentos de confecção de gráficos utilizados na quantificação e avaliação do intervalo hídrico ótimo como um índice da qualidade física do solo. Outra vantagem é que o algoritmo pode ser modificado ou adaptado para outros softwares de acordo com o conhecimento e/ou condições experimentais do usuário. $\mathrm{O}$ código SAS e o arquivo SKP.dat estao disponíveis através de contato com o autor: trpleao@hotmail.com. 


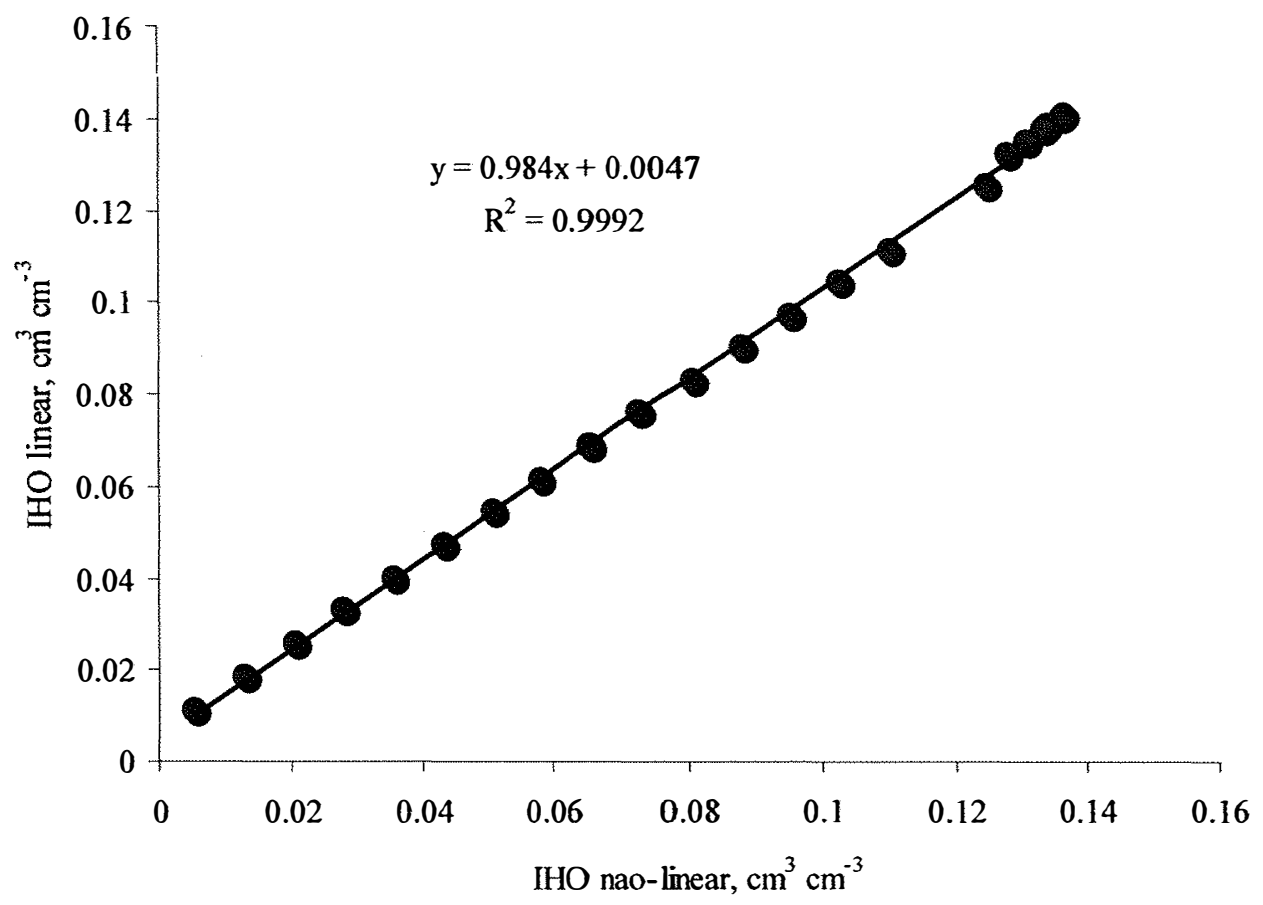

Figura 2 - Gráfico 1:1 para o intervalo hídrico ótimo (IHO) estimado pelo método nãolinear proposto neste trabalho (IHO não-linear) e o IHO estimado por regressão linear 


\section{MÉTOdO ESTATÍSTICO-MATEMÁTICO PARA DETERMINAÇÃO DA PRESSÃO DE PRÉ-CONSOLIDAÇÃO DO SOLO}

\section{Resumo}

O conhecimento da pressão de pré-consolidação é importante para determinar a capacidade de suporte de carga de um solo, e assim, a trafegabilidade do mesmo para máquinas e implementos. A pressão de pré-consolidação tem sido determinada pelo método proposto por Casagrande há várias décadas, no entanto, ainda não foi descrito um método rápido, preciso e eficaz para determinar a pressão de pré-consolidação através deste princípio. Assim, o objetivo deste trabalho foi propor um método estatístico-matemático para determinação da pressão de pré-consolidação do solo, desenvolvido na forma de um algoritmo no software SAS. O método realiza uma interpolação na curva de compressão para aumentar o número de pontos e em seguida ajusta um polinômio à estes pontos. Através de métodos matemáticos e de otimização, os passos do método de Casagrande são implementados e a pressão de pré-consolidação calculada. Os valores estimados pelo método proposto aqui não diferiram estatisticamente dos valores calculados por um método descrito em literatura, seja pelo teste $t(t=-0,75 ; \mathrm{p}>|t|=0,45)$ ou pelo teste $F(F=1,42 ; \mathrm{p}>F=0,23)$. A equivalência quantitativa entre os dois métodos foi também confirmada comparando-se os parâmetros inclinação e intercepto para as duas retas de regressão da pressão de pré-consolidação estimada pelos dois métodos em função da densidade do solo. Nem a inclinação nem o intercepto diferiram estatisticamente entre si quando comparados pelo teste $t$ (inclinação $t=-0,23 ; \mathrm{p}>|t|=0,82$ e intercepto $t=-0,39 ; \mathrm{p}>|t|=0,70)$. O método proposto neste trabalho foi capaz de estimar a pressão de pré-consolidação do solo de forma rápida e 
quantitativamente precisa com relação a um método publicado em literatura, confirmando a hipótese testada.

Termos para indexação: trafegabilidade, método de Casagrande, curva de compressão.

\section{A STATISTICAL-MATHEMATICAL METHOD FOR DETERMINATING SOIL PRECONSOLIDATION PRESSURE}

\section{Summary}

The knowledge of soil preconsolidation pressure is important to determine the load support capacity of a given soil, and therefore, its trafegability to agricultural machinery. The preconsolidation pressure has been determined using Casagrande's method for decades. However, it was still not described a fast, reliable and accurate method for calculating the preconsolidation pressure using Casagrande's method. Thus, the objective of this research was to propose a statistical-mathematical method for determination of soil preconsolidation pressure, developed in the form of a SAS system algorithm. The method proposed here interpolates the compression curve to increase the number of points and then fits a polynomial equation to the points. Using optimization mathematical methods, the Casagrande's method steps are implemented and the preconsolidation pressure calculated. The values estimated by the method proposed in this work did not differed statistically from the values calculated by a method described in literature as evaluated by $t$ test $(t=-0.75 ; \mathrm{p}>|t|=0.45)$ and $F$ test $(F=1.42 ; \mathrm{p}>F=$ $0.23)$. The quantitative equivalence between the methods was also confirmed comparing the parameters slope and intercept for the regression lines of the preconsolidation stress estimated by both methods as a function of soil bulk density. The slope and the intercept did not differed statistically when compared by $t$ test (slope $t=-0.23 ; \mathrm{p}>|t|=0.82$ and intercept $t=-0.39 ; \mathrm{p}>|t|=0.70$ ). The method proposed in this work was able to estimate the soil preconsolidation stress in a fast and quantitatively reliable way in relation to a method published in literature, confirming the hypothesis tested.

Index terms: trafegability, Casagrande method, compression curve. 


\subsection{Introdução}

A qualidade física de solos agrícolas refere-se as características de resistência do solo e capacidade de transmissão e armazenamento de fluidos na zona radicular das culturas (Topp et al., 1997). Dentre os indicadores estruturais da qualidade física do solo, os indicadores de trafegabilidade e trabalhabilidade têm tido atenção crescente nos últimos anos (Godwin \& Spoor, 1977; Earl, 1997; Imhoff, 2002). A resposta de um solo estruturado a uma força mecânica externa é dependente das características da estrutura do solo e da força aplicada. Por definição, o solo se deformará quando a força aplicada exceder a resistência mecânica do solo à deformação. Dentre os indicadores estruturais de trafegabilidade do solo, aqueles obtidos a partir da curva de compressão do solo, como a pressão de pré-consolidação e o índice de compressão têm sido freqüentemente utilizados na avaliação da qualidade física do solo (Larson et al., 1980; Etana et al., 1997; Imhoff et al., 2001).

Em solos agrícolas, o conhecimento da pressão de pré-consolidação é importante para determinar a capacidade de suporte de carga de um solo, e assim, a rafegabilidade do mesmo para máquinas e implementos com diferentes combinações de peso $\mathrm{x}$ área de contato do rodado. A primeira metodologia para cálculo da pressão de pré-consolidação a partir da curva de compressão foi a de Casagrande (1936). A determinação da pressão de pré-consolidação pode ser feita através da curva de índice de vazios ou densidade do solo como função da pressão aplicada, em escala logarítmica (Figura 1). Sobre essa curva, estima-se o ponto de máxima curvatura, e desse ponto traça-se uma horizontal (Figura 2b), e uma tangente à curva (Figura 2c). Marca-se a bissetriz do ângulo formado entre a horizontal e a tangente (Figura 2d). A abscissa do ponto de intersecção da bissetriz com o prolongamento da reta virgem representa a pressão de pré-consolidação (Casagrande, 1936; Taylor, 1958). 
Imhoff et al. (2004) desenvolveram um algoritmo no software MathCad ${ }^{\circledR}$ (Mathsoft, 2000) para quantificação da pressão de pré-consolidação pelo método de Casagrande (1936). Resumidamente, o programa usa a derivada segunda de um ajuste por "splines cúbicas" para encontrar o ponto de máxima curvatura. Em seguida, através de procedimentos matemáticos, o programa ajusta os demais passos do método, chegando à pressão de pré-consolidação (ver a descrição da Figura 1). Imhoff et al. (2004) também desenvolveram funções de pedotransferência entre os parâmetros de ajuste da curva de compressão e propriedades físicas do solo. Imhoff et al. (2004) observaram que o índice de compressão correlacionou-se com o conteúdo de argila (até $29,42 \%$ ), e com a densidade do solo, enquanto que a pressão de pré-consolidação correlacionou-se com a densidade do solo, o conteúdo de argila e o conteúdo de água do solo.

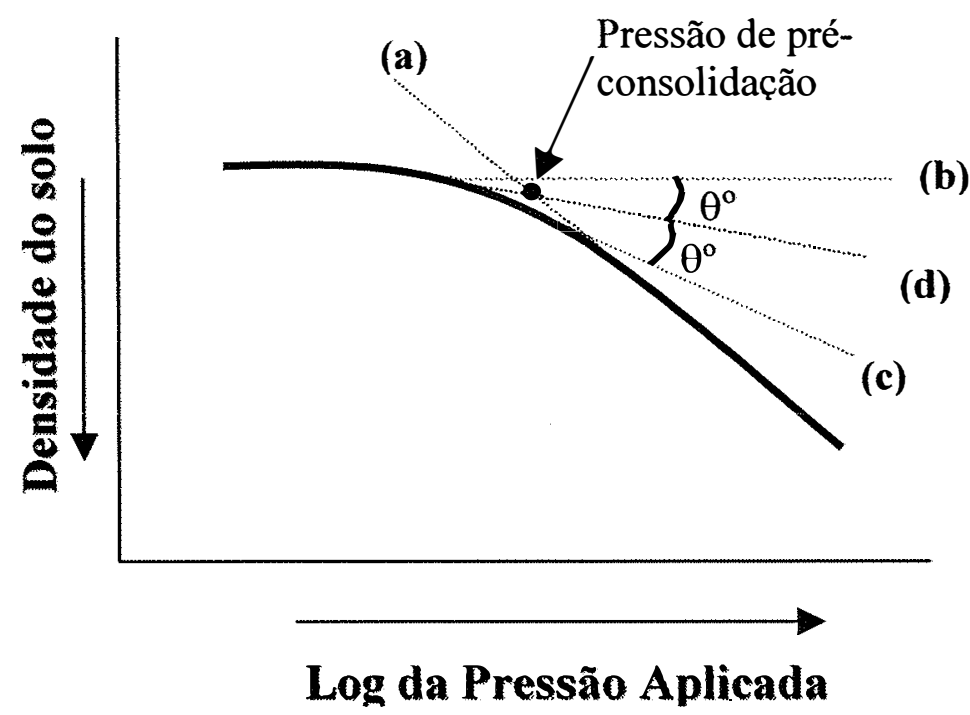

Figura 1 - Estimativa da pressão de pré-consolidação através do método de Casagrande.

(a) Reta de compressão virgem, (b) Reta no ponto de máxima curvatura, (c) Tangente no ponto de máxima curvatura, e (d) Bissetriz às retas $b$ e $c$

Neste trabalho foi desenvolvido um algoritmo em ambiente SAS para ajuste da curva de compressão do solo e cálculo da pressão de pré-consolidação e índice de compressão do solo. A principal diferença deste algoritmo daquele desenvolvido por Imhoff et al. (2004) é que os pontos da curva de compressão não serão interpolados, 
como ocorre no caso do uso de algoritmos de interpolação por "splines cúbicas" e alguns algoritmos para suavização de polinômios como os de Lagrange e Neville (Press et al., 1994). No caso do presente trabalho, foi realizado um ajuste estatístico para determinar o polinômio que melhor se ajuste (best fit polynomial) ao conjunto de pontos da curva de compressão.

A hipótese deste capítulo é de que a pressão de pré-consolidação pode ser calculada de forma mais rápida e estatisticamente precisa modificando-se o método de ajuste estatístico da curva de compressão do solo. O objetivo foi propor um método estatístico-matemático para determinação da pressão de pré-consolidação dos solos, desenvolvida na forma de um algoritmo no software $\mathrm{SAS}^{\circledR}$, melhorando a qualidade e reduzindo o tempo de obtenção dos resultados

\subsection{Material e Métodos}

\subsubsection{Descrição do algoritmo}

O algoritmo para determinação da pressão de pré-consolidação será desenvolvido tendo como base uma curva de compressão construída à partir de dez pontos de densidade do solo (Ds) versus o logaritmo da pressão aplicada $(\sigma)$. As pressões utilizadas são 25, 50, 100, 200, 400, 600, 800, 1000, 1300 e $1600 \mathrm{kPa}$. Para aumentar a precisão dos passos posteriores do algoritmo, é feita uma interpolação entre os intervalos da curva, onde para cada ponto de Ds $x \log \sigma$ são criados 100 novos valores através do procedimento de interpolação.

Em seguida, a curva de compressão do solo é ajustada a um polinômio de grau $n$ (eq. 1). O ajuste é realizado pelo mesmo procedimento de ajuste que no caso de uma equação linear (que nada mais é do que um polinômio de primeiro grau). A metodologia se baseia na minimização da soma dos quadrados dos desvios (Souza. 1998).

$$
y=\beta_{n} \cdot \mathrm{x}^{\mathrm{n}}+\beta_{\mathrm{n}-1} \cdot \mathrm{x}^{\mathrm{n}-1}+\beta_{\mathrm{n}-2} \cdot \mathrm{x}^{\mathrm{n}-2}+\ldots+\beta_{2} \cdot \mathrm{x}^{2}+\beta_{1} \cdot \mathrm{x}^{1}+\beta_{0}+\varepsilon
$$

Em que:

$y=$ Variável resposta. 
$\mathrm{x}=$ Variável independente.

$\beta_{\mathrm{n}}, \beta_{\mathrm{n}-1}, \beta_{\mathrm{n}-2}, \beta_{2}, \beta_{1}, \beta_{0}=$ Coeficientes do polinômio.

$\varepsilon=$ Erro aleatório.

O grau do polinômio de melhor ajuste para o conjunto de dados avaliado é determinado através da metodologia descrita por Neter et al. (1983). Um polinômio de grau $n$ foi ajustado ao conjunto de dados e a hipótese de que o coeficiente $\beta_{n}$ é igual a zero testada (eq. 2 e 3 ).

$$
\begin{aligned}
& H_{0}: \beta_{\mathrm{n}}=0 \\
& H_{a}: \beta_{\mathrm{n}} \neq 0
\end{aligned}
$$

O teste de hipótese é realizado por meio de teste $t$, aplicável a modelos de regressão (Neter et al., 1983). Caso a hipótese nula seja verificada (eq. 2) o coeficiente $\beta_{\mathrm{n}}$ é removido do modelo, procedendo-se da mesma forma com os demais coeficientes até que a equação polinomial resultante contenha apenas coeficientes estatisticamente diferentes de zero.

Uma vez definido o polinômio de melhor ajuste, o algoritmo passa implementar o método de Casagrande (1936) para determinar a pressão de pré-consolidação do solo (Figura 2). O ponto de máxima curvatura é calculado através de técnicas numéricas, maximizando a função citada por Kells (1954) (eq. 4) no intervalo de valores do polinômio adotado.

$$
K=\left(\mathrm{d}^{2} y / \mathrm{dx}\right) /\left[1+(\mathrm{d} y / \mathrm{dx})^{2}\right]^{3 / 2}
$$

Em que:

$K=$ Ponto de máxima curvatura para o polinômio de melhor ajuste.

$\mathrm{d} y / \mathrm{dx}=$ Derivada primeira do polinômio de melhor ajuste.

$\mathrm{d}^{2} y / \mathrm{dx}^{2}=$ Derivada segunda do polinômio de melhor ajuste. 
Do ponto de máxima curvatura é traçada uma reta horizontal (função constante) e é calculada a reta tangente a este ponto, a partir da derivada primeira do polinômio de melhor ajuste (Figura 1). A equação da reta bissetriz do ângulo formado entre a reta tangente ao ponto de máxima curvatura e a reta horizontal (Figura 2) foi calculada através da equação descrita por Giovanni \& Bonjorno (1992) (eq. 5).

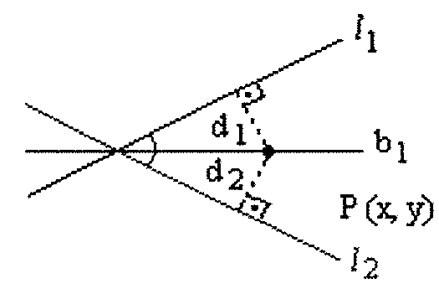

Figura 2 - Ilustração da bissetriz entre duas retas [Adaptado de Giovanni e Bonjorno (1992)]

Conforme a Figura 4, seja $l_{1}=\mathrm{a}_{1} \mathrm{x}+\mathrm{b}_{1} \mathrm{y}+\mathrm{c}_{1}$, então, se e somente se $\mathrm{d}_{1}=\mathrm{d}_{2}$ a bissetriz entre as retas $l_{1}$ e $l_{2}$ é dada por:

$$
b_{1}=\left(a_{1} x+b_{1} y+c_{1}\right) / \sqrt{ }\left(a_{1}^{2}+b_{1}^{2}\right)
$$

Em que os coeficientes $a_{1}, b_{1}, c_{1}$ e as variáveis $x$ e y são os mesmos representados na Figura 4.

Em seguida, a reta de compressão virgem é ajustada aos pontos finais da curva de compressão, por meio de regressão linear simples, e o ponto de interseção entre a reta de compressão virgem e a bissetriz, determinada pelo procedimento descrito anteriormente, corresponde à pressão de pré-consolidação do solo (Figura 1).

Todos os procedimentos foram desenvolvidos no software $\mathrm{SAS}^{\circledR}$, utilizando os módulos STAT (SAS Institute, 1999a) para ajuste da função polinomial, OR (SAS Institute, 1999b) para os procedimentos de otimização, GRAPH (SAS Institute, 2000a) para a confecção dos gráficos e ETS (SAS Institute, 2000b) para a interpolação. 


\subsubsection{Validação do algoritmo}

Para validação do método foi utilizado um conjunto de curvas de compressão descrito por Imhoff et al. (2004). As propriedades físicas deste solo estão sumarizadas na Tabela 1. A qualidade do método proposto foi avaliada estatisticamente, comparando os valores de pressão de pré-consolidação obtidos com aqueles obtidos por Imhoff et al. (2004). Foram utilizados os coeficiente de determinação da reta 1:1 dos valores de pressão de pré-consolidação obtidos pelo método proposto $\left(\sigma_{\mathfrak{t}}\right)$ versus aqueles obtidos por Imhoff et al. (2004) $(\sigma)$ e a comparação das retas de ajuste da pressão de préconsolidação versus a densidade do solo (Ds) para os dois métodos.

Tabela 1. Parâmetros estatísticos das propriedades físicas do solo utilizado na determinação das curvas de compressão e pressão de pré-consolidação do solo (de Imhoff et al. 2004)

\begin{tabular}{lccccc}
\hline & Mesvio & & & \\
Variável & Padrão & $\mathrm{CV}(\%)$ & Mínimo & Máximo \\
\hline Conteúdo de água $\left(\mathrm{g} \mathrm{g}^{-1}\right)$ & 0,20 & 0,06 & 31 & 0,08 & 0,28 \\
Argila $\left(\mathrm{g} \mathrm{kg}^{-1}\right)$ & 374 & 141,3 & 38 & 153 & 615 \\
Areia $\left(\mathrm{g} \mathrm{kg}^{-1}\right)$ & 514 & 208,6 & 41 & 216 & 818 \\
Silte $\left(\mathrm{g} \mathrm{kg}^{-1}\right)$ & 112 & 68,1 & 61 & 15 & 239 \\
Densidade do solo $\left(\mathrm{g} \mathrm{cm}^{-3}\right)$ & 1,56 & 0,15 & 10 & 1,26 & 1,82 \\
Densidade de partículas $\left(\mathrm{g} \mathrm{cm}^{-3}\right)$ & 2,80 & 0,08 & 3 & 2,65 & 2,96 \\
\hline
\end{tabular}




\subsection{Resultados e Discussão}

\subsubsection{Comparações quantitativas entre os métodos}

A média, mínimo, máximo e o desvio padrão dos valores de pressão de préconsolidação estimados pelo método proposto neste trabalho $\left(\sigma_{t}\right)$ e pelo método utilizado por Imhoff et al. (2004) ( $\sigma$ ) são apresentados na Tabela 2.

Tabela 2. Parâmetros estatísticos dos valores da pressão de pré-consolidação determinados pelo método proposto $\left(\sigma_{t}\right)$ e pelo método de Imhoff et al. (2004) $(\sigma)$

\begin{tabular}{lccccc}
\hline & $\mathrm{N}$ & Média & Desvio & Mínimo & Máximo \\
\hline$\sigma_{\mathrm{t}}(\mathrm{kPa})$ & 43 & 158 & 105,2 & 30 & 449 \\
$\sigma(\mathrm{kPa})$ & 50 & 143 & 88,17 & 22 & 367 \\
\hline
\end{tabular}

Para todas as curvas ajustadas pelo novo método, verificou-se que um polinômio de quarto grau era adequado para ajustar a curva de compressão do solo, para que os demais passos do método pudessem ser implementados. Para um polinômio de terceiro grau, o procedimento não identificou ponto de máxima curvatura dentro do intervalo de valores analisado, enquanto que polinômios de grau maior que quatro proporcionaram oscilações indesejadas da função. Arvidsson \& Keller (2004) utilizaram um procedimento similar ao descrito aqui, baseado em polinômios de quarto grau e derivadas primeira, segunda e terceira desta função. No entanto Arvidsson \& Keller (2004) não detalharam o procedimento utilizado, incluindo a descrição de sua implementação.

Em sete das 50 curvas analisadas, o método proposto neste trabalho falhou em estimar a pressão de pré-consolidação do solo. Isto ocorreu porque o algoritmo não identificou um ponto da máxima curvatura no intervalo de valores para o polinômio ajustado. Quando isto ocorre, é verificado que não existe ponto de máxima curvatura 
dentro do intervalo de valores analisado ou que este ponto se localiza nos extremos da função.

Ainda assim, as médias indicadas na Tabela 2 não foram diferentes entre si quando comparadas pelo teste $t(t=-0,75 ; \mathrm{p}>|t|=0,45)$ ou pelo teste $F(F=1,42 ; \mathrm{p}>F=0,23)$ indicando a equivalência quantitativa entre os métodos. $O$ teste de correlação simples entre os valores estimados pelos dois métodos e algumas propriedades físicas do solo também mostrou não haver grandes diferenças entre eles, a exceção da correlação com o índice de compressão, ou inclinação da reta de compressão virgem (Tabela 3).

Tabela 3. Correlação simples entre os valores de pressão de pré-consolidação pelo método proposto $\left(\sigma_{t}\right)$ e o método utilizado por Imhoff et al. $(2004)(\sigma)$ com algumas propriedades físicas do solo

\begin{tabular}{cccccccc}
\hline & Argila & Ds & Dp & $\theta \mathrm{g}$ & PT & IC & $\sigma_{\mathrm{t}}$ \\
\hline$\sigma_{\mathrm{t}}(\mathrm{kPa})$ & $-0,13$ & 0,69 & $-0,13$ & $-0,24$ & $-0,64$ & $-0,22$ & - \\
$\sigma(\mathrm{kPa})$ & $-0,20$ & 0,78 & $-0,15$ & $-0,32$ & $-0,70$ & $-0,01$ & 0,90 \\
\hline
\end{tabular}

$\mathrm{Ds}=$ Densidade do solo; $\mathrm{Dp}=$ Densidade de partículas; $\theta \mathrm{g}=$ Umidade gravimétrica; $\mathrm{PT}=$ Porosidade total; IC = Índice de compressão (Inclinação da reta de compressão virgem, ver Figura 2)

A regressão 1:1 entre valores de $\sigma$ e $\sigma_{\mathrm{t}}$ é apresentada na Figura 3. O coeficiente de determinação $\mathrm{r}^{2}=0,84$ indica que os dois métodos tiveram resultados próximos entre si para a pressão de pré-consolidação. $\mathrm{O}$ intercepto não foi estatisticamente diferente de zero, de modo que a regressão foi realizada através da origem (Figura 3).

Para investigar mais profundamente a qualidade do método proposto, os dois métodos foram plotados como função da densidade inicial do solo (Ds) (Figura 4). A Ds é um dos principais fatores afetando a pressão de pré-consolidação do solo, no entanto, a variabilidade entre os valores observados na Figura 4 para os dois métodos pode também ser explicada por outras propriedades físicas do solo, como conteúdo de argila, umidade dentre outras (Imhoff et al., 2004). 


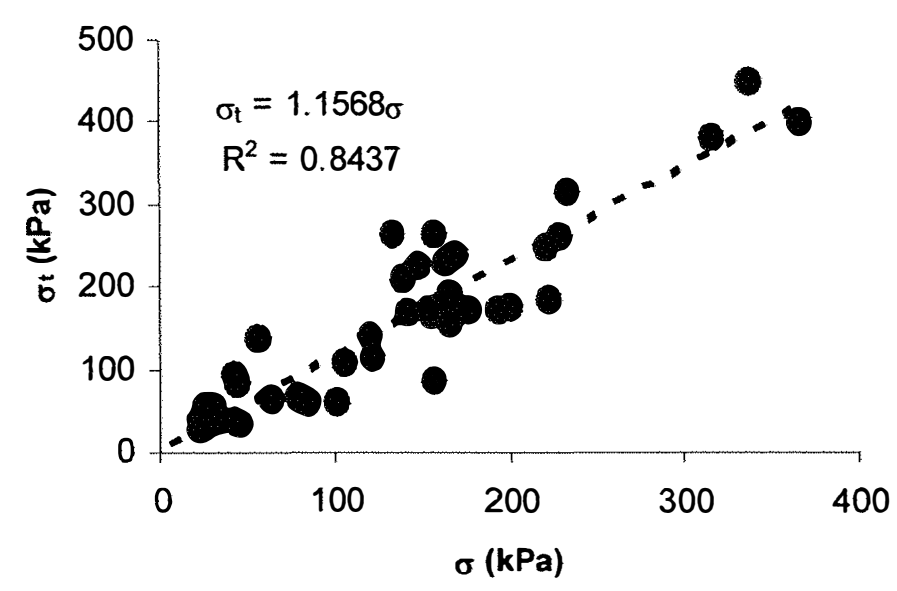

Figura 3 - Regressão simples 1:1 entre os valores de pressão de pré-consolidação pelo método proposto $\left(\sigma_{t}\right)$ e o método utilizado por Imhoff et al. $(2004)(\sigma)$

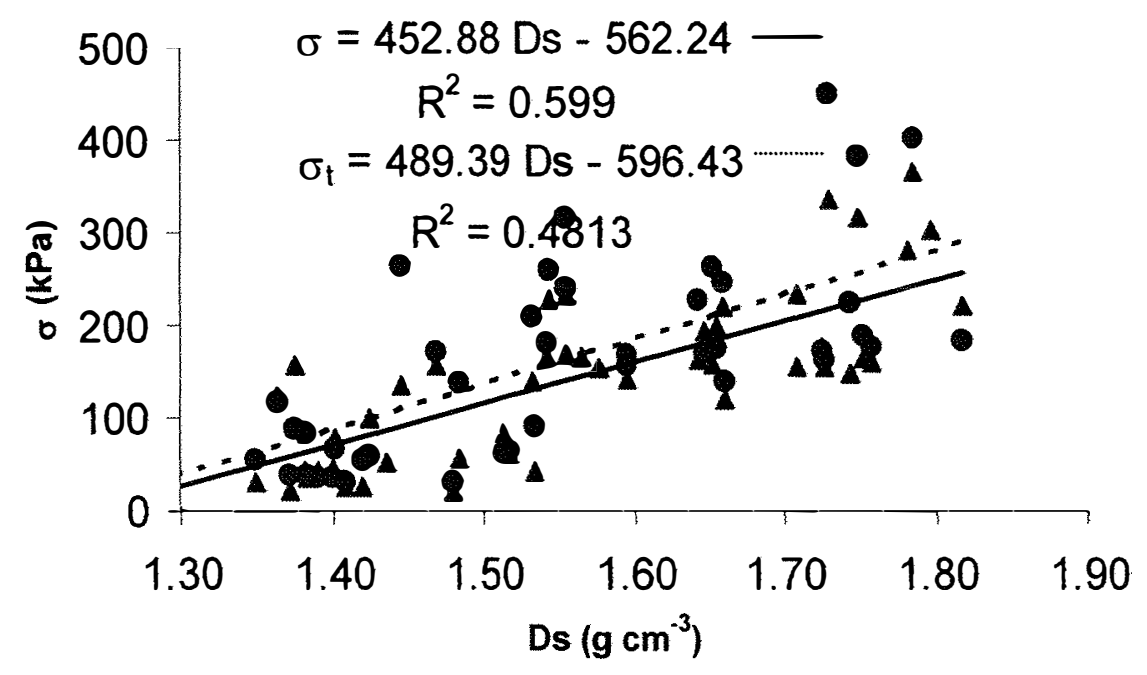

Figura 4 - Regressão simples entre os valores de pressão de pré-consolidação pelo método proposto $\left(\sigma_{t}\right)$ e o método utilizado por Imhoff et al. (2004) $(\sigma)$ e a densidade do solo (Ds) 
A equivalência quantitativa entre os dois métodos foi também confirmada comparando-se os parâmetros inclinação e intercepto para as duas retas de regressão de $\sigma$ e $\sigma_{\mathrm{t}}$ em função da Ds. Nem a inclinação nem o intercepto diferiram estatisticamente entre si quando comparados pelo teste $t$ (inclinação $t=-0,23 ; \mathrm{p}>|t|=0,82$ e intercepto $t$ $=-0,39 ; \mathrm{p}>|t|=0,70)$.

\subsubsection{Avaliações qualitativas entre os métodos}

O método proposto teve como principal vantagem a redução de tempo para obtenção dos resultados. Uma vez que o conjunto de dados é inserido no arquivo SAS, o resultado para cada curva pode ser obtido em questão de segundos, apenas rodando o programa (ver Anexo A2 para detalhes). Caso o usuário precise modificar o intervalo de valores para a obtenção da reta de compressão virgem, ele poderá fazê-lo apenas modificando as instruções de macro no início do programa.

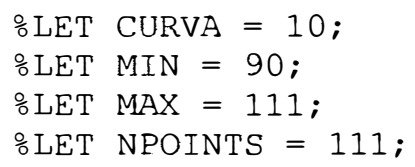

Para usuários mais familiarizados com a linguagem SAS, os passos do algoritmo podem ser modificados de acordo com suas necessidades, incluindo o procedimento de interpolação (PROC EXPAND), procedimentos de otimização (PROC NLP), regressão (PROC REG) e confecção de gráficos (PROC GPLOT).

Outra vantagem do método é que a seleção do ponto de máxima curvatura não depende da interação com o usuário, sendo puramente matemático. Porém, conforme discutido anteriormente, para curvas pouco representativas ou com muitas observações discrepantes, o procedimento pode falhar na identificação do ponto de máxima curvatura e o procedimento não deve ser utilizado quando isto ocorrer. 


\subsection{Conclusão}

O método proposto neste trabalho foi capaz de estimar a pressão de préconsolidação do solo de forma rápida e quantitativamente precisa com relação a um método publicado em literatura, confirmando a hipótese testada. Desta forma, ele é útil na redução do tempo de obtenção de dados em estudos da compressibilidade dos solos. $\mathrm{O}$ algoritmo resultante desenvolvido na linguagem SAS é apresentado no Anexo A2. 


\section{CRITÉRIOS ESTATÍSTICOS PARA A SELEÇÃO DE PARÂMETROS UTILIZADOS NA AVALIAÇÃO DA RESISTÊNCIA DO SOLO À PENETRAÇÃO}

\section{Resumo}

A quantificação da resistência do solo à penetração (RP) é freqüntemente utilizada na avaliação da qualidade estrutural do solo para o crescimento de plantas. Entretanto, diferentes abordagens têm sido utilizadas na análise de dados de RP, e na maioria dos casos, sem uma avaliação prévia da qualidade estatística destes parâmetros para a quantificação do impacto do uso e manejo sobre a qualidade física do solo. Neste trabalho foi testada a hipótese de que a média é o parâmetro com melhores propriedades estatísticas como critério para avaliação de alterações na resistência à penetração do solo em resposta ao uso e manejo do solo, em relação a outros parâmetros estatísticos derivados de conjuntos de dados de RP. Amostras indeformadas de solo $(5 \times 5 \mathrm{~cm})$ foram coletadas em locais com diferentes graus de compactação: Cerrado nativo $(\mathrm{CN})$; pastejo rotacionado, com nível de resíduo pós-pastejo mantido entre 2,0 e $2,5 \mathrm{Mg}$ (Matéria Seca Total) MST ha ${ }^{-1}(\mathrm{RB})$; e pastejo rotacionado, com nível de resíduo póspastejo mantido entre 3,0 e 3,5 Mg MST ha ${ }^{-1}$ (RA). Perfis de resistência à penetração foram obtidos com um penetrômetro eletrônico em amostras de solo equilibradas em três potencias mátricos $(-0,003,-0,01$ e $-0,1 \mathrm{MPa})$. A qualidade estatística dos parâmetros obtidos dos perfis de RP: média $(\bar{x})$, mediana $(M)$, máximo (max), percentagem linear de penetrabilidade à $2 \mathrm{MPa}\left(\mathrm{PLP}_{2 \mathrm{MPa}}\right)$, e os parâmetros da análise Probit: intercepto $(n) \mathrm{e}$ inclinação $(m)$ foi avaliada por meio de teste ANOVA. Os maiores valores $F$ e menores $\mathrm{p}>F$ corresponderam aos parâmetros de RP: média $(\bar{x})$, máximo $(\max )$ e percentagem 
linear de penetrabilidade à $2 \mathrm{MPa}\left(\mathrm{PLP}_{2 \mathrm{MPa}}\right)$. A habilidade destes três parâmetros em detectar variações na RP entre os ratamentos foi ainda investigada através do teste de comparação de médias Diferença Mínima Significativa (DMS). Os resultados da razão $F, \mathrm{p}>F$ e do teste DMS confirmaram a hipótese de que a média é o parâmetro com melhores propriedades estatísticas como critério para avaliar as alterações na resistência a penetração do solo em resposta ao uso e manejo quando comparada aos parâmetros estatísticos de RP: mediana, máximo, $m, n$, e PLP no valor crítico de $2 \mathrm{MPa}\left(\mathrm{PLP}_{2 \mathrm{MPa}}\right)$.

Termos de indexação: Análise Probit, teste de comparação de médias, DMS, avaliação da qualidade física.

\section{A STATISTICAL BASIS FOR SELECTING PARAMETERS FOR SOIL PENETRATION RESISTANCE EVALUATION}

\section{Summary}

The quantification of soil penetration resistance (SR) has been frequently used in the evaluation of the soil structural quality for plant growth. However, different data analysis approaches have been used, without a previous evaluation of their statistical quality for assessment of the impact of use and/or management over soil physical quality. In this paper we tested the hypothesis that the mean is the parameter with better statistical properties as criteria to evaluate alterations in soil penetration resistance in response to soil use and management as compared to other SR statistical parameters. Undisturbed $(5 \times 5 \mathrm{~cm})$ soil cores were collected in three sampling sites with different compaction degrees: an undisturbed site under native scierophylous forest (NC); a site under short-duration grazing with post-grazing residue maintained in 2.0 to $2.5 \mathrm{Mg}$ (Total Dry Matter) TDM ha ${ }^{-1}$ (LR); and a site under short-duration grazing with postgrazing residue maintained in 3.0 to $3.5 \mathrm{Mg} \mathrm{TDM} \mathrm{ha}^{-1}$ (HR). Soil resistance profiles were evaluated with an electronic penetrometer device at the three water potentials ($0.003,-0.01$ and $-0.1 \mathrm{MPa}$ ). The statistical quality of the parameters from the SR profile: mean $(\bar{x})$, median $(M)$, maximum $(\max )$, percentage of linear penetrability at $2 \mathrm{MPa}$ 
$\left(\mathrm{PLP}_{2 \mathrm{MPa}}\right)$, and the parameters from Probit analysis intercept $(n)$ and slope $(m)$ was evaluated by the ANOVA from sampling sites comparison test for each parameter. The higher $F$ ratio and lower $\mathrm{p}>F$ value were found for the SR statistical parameters mean $(\bar{x})$, maximum $(\max )$ and percentage linear penetrability at $2 \mathrm{MPa}\left(\mathrm{PLP}_{2 \mathrm{MPa}}\right)$. The ability of the three parameters to identify SR changes between the sites and for different water potentials was further investigated by LSD means comparison test. Results from $F$ ratio, $p>F$ values and LSD tests confirmed the hypothesis that the mean was the parameter with better statistical properties as criteria to evaluate alterations in soil penetration resistance in response to soil use and management as compared to the statistical SR parameters: median, maximum, $m, n$, and PLP at the critical value of 2 $\mathrm{MPa}\left(\mathrm{PLP}_{2 \mathrm{MPa}}\right)$.

Key Words: Probit analysis, means comparison test, LSD, soil physical quality assessment.

\subsection{Introdução}

A quantificação da resistência do solo à penetração (RP) tem sido freqüentemente utilizada na avaliação da qualidade estrutural do solo para o crescimento de plantas (Busscher \& Sojka, 1987; Silva et al., 1994; Betz et al., 1998). Entretanto, diferentes abordagens para análise dos dados têm sido empregadas, normalmente sem uma avaliação prévia da qualidade estatística destes parâmetros para avaliação do impacto do uso e manejo do solo sobre a qualidade física. A maior parte dos estudos empregando a RP é desenvolvida à partir de dados coletados com penetrômetros estáticos ou dinâmicos (Herrick \& Jones, 2002). A média ou o máximo valor de RP em uma camada de solo são os parâmetros estatísticos comumente utilizados para avaliar quantitativamente a RP (Corrêa \& Reichardt, 1995; Sojka et al., 2001; Villamil et al., 2001).

Uma metodologia ideal para caracterização da resistência da matriz do solo à deformação causada por uma raiz em crescimento deveria levar em consideração tantas das características do processo de crescimento radicular quantas possível. Dentre estas, 
pode-se citar: tamanho da raiz, sistema de lubrificação, pressões diferencias exercidas pelas laterais e o ápice da raiz e principalmente a capacidade da raiz de "buscar" por poros de tamanho e resistência à penetração adequados durante o processo de crescimento (Groenevelt et al., 1984). Parâmetros estatísticos, tais como, a média ou a máxima resistência do solo em uma camada de solo dão apenas uma idéia aproximada da verdadeira limitação oferecida pela matriz do solo ao crescimento radicular. A heterogeneidade estrutural do solo, expressada na forma de poros e fissuras não pode ser expressada adequadamente por um único valor médio. Poros e fissuras são frequentemente utilizados como caminhos preferenciais para o crescimento radicular em solos compactados. Ainda mais controverso é o uso do valor máximo de RP em uma camada de solo. O valor máximo de RP é extremamente sujeito a erros experimentais, uma vez que um único valor representaria toda uma camada de solo.

Para minimizar a influência da heterogeneidade estrutural na avaliação da qualidade física do solo, Groenevelt et al. (1984) definiram a Percentagem Linear de Penetrabilidade (PLP) como a percentagem da trajetória linear através do solo na qual a resistência do solo experimentada pelo "cone" de um penetrômetro é menor que um determinado valor crítico. Deste modo, a um dado valor crítico, normalmente $2 \mathrm{MPa}$, uma determinada percentagem da distância da trajetória linear de um penetrômetro através do solo seria penetrável a valores de resistência inferiores à $2 \mathrm{MPa}$. Perfect et al. (1990) aprimoraram o conceito da PLP utilizando análise de regressão linear em dados de PLP transformados através de análise Probit (Finey, 1952; Tietjen, 1986). Os procedimentos de regressão resultaram em dois parâmetros empíricos, a inclinação $(m)$ e o intercepto $(n)$ das retas. Perfect et al. (1990) sugeriram que a inclinação $m$, reflete a dispersão na resistência à penetração dos agregados, enquanto o intercepto $n$, reflete a macroporosidade do solo. Apesar da potencial utilidade destes parâmetros na avaliação quantitativa da qualidade estrutural do solo, até então eles não foram utilizados em estudos posteriores na avaliação da qualidade fỉsica do solo. A média é reconhecida como o parâmetro estatístico mais comumente utilizado na avaliação da resistência do solo à penetração em resposta ao uso e manejo do solo em comparação com os parâmetros estatísticos de RP: mediana, máximo, $m$, $n$, e PLP no valor crítico de $2 \mathrm{MPa}$ 
$\left(\mathrm{PLP}_{2 \mathrm{MPa}}\right)$. Assim, o objetivo deste trabalho foi avaliar comparativamente a qualidade estatística dos parâmetros obtidos do perfil de resistência à penetração do solo: média, mediana, máximo, $m, n$, e PLP no valor crítico de $2 \mathrm{MPa}\left(\mathrm{PLP}_{2 \mathrm{MPa}}\right)$.

\subsection{Material e Métodos}

O estudo foi conduzido em amostras indeformadas de solo (anéis volumétricos de 5 x $5 \mathrm{~cm}$ ) coletadas na Embrapa Gado de Corte localizada no estado de Mato Grosso

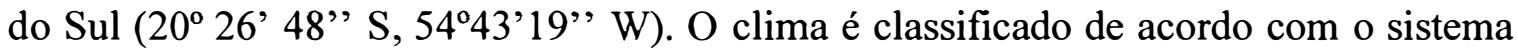
de Köppen's como de transição entre Cfa e Aw, com médias anuais de precipitação de $1500 \mathrm{~mm}$ e de $22{ }^{\circ} \mathrm{C}$ de temperatura. O solo é classificado como Latossolo Vermelho Distrófico (Embrapa, 1999) com $399 \mathrm{~g} \mathrm{~kg}^{-1}$ de argila, $66 \mathrm{~g} \mathrm{~kg}^{-1}$ de silte, e $535 \mathrm{~g} \mathrm{~kg}^{-1} \mathrm{de}^{-}$ areia.

Três locais de amostragem foram selecionados para o estudo:

(i) Cerrado Nativo $(\mathrm{CN})$ : solo sob vegetação regional nativa;

(ii) Pastejo Rotacionado com Baixo Resíduo Pós-Pastejo (RB): solo sob piquete ( 0,18 ha) cultivado com capim tanzânia (Panicum maximum cv. Tanzania) e pastejado por sete dias, seguidos por um período de pousio de 35 dias. Este piquete é parte de um experimento de pastejo rotacionado da Embrapa Gado de Corte iniciado em 1999. O experimento foi planejado para manter uma saturação por bases entre 45 e 50\%; níveis de fósforo disponível em Mehlich-1 (Nelson et al., 1953) entre 4 e $8 \mathrm{mg} \mathrm{dm}^{-3}$; e potássio entre 60 e $80 \mathrm{mg} \mathrm{dm}^{-3}$, na camada de 0 a $20 \mathrm{~cm}$. A taxa de adubação nitrogenada foi de $100 \mathrm{~kg} \mathrm{~N} \mathrm{ha}^{-1} \mathrm{ano}^{-1}$. O resíduo pós-pastejo foi mantido entre 2,0 to 2,5 Mg (Matéria Seca Total) MST ha ${ }^{-1}$. As taxas de lotaçãoo animal médias foram de 4,12 (Unidade Animal) UA ha ${ }^{-1}$ e 2,26 $\mathrm{UA} \mathrm{ha}^{-1}$ para as estações chuvosa e seca, respectivamente.

(iii) Pastejo Rotacionado com Alto Resíduo Pós-Pastejo (RA): Mesmas características do piquete $\mathrm{RB}$, exceto que o resíduo pós-pastejo foi mantido entre 
3,0 a 3,5 Mg MST ha ${ }^{-1}$. As taxas de lotação animal médias foram de 4,8 UA ha ${ }^{-1}$ e 2,26 UA ha ${ }^{-1}$ para as estações seca e úmida, respectivamente.

Dezoito amostras indeformadas de solo (anéis volumétricos de $5 \times 5 \mathrm{~cm}$ ) foram coletadas em cada local de amostragem. As amostras foram subdivididas em três grupos de seis amostras. Cada grupo foi equilibrado em um dos seguintes potenciais mátricos: $0,003,-0,01, \mathrm{e}-0,1 \mathrm{MPa}$. Após o equilíbrio os anéis foram armazenados em ambiente refrigerado por um mês e em seguida utilizados na avaliação dos perfis de resistência do solo à penetração (RP). O perfil de RP é definido como o conjunto de valores de resistência à penetração coletados ao longo da trajetória vertical do penetrômetro em uma amostra indeformada de solo (Figura 1). Os perfis foram coletados utilizando um penetrômetro eletrônico acoplado a um sistema de aquisição de dados. O penetrômetro utilizado possui um cone com semi-ângulo de $30^{\circ}$ e área basal de $0,1167 \mathrm{~cm}^{2}$. A taxa de penetração adotada foi de $1,0 \mathrm{~cm} \mathrm{~min}^{-1}$, com valores registrados a cada 0,7 segundos. Imediatamente após os testes de RP as amostras de solo foram secas em estufa a $105^{\circ} \mathrm{C}$ por 24 horas e o conteúdo volumétrico de água $(\theta)$ e a densidade do solo (Ds) determinados.

Para cada perfil de RP os parâmetros estatísticos: média $(\bar{x})$, mediana $(\mathrm{M})$, máximo (max), e os parâmetros da análise Probit: inclinação $(m)$, intercepto $(n)$ e percentagem linear de penetrabilidade no valor crítico de $2 \mathrm{MPa}\left(\mathrm{PLP}_{2 \mathrm{MPa}}\right.$ ) (Groenevelt et al., 1984; Perfect et al., 1990) foram calculados. Para cada potencial mátrico, o conjunto de parâmetros estatísticos para os locais de amostragem (CN, RA, RB) foi avaliados usando a razão $F$ da ANOVA (Gravetter \& Wallnau, 1995) e comparação de médias pelo teste da Diferença Mínima Significativa (DMS) (Hsu, 1996). Todas as análises estatísticas foram realizadas utilizando o software SAS/STAT (SAS Institute, 1999). 


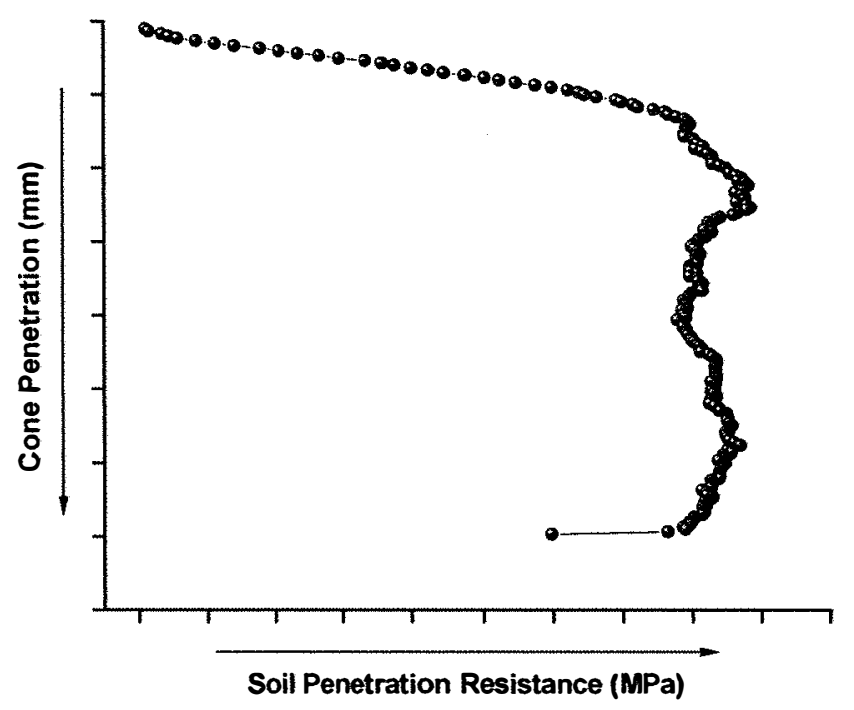

Figura 1 - Perfil de resistência à penetração para um anel volumétrico de solo com $5 \mathrm{~cm}$ de altura

\subsection{Resultados e Discussão}

Os parâmetros estatísticos obtidos a partir das amostras de solo utilizadas neste estudo são apresentados na Tabela 1. Os valores médios para o conteúdo volumétrico de água $(\theta)$, densidade do solo seco (Ds), e para os parâmetros estatísticos obtidos do perfil de resistência à penetração do solo $(\mathrm{RP})$ : média $(\bar{x})$, mediana $(\mathrm{M})$, máximo ( $\max )$, inclinação $(m)$, intercepto $(n)$ e percentagem linear de penetrabilidade no valor crítico de $2 \mathrm{MPa}\left(\mathrm{PLP}_{2 \mathrm{MPa}}\right)$ são apresentados. Os parâmetros são agrupados por local de amostragem e potencial mátrico $(\Psi)$. Os três valores de $\Psi$ utilizados neste estudo resultaram em três diferentes níveis de conteúdo de água no solo para os conjuntos de amostras obtidas em cada local de amostragem. Deste modo, os parâmetros estatísticos dos perfis de RP foram avaliados não somente de acordo com sua sensibilidade ao uso e manejo do solo. A influência do conteúdo de água sobre estas relações foi também avaliada. 
Tabela 1. Parâmetros estatísticos para as amostras de solo obtidas nos locais de amostragem: CN, RB e RA equilibradas em três potenciais mátricos

\begin{tabular}{|c|c|c|c|c|c|c|c|c|c|}
\hline \multicolumn{10}{|l|}{ Local de } \\
\hline \multirow{2}{*}{ Amostragem } & $\Psi$ & $\theta$ & \multirow[t]{2}{*}{$\mathrm{D}_{\mathrm{s}}$} & \multicolumn{3}{|c|}{ Parâmetros dos Perfis de } & \multicolumn{3}{|c|}{ Resistência a Penetração } \\
\hline & $(\mathrm{MPa})$ & $\mathrm{cm}^{3} \mathrm{~cm}^{-3}$ & & $\begin{array}{c}\bar{x} \\
(\mathrm{MPa})\end{array}$ & $\begin{array}{c}M \\
(\mathrm{MPa})\end{array}$ & $\begin{array}{c}\max \\
(\mathrm{MPa})\end{array}$ & $m$ & $n$ & $\begin{array}{c}\mathrm{PLP}_{2 \mathrm{Mp}} \\
(\%)\end{array}$ \\
\hline$C N$ & $-0,003$ & 0,3637 & 0,95 & 0,67 & 0,69 & 1,03 & 4,95 & 2,79 & 100 \\
\hline$R B$ & $-0,003$ & 0,4201 & 1,43 & 2,44 & 2,61 & 3,51 & 0,74 & 3,05 & 94,57 \\
\hline$R A$ & $-0,003$ & 0,4057 & 1,28 & 1,11 & 1,13 & 1,64 & 2,73 & 2,56 & 35,95 \\
\hline$C N$ & $-0,01$ & 0,2918 & 0,98 & 0,88 & 0,92 & 1,46 & 3,37 & 2,81 & 90,22 \\
\hline$R B$ & $-0,01$ & 0,3522 & 1,40 & 2,11 & 2,24 & 3,04 & 0,93 & 2,96 & 24,39 \\
\hline$R A$ & $-0,01$ & 0,3151 & 1,33 & 1,40 & 1,44 & 2,15 & 1,63 & 2,66 & 85,84 \\
\hline$C N$ & $-0,1$ & 0,2375 & 0,97 & 0,90 & 0,94 & 1,48 & 2,64 & 2,83 & 96,36 \\
\hline$R B$ & $-0,1$ & 0,2716 & 1,43 & 4,09 & 4,16 & 5,12 & 0,46 & 2,66 & 14,15 \\
\hline$R A$ & $-0,1$ & 0,2317 & 1,30 & 2,45 & 2,58 & 3,79 & 0,85 & 2,74 & 28,08 \\
\hline
\end{tabular}

Os locais de amostragem utilizados neste estudo foram selecionados de modo que três diferentes graus de compactação pudessem ser utilizados na avaliação dos parâmetros obtidos dos perfis de resistência do solo à penetração (RP). Os valores médios de Ds foram mais baixos no CN, Ds $=0,97 \mathrm{~g} \mathrm{~cm}^{-3}$, e aumentaram com o aumento da taxa de lotação animal nos piquetes com sistema de pastejo rotacionado, Ds $=1,30 \mathrm{~g} \mathrm{~cm}^{-3}$ no RA e Ds $=1,42 \mathrm{~g} \mathrm{~cm}^{-3}$ no RB. Para Latossolos argilosos como o avaliado neste estudo, estes valores de Ds são associados a solo não compactado $(\mathrm{CN})$ (Normalmente sob vegetação nativa), levemente compactado (RA), e altamente compactado (RB). Sabendo-se que o grau de compactação em cada local de amostragem era previamente conhecido, a qualidade estatística de cada parâmetro do perfil de RP foi inicialmente avaliada pela magnitude da razão $F$ da ANOVA e pelo seu nível de significância estatística $(p>F)$ (Gravetter \& Wallnau, 1995). 
Quanto maior a razão $F$ e menor o valor de $p>F$ melhor a qualidade estatística do parâmetro indicador (Gravetter \& Wallnau, 1995). Entretanto, vale ressaltar que não somente a qualidade estatística do parâmetro, mas também seu significado físico no processo sob investigação foram levados em consideração na discussão (Webster, 2001). A razão $F, p>F, \mathrm{r}^{2}$, e coeficiente de variação (CV) obtidos da ANOVA para a comparação dos parâmetros dos perfis de RP entre os locais de amostragem são apresentados nas Tabelas 2,3 e 4 para os potenciais de $-0,003 ;-0,01$ e $-0,1 \mathrm{MPa}$ respectivamente.

Tabela 2. Resultados da ANOVA para a comparação entre os parâmetros de RP das amostras obtidas nos locais de amostragem $\mathrm{CN}, \mathrm{RB}$ e RA equilibradas no potencial mátrico de $-0,003 \mathrm{MPa}$

\begin{tabular}{ccccc}
\hline & $F$ & $p>F$ & $r^{2}$ & $C V$ \\
\hline$n$ & 1,92 & 0,1816 & 0,20 & 15,52 \\
$P L P_{2 M P a}$ & 22,92 & $<0,0001$ & 0,75 & 23,64 \\
$x$ & 21,89 & $<0,0001$ & 0,74 & 34,47 \\
$M$ & 18,68 & $<0,0001$ & 0,71 & 38,51 \\
$M a x$ & 33,82 & $<0,0001$ & 0,82 & 26,44 \\
$M$ & 7,99 & 0,0043 & 0,52 & 65,12 \\
\hline
\end{tabular}

Para os três potenciais mátricos avaliados os maiores valores da razão $F$ e menores valores de $p>F$ corresponderam aos parâmetros estatísticos média, máximo e percentagem linear de penetrabilidade à $2 \mathrm{MPa}\left(\mathrm{PLP}_{2 \mathrm{MPa}}\right)$ (Tabelas $\left.2 \mathrm{a} 4\right)$. Média $(\bar{x}) \mathrm{e}$ máximo ( $\max$ ) são os parâmetros estatísticos mais comumente utilizados na avaliação da qualidade física do solo e/ou no grau de compactação (Corrêa \& Reichardt, 1995; Sojka et al., 2001; Villamil et al., 2001). Os resultados apresentados aqui somente confirmam que estes parâmetros são adequados para quantificar a RP em estudos de avaliação da qualidade física do solo. Entretanto, a $\mathrm{PLP}_{2 \mathrm{MPa}}$ pode ser um parâmetro com um significado fisico mais adequado, uma vez que indica a porcentagem da trajetória linear 
do penetrômetro através da amostra de solo (ou camada) que é penetrável a valores de resistência menores que $2 \mathrm{MPa}$ (Groenevelt et al., 1984). Valores médios e máximos dão somente uma idéia aproximada do grau de limitação mecânica oferecido por um solo. Além do fato de eles representarem toda uma camada de solo em um único valor, eles podem ser altamente influenciados por observações influentes. Por outro lado, a porcentagem linear de penetrabilidade (PLP) estima a fração da trajetória linear através do solo que é realmente penetrável por uma raiz em crescimento, dado um determinado valor crítico de resistência a penetração. Deste modo, a PLP poderia representar melhor o grau de penetrabilidade de uma camada de solo do que qualquer outro índice (Groenevelt et al., 1984).

Tabela 3. Resultados da ANOVA para a comparação entre os parâmetros de RP das amostras obtidas nos locais de amostragem $\mathrm{CN}, \mathrm{RB}$ e RA equilibradas no potencial mátrico de $-0,01 \mathrm{MPa}$

\begin{tabular}{ccccc}
\hline & $F$ & $p>F$ & $r^{2}$ & $C V$ \\
\hline$n$ & 1,59 & 0,2361 & 0,18 & 10,46 \\
$P L P_{2 M P a}$ & 20,70 & $<0,0001$ & 0,73 & 29,65 \\
$x$ & 9,77 & 0,0019 & 0,57 & 33,13 \\
$M$ & 7,60 & 0,0053 & 0,50 & 38,31 \\
$\max$ & 8,71 & 0,0031 & 0,54 & 29,53 \\
$m$ & 5,48 & 0,0163 & 0,42 & 66,63 \\
\hline
\end{tabular}

O valor crítico de RP de $2 \mathrm{MPa}$ para o cálculo da PLP foi escolhido uma vez que existem evidências experimentais que o crescimento radicular é severamente restrito a este valor de RP (Taylor et al., 1966; Materechera et al., 1991). Assim, na porcentagem linear de penetrabilidade à $2 \mathrm{MPa}\left(\mathrm{PLP}_{2 \mathrm{MPa}}\right)$ uma determinada percentagem do perfil de solo seria penetrável a valores de resistência inferiores a $2 \mathrm{MPa}$. Para qualquer potencial mátrico, a $\mathrm{PLP}_{2 \mathrm{MPa}}$ foi mais alta no $\mathrm{CN}$ (variando de 90 a $100 \%$ ) e muito menor no $\mathrm{RB}$ 
(variando de 14 a 35\%). Entretanto, não se sabe qual a percentagem do perfil de um solo deve ser penetrável a valores de resistência inferiores a um determinado valor crítico para que o crescimento radicular efetivamente ocorra. $\mathrm{O}$ que se sabe é que as raízes das plantas são capazes de localizar caminhos preferenciais de crescimento através do solo, tais como poros, fissuras e zonas de menor resistência mecânica no solo (Groenevelt et al., 1984). Perfect et al. (1990) sugeriram que os parâmetros $m$ e $n$ obtidos através da análise Probit poderiam representar melhor a heterogeidade estrutural do solo. O parâmetro $m$ representaria a dispersão na distribuição das resistências dos agregados enquanto o parâmetro $n$ representaria a macroporosidade (Perfect et al. 1990). Entretanto a qualidade estatística destes parâmetros como critério para avaliar diferenças na RP entre diferentes manejos do solo foi inferior a outros parâmetros estatísticos de RP avaliados (Tabelas 2 a 4 ).

Tabela 4. Resultados da ANOVA para a comparação entre os parâmetros de RP das amostras obtidas nos locais de amostragem $\mathrm{CN}, \mathrm{RB}$ e RA equilibradas no potencial mátrico de $-0,1 \mathrm{MPa}$

\begin{tabular}{ccccc}
\hline & $F$ & $p>F$ & $r^{2}$ & $C V$ \\
\hline$n$ & 0,46 & 0,6398 & 0,06 & 11,14 \\
$P L P_{2 M P a}$ & 53,06 & $<0,0001$ & 0,88 & 33,05 \\
$x$ & 63,23 & $<0,0001$ & 0,89 & 19,79 \\
$M$ & 64,00 & $<0,0001$ & 0,90 & 19,24 \\
$\max$ & 49,13 & $<0,0001$ & 0,87 & 18,57 \\
$m$ & 6,05 & 0,019 & 0,45 & 88,22 \\
\hline
\end{tabular}

Para investigar com mais detalhe a habilidade dos parâmetros estatísticos em categorizar a RP entre tratamentos com diferentes graus de compactação, foram realizados testes de comparação de médias para os parâmetros de RP com maiores valores para a razão $F$ e menores valores para $p>F$. As Tabelas 5, 6 e 7 apresentam os 
resultados do teste de comparação de médias DMS para os parâmetros $\operatorname{PLP}_{2 \mathrm{MPa}}, \bar{x}$ e max, respectivamente, entre locais de amostragem. Teoricamente, quanto mais sensível o parâmetro a alterações na RP causadas pelo manejo do solo, mais facilmente o teste DMS poderia identificar diferenças estatisticamente significativas entre tratamentos. Os três parâmetros do perfil de resistência à penetração do solo: $\mathrm{PLP}_{2 \mathrm{MPa}}, \bar{x}$ e $\max$, identificaram a mesma tendência de decréscimo da qualidade física do solo independentemente do potencial mátrico em que as amostras foram equilibradas (Tabelas 5 a 7). Entretanto, a interpretação dos resultados de $\mathrm{PLP}_{2 \mathrm{MPa}}$ é diferente, uma vez que os tratamentos com melhor qualidade física apresentarão os valores mais elevados de $\mathrm{PLP}_{2 \mathrm{MPa}}$ (Table 5). Deste modo, em qualquer dos potenciais mátricos, os valores da $\mathrm{PLP}_{2 \mathrm{MPa}}$ foram mais baixos no $\mathrm{RB}$, mas não diferiram estatisticamente entre os tratamentos CN e RA nos potenciais mátricos de $-0,003$ e -0,01 MPa. No potencial mátrico de -0,1 $\mathrm{MPa}$ a PLP ${ }_{2 \mathrm{MPa}}$ não diferiu estatisticamente entre os tratamentos $\mathrm{RB}$ e RA. Este comportamento pode ser explicado pelo fato de que em solos compactados, a RP aumenta acentuadamente com o decréscimo no conteúdo de água, equanto a magnitude deste aumento tende a ser menor em solos não compactados (Imhoff et al., 2000a).

Tabela 5. Valores de percentagem linear de penetrabilidade a $2 \mathrm{MPa}\left(\mathrm{PLP}_{2 \mathrm{MPa}}\right)$ para cada local de amostragem e potencial mátrico ${ }^{\mathrm{a}}$

\begin{tabular}{cccc}
\hline Local de & \multicolumn{3}{c}{} \\
Amostragem & Potencial Matrico (MPa) \\
& $-0,003$ & $-0,01$ & $-0,1$ \\
\hline CN & $100,00 \mathrm{~A}$ & $90,22 \mathrm{~A}$ & $96,36 \mathrm{~A}$ \\
RA & $94,57 \mathrm{~A}$ & $85,84 \mathrm{~A}$ & $28,08 \mathrm{~B}$ \\
RB & $35,95 \mathrm{~B}$ & $24,39 \mathrm{~B}$ & $14,15 \mathrm{~B}$
\end{tabular}

${ }^{\mathrm{a}}$ Médias seguidas pela mesma letra nas colunas não diferem estatisticamente entre si (DMS: $p<0.05$ ) 
Tabela 6. Valores médios de resistência do solo à penetração $(\bar{x})(\mathrm{MPa})$ para cada local de amostragem e potencial mátrico ${ }^{b}$

\begin{tabular}{cccc}
\hline \multicolumn{2}{c}{ Local de } & \multicolumn{3}{c}{} \\
Amostragem & \multicolumn{3}{c}{ Potencial Mátrico (MPa) } \\
& $-0,003$ & $-0,01$ & $-0,1$ \\
\hline $\mathrm{RB}$ & $2,44 \mathrm{~A}$ & $2,11 \mathrm{~A}$ & $4,09 \mathrm{~A}$ \\
$\mathrm{RA}$ & $1,11 \mathrm{~B}$ & $1,40 \mathrm{~B}$ & $2,45 \mathrm{~B}$ \\
$\mathrm{CN}$ & $0,67 \mathrm{~B}$ & $0,88 \mathrm{~B}$ & $0,90 \mathrm{C}$
\end{tabular}

${ }^{\mathrm{b}}$ Médias seguidas pela mesma letra nas colunas não diferem estatisticamente entre si (DMS: $p<0.05$ )

A mesma tendência estatística foi observada entre locais de amostragem para os parâmetros $\bar{x}$ e max. Em qualquer dos potenciais mátricos, os valores de $\bar{x}$ e max foram mais elevados no RB. Conforme esperado, o piquete RB apresentou as piores propriedades estruturais, o que também havia sido observado através da análise de outros parâmetros físicos do solo, como Ds (Tabela 1), valores de densidade crítica do solo e intervalo hídrico ótimo (Leão et al., 2004). Nos potenciais mátricos mais elevados (-0,003 MPa e -0,01 MPa) o teste da DMS para os parâmetros $\bar{x}$, max e PLP $2 \mathrm{MPa}$ identificou a mesma tendência estatística (Tabelas 5 a 7). As propriedades de RP foram melhores e não estatisticamente diferentes para os locais de amostragem CN e RA. Por outro lado, mesmo com o solo úmido, o piquete RB apresentou má qualidade estrutural quando analisada por qualquer dos parâmetros de RP (Tabelas 5 a 7).

Com o solo relativamente seco, no potencial de $-0,1 \mathrm{MPa}$, a sensibilidade do teste DMS foi maior para os parâmetros $\bar{x}$ e $\max$ (Tabelas 6 e 7). Neste potencial $(-0,1 \mathrm{MPa})$ o teste DMS para os parâmetros $\bar{x}$ e max identificou os três locais de amostragem como estatisticamente diferentes, sendo que os valores de $\bar{x}$ e $\max$ decresceram na ordem RB $>\mathrm{RA}>\mathrm{CN}$. As características de RP em um solo são influenciadas principalmente pela densidade do solo e conteúdo de água e pelas interações entre estes dois fatores (Sojka et al., 2001). Entretanto, como se pode observar em representações gráficas tridimensionais 
da RP em função de densidade do solo e conteúdo de água (Imhoff et al., 2000a; Sojka et al., 2001) a influência da densidade do solo sobre a RP aumenta à medida que o conteúdo de água decresce. $\mathrm{O}$ decréscimo na $\mathrm{RP}$ com o aumento da $\theta$ é devido à redução na coesão e no ângulo de fricção interna à medida que o conteúdo de água aumenta (Camp \& Gill, 1969). O aumento na RP com a Ds é atribuído ao efeito da compactação na matriz do solo, e ao aumento na fricção entre as partículas de solo à medida que as partículas se aproximam no processo de compactação do solo (Vepraskas, 1984; Sojka et al., 2001). Neste estudo, os parâmetros estatísticos $\bar{x}$ e max foram mais sensíveis em detectar estas relações que qualquer outro parâmetro obtido a partir dos perfis de RP.

Tabela 7. Valores máximos de resistência do solo à penetração (max) $(\mathrm{MPa})$ para cada local de amostragem e potencial mátrico ${ }^{c}$

\begin{tabular}{cccc}
\hline Local de & & & \\
Amostragem & \multicolumn{3}{c}{ Potencial Mátrico (MPa) } \\
& $-0,003$ & $-0,01$ & $-0,1$ \\
\hline RB & $3,51 \mathrm{~A}$ & $3,04 \mathrm{~A}$ & $5,12 \mathrm{~A}$ \\
$\mathrm{RA}$ & $1,64 \mathrm{~B}$ & $2,15 \mathrm{~B}$ & $3,79 \mathrm{~B}$ \\
$\mathrm{CN}$ & $1,03 \mathrm{~B}$ & $1,46 \mathrm{~B}$ & $1,48 \mathrm{C}$
\end{tabular}

${ }^{\mathrm{c}}$ Médias seguidas pela mesma letra nas colunas não diferem estatisticamente entre si (DMS: $p<0.05$ )

\subsection{Conclusões}

Os resultados da razão $F$, valores de $p>F$ e teste de DMS confirmam a hipótese de que a média é o parâmetro com melhores propriedades estatísticas como critério para avaliar alterações na resistência à penetração do solo em resposta ao uso e manejo quando comparada com os parâmetros estatísticos: mediana, máximo, $m, n$, e percentagem linear de penetrabilidade no valor crítico de $2 \mathrm{MPa}\left(\mathrm{PLP}_{2 \mathrm{MPa}}\right)$. A principal conclusão deste estudo é que a média, indicador de RP utilizado tradicionalmente, é adequada para avaliar alterações na RP em consequência do uso e manejo do solo. 
Entretanto, a média discrimina melhor valores de RP obtidos com o solo mais seco (baixos potenciais mátricos) do que com o solo úmido. Um novo parâmetro $\mathrm{PLP}_{2 \mathrm{MPa}} \mathrm{e}$ também proposto, mas sua sensibilidade à mudanças na RP deve ainda ser objeto de estudos futuros. 


\section{CONCLUSÕES GERAIS}

O algoritmo simplificado, desenvolvido em Excel ${ }^{\circledR}$, apresentado no terceiro capítulo é uma alternativa na redução do tempo para realização das análises estatísticas e confecção dos gráficos utilizados na quantificação e avaliação do intervalo hídrico ótimo como um índice da qualidade física do solo. Apesar da simplicidade dos procedimentos e técnicas numéricas de otimização utilizadas, o procedimento de regressão não-linear produziu resultados confiáveis quando comparados àqueles encontrados em literatura.

$\mathrm{O}$ algoritmo $\mathrm{SAS}^{\circledR}$, apresentado no quarto capítulo mostrou ser uma ferramenta estatística confiável e eficiente para a quantificação do intervalo hídrico ótimo dos solos. É uma alternativa que reduz o tempo para as análises estatísticas e procedimentos de confecção de gráficos utilizados na quantificação e avaliação do intervalo hídrico ótimo como um índice da qualidade física do solo. Outra vantagem é que o algoritmo pode ser modificado ou adaptado para outros softwares de acordo com o conhecimento e/ou condições experimentais do usuário.

No que se refere à avaliação da curva de compressão do solo, o método proposto neste trabalho foi capaz de estimar a pressão de pré-consolidação do solo de forma rápida e quantitativamente precisa com relação a um método publicado em literatura, confirmando a hipótese testada. Desta forma, ele é útil na redução do tempo de obtenção de dados em estudos da compressibilidade dos solos.

Finalmente, quanto à avaliação de parâmetros de resistência do solo à penetração, os resultados da razão $F$, valores de $p>F$ e teste de DMS confirmam a hipótese de que a média é o parâmetro com melhores propriedades estatísticas como critério para avaliar alterações na resistência à penetração do solo em resposta ao uso e manejo quando 
comparada com os parâmetros estatísticos: mediana, máximo, $m, n$, e percentagem linear de penetrabilidade no valor crítico de $2 \mathrm{MPa}\left(\mathrm{PLP}_{2 \mathrm{MPa}}\right)$.

Os códigos $\mathrm{SAS}^{\circledR}$ para o intervalo hídrico ótimo e pressão de pré-consolidação, a planilha excel para o intervalo hídrico ótimo e o arquivo SKP.dat estão disponíveis através de contato com o autor: trpleao@hotmail.com. 
ANEXOS 


\section{Anexo A - Programa SAS para determinação do intervalo hídrico ótimo do solo}

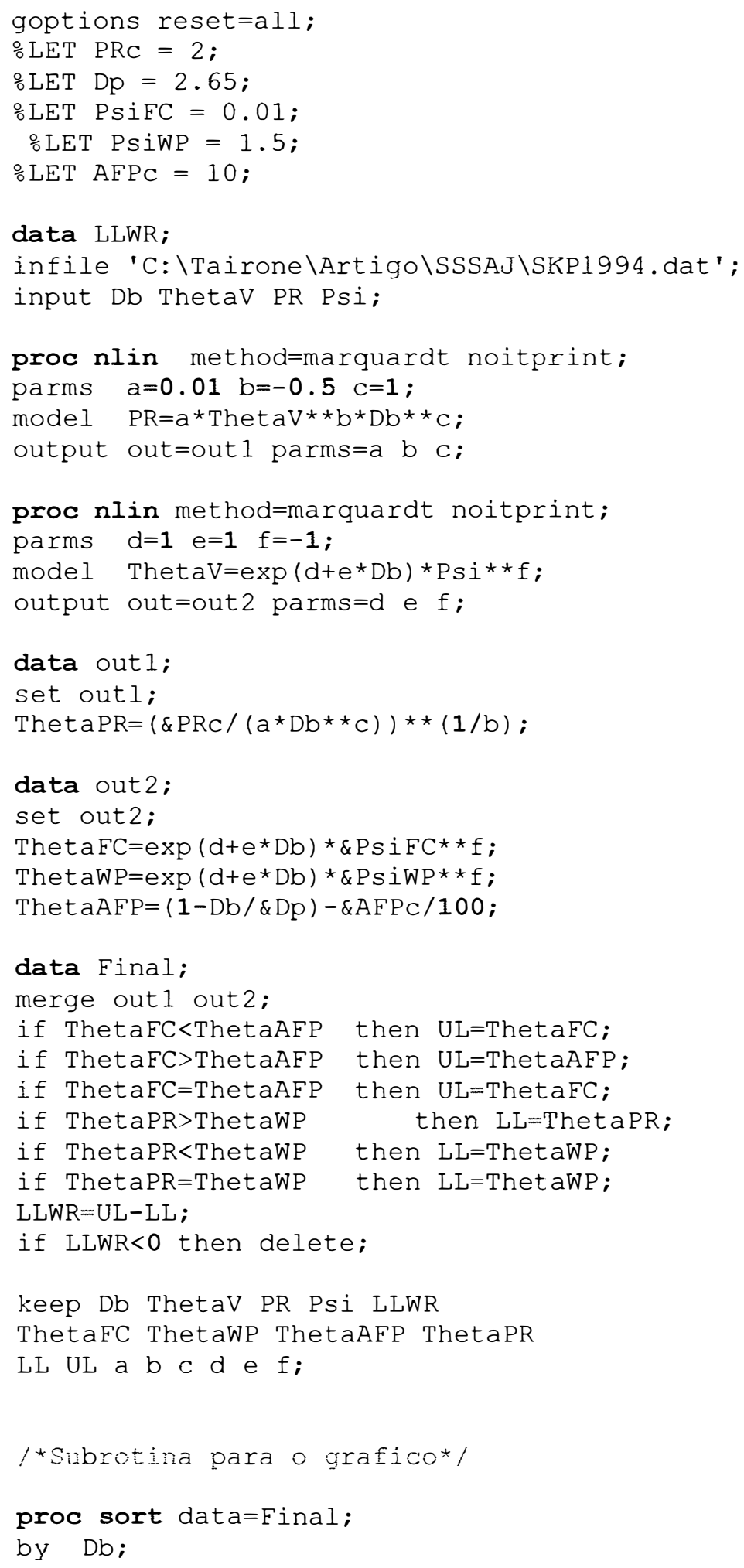




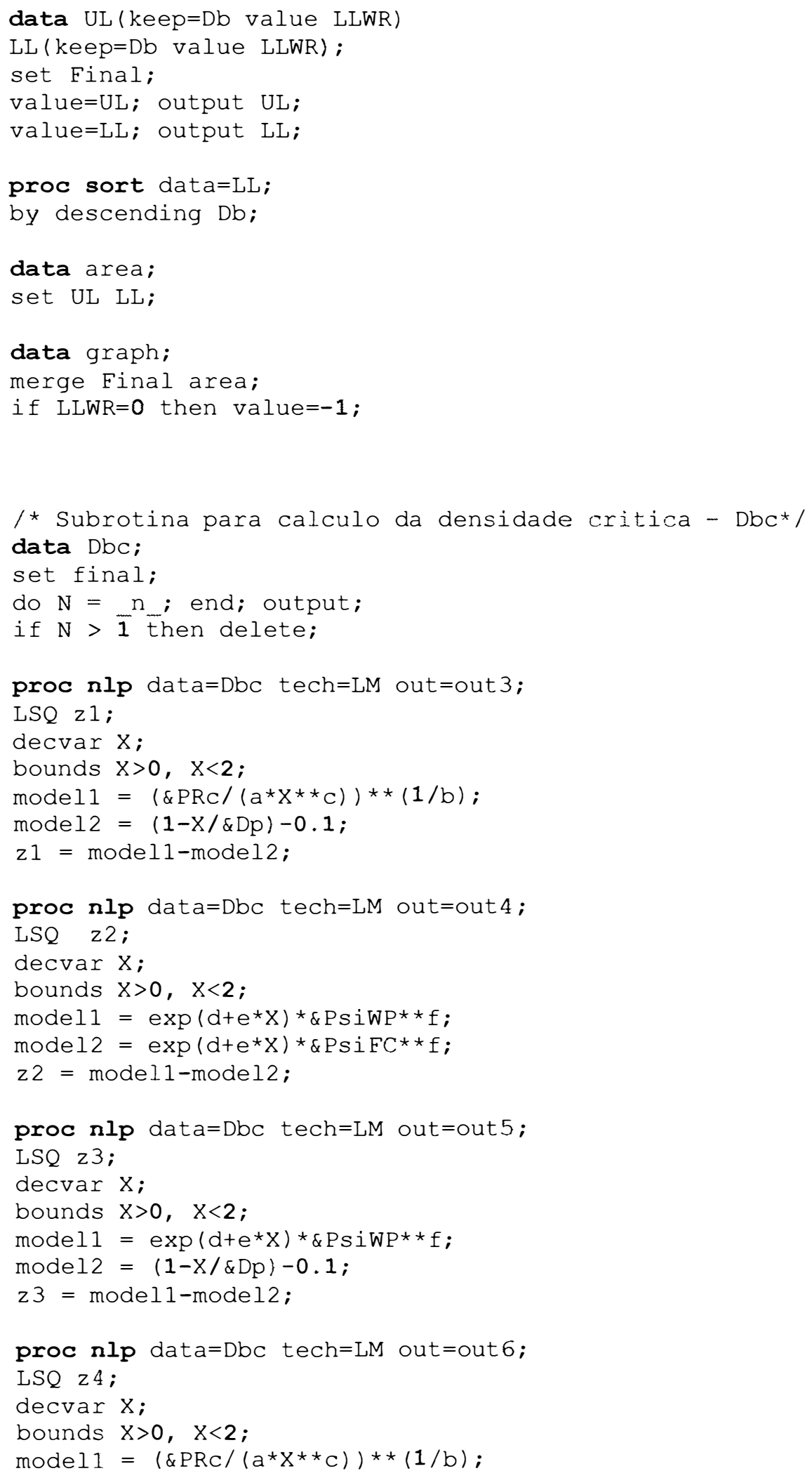




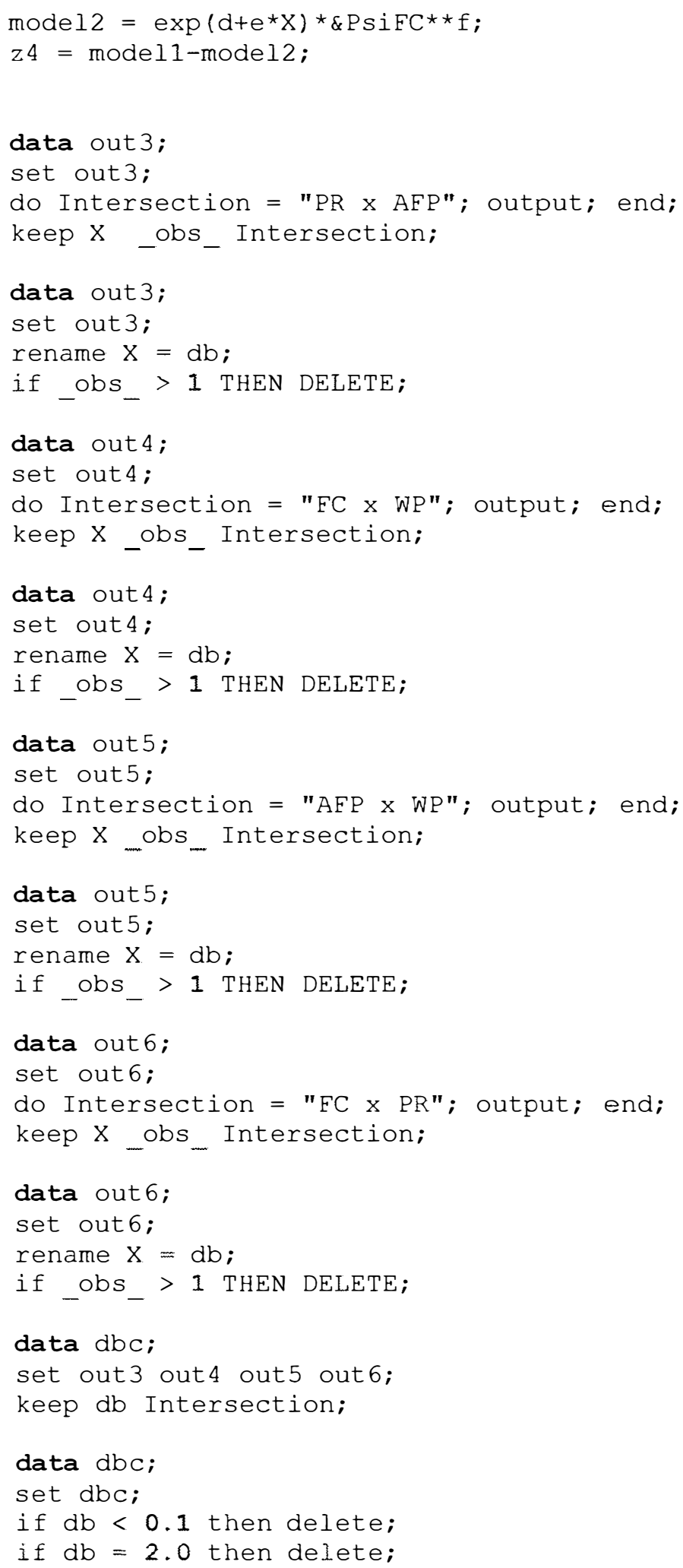




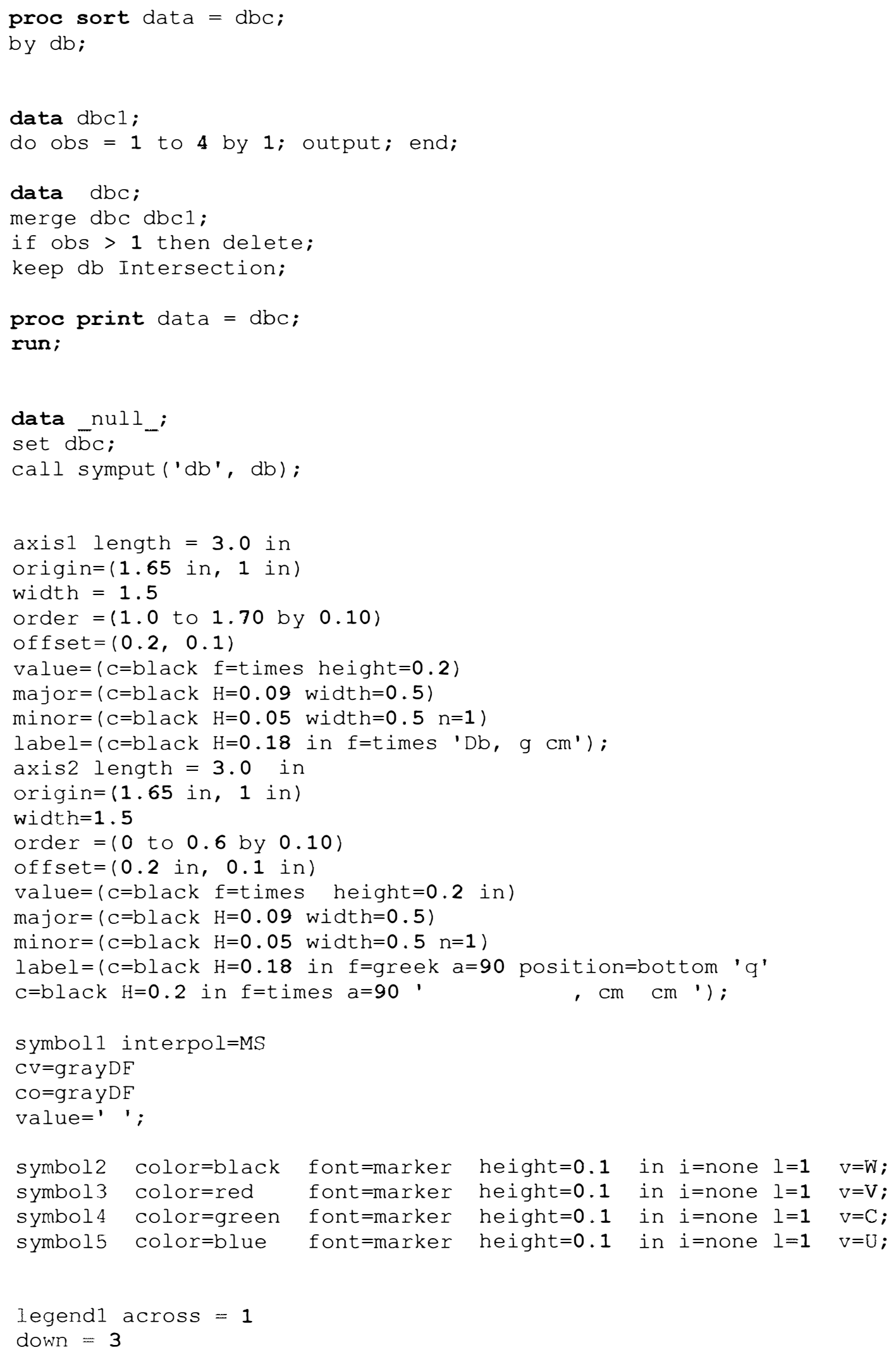




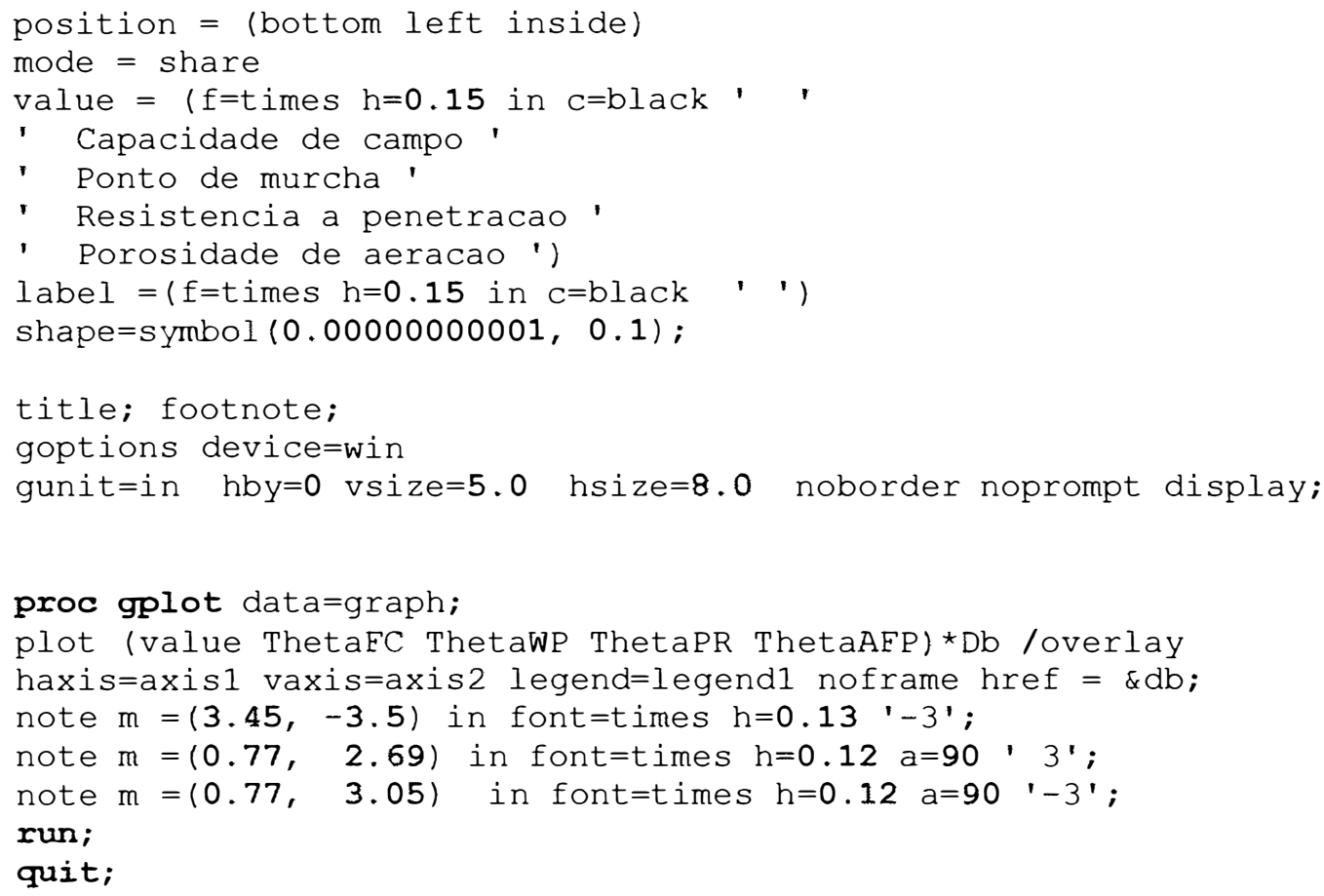




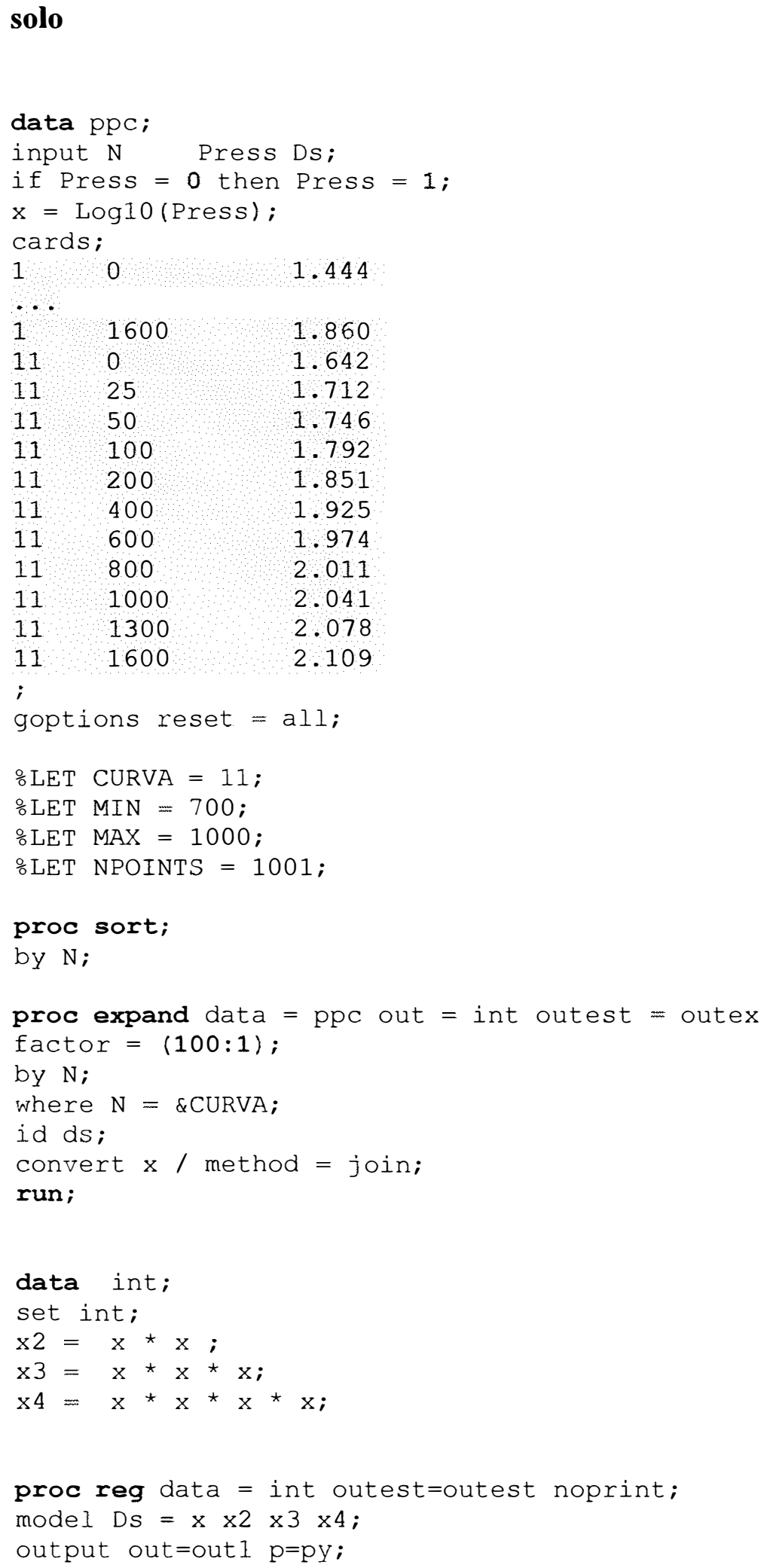




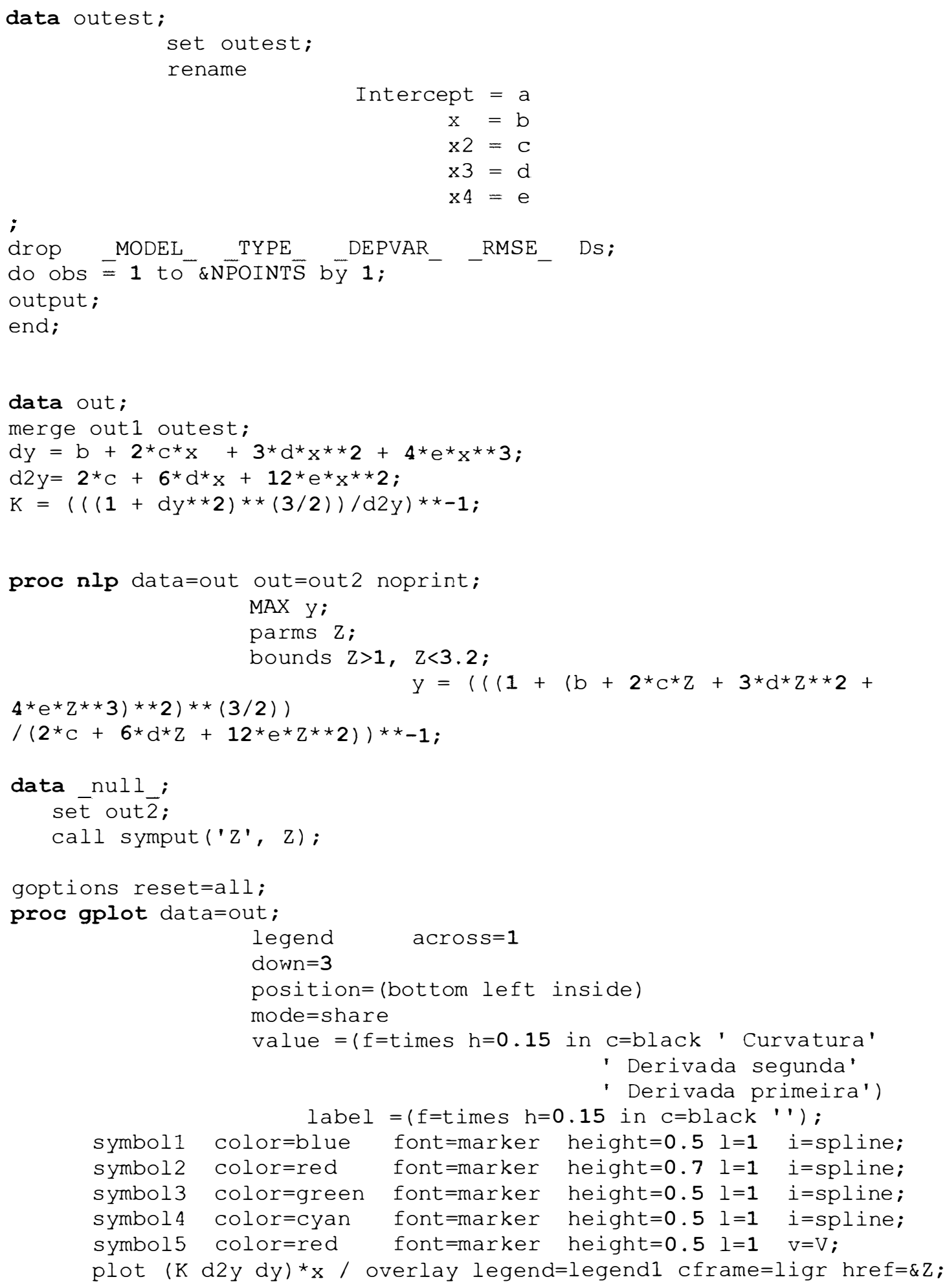

data out; 


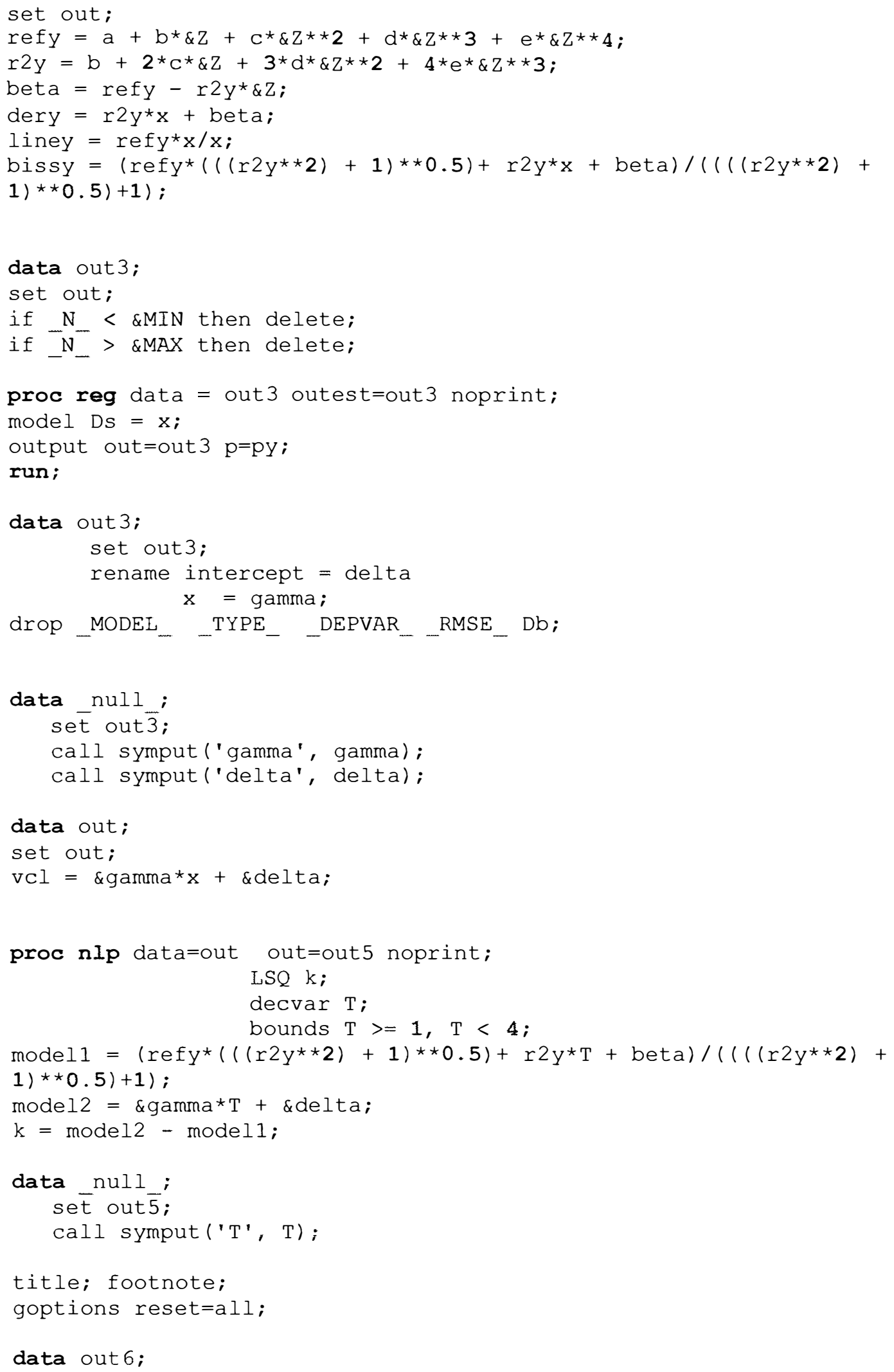




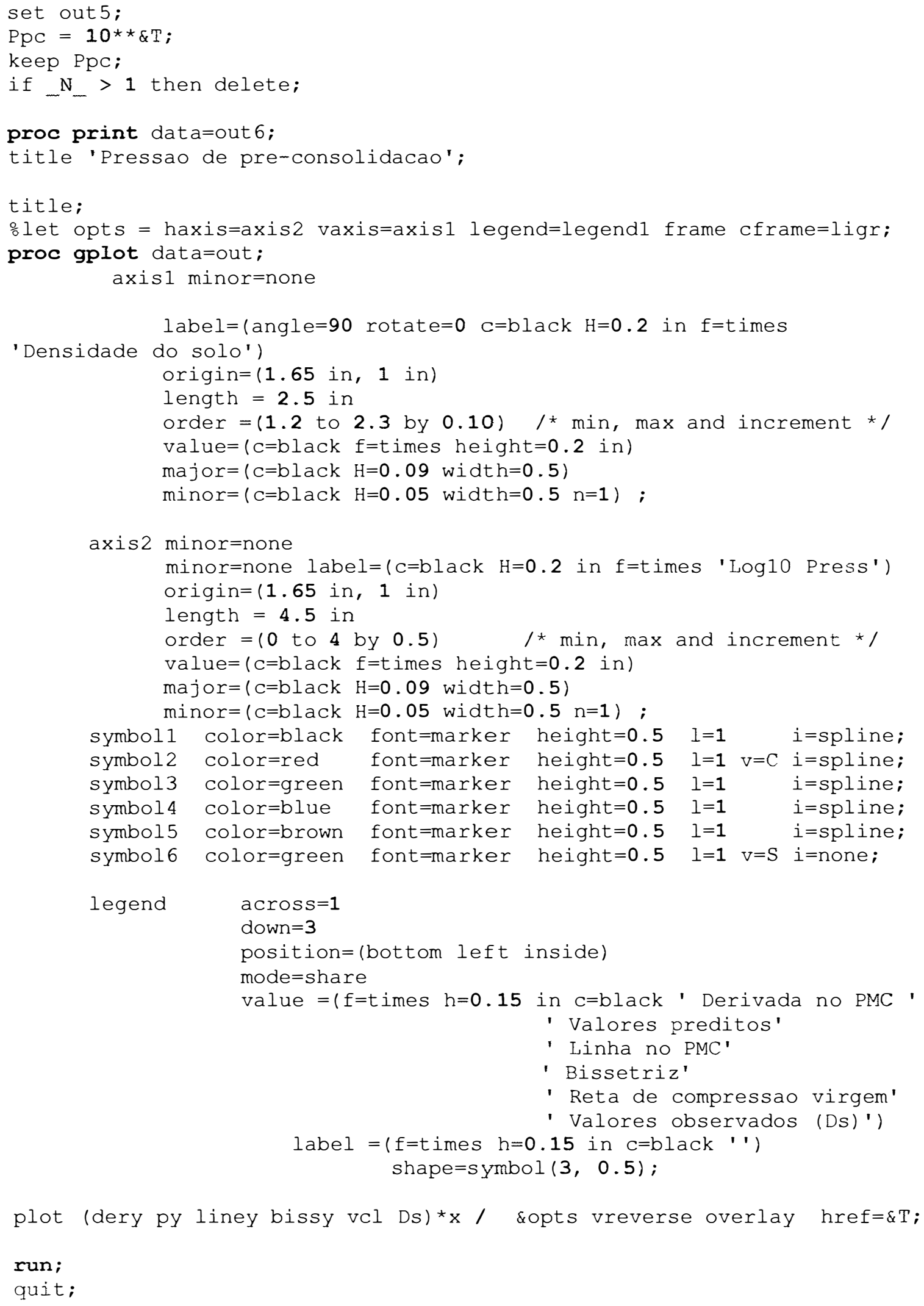




\section{REFERÊNCIAS BIBLIOGRÁFICAS}

ANDREWS, S.S.; FLORA, C.B.; MITCHELL, D.L.; KARLEN, D.L. Grower's perception and acceptance of soil quality indices. Geoderma, v.114, p.187-213, 2003.

ARVIDSSON, J.; KELLER, T. Soil precompression stress. I. A survey of Swedish arable soils. Soil and Tillage Research, v.77, p.85-95, 2004.

ASSOULINE, S. Modeling soil compaction under uniaxial compression. Soil Science Society of America Journal, v.66, p.1784-1787, 2002.

ASSOULINE, S.; TAVARES-FILHO, J.; TESSIER, D. Effect of compaction on soil physical and hydraulic properties: experimental results and modeling. Soil Science Society of America Journal, v.61, p.390-398, 1997.

AYRES, P.D.; PERUMPRAL, J.V. Moisture and density effect on cone index. Transactions of the ASAE, v.25, n.5, p.1169-1172, 1982.

BAILEY, A.C.; VANDENBERG, G.E. Yielding by compaction and shear in unsaturated soils. Transactions of the ASAE, v.11, p.307-311, 317, 1968.

BAILEY, A.C.; JOHNSON, C.E.; SCHAFER, R.L. A model for agricultural soil compaction. Journal of Agricultural Research, v.33, p.257-262, 1986.

BATES, D.M.; WATTS, D.G. Nonlinear regression analysis and its applications. New York: John Wiley, 1988. 365p.

BETZ, C.L.; ALLMARAS, R.R.; COPELAND, S.M.; RANDALL, G.W. Least limiting water range: traffic and long-term tillage influences in a Webster soil. Soil Science Society of America Journal, v.62, p.1384-1393, 1998.

BRADFORD, J.M. The penetration resistance in a soil with well-defined structural units. Soil Science Society of America Journal, v.44, p.601-606, 1980. 
BRADFORD, J.M. Penetrability. In: KLUTE, A. (Ed.). Methods of soil analysis: physical and mineralogical methods. 2.ed. Madison: American Society of Agronomy, 1986. cap.11, p.463-478.

BRADY, N. C.; WEIL, R. R. The nature and properties of soils. 12.ed. New Jersey: Prentice Hall, 1999. 881p.

BUSSCHER, W.J. Adjustment of flat-tipped penetrometer resistance data to a common water content. Transactions of the ASAE, v.33, p.519-524, 1990.

BUSSCHER, W.J.; SOJKA, R.E. Enhancement of subsoiling effect on soil strength by conservation tillage. Transactions of the ASAE, v.30 p.888-892, 1987.

CAMP, C.R.; GILL, W.R. The effect of drying on soil strength parameters. Soil Science Society of America Proceedings, v.33, p.641-644. 1969.

CARANACHE, A. PENETR - a generalized semi-empirical model estimating soil resistance to penetration. Soil and Tillage Research, v.19, p.51-70, 1987.

CASAGRANDE, A. Determination of the preconsolidation load and its practical significance. In: INTERNATIONAL CONFERENCE ON SOIL MECHANICS AND FOUNDATION ENGINEERING, Cambridge, Procedings. Cambridge: Harvard University, 1936. v.3, p.60-64.

CHAMBERS, J.M. Fitting nonlinear models: numerical techniques. Biometrika, v.60, p.1-13. 1973.

CHANCELLOR, W.J. Soil physical properties. In: UPADHYAYA, S.K.; CHANCELLOR, W.J.; PERUMPRAL， J.V.; SCHAFER， R.L.; GILL，W.R.; VANDENBERG, G.E. (Ed.). Advances in soil dynamics. Michigan: ASAE, 1994. cap.2, p.21-245.

CHILDS, E.C. An introduction to the physical basis of soil water phenomena. London: John Wiley, 1969. 493p.

COOK, F.J.; KNIGHT, J.H. Oxygen transport to plant roots: modeling for physical understanding of soil aeration. Soil Science Society of America Journal, v.67, p.20-31, 2003. 
CORREA, J.C.; REICHARDT, K. Efeito do tempo de uso das pastagens sobre as propriedades de um Latossolo Amarelo da Amazônia Central. Pesquisa Agropecuária Brasileira, v.30, n.1, p.107-114, 1995.

CULLEY, J.L.B.; LARSON, W.E. Susceptibility to compression of a clay loam Haplaquoll. Soil Science Society of America Journal, v.51, p.562-567, 1987.

DEXTER, A.R. Advances in characterization of soil structure. Soil and Tillage Research, v.11, p.199-238, 1988.

DEXTER, A.R. Soil physical quality. Part I. Theory, effects of soil texture, density, and organic matter, and effects on root growth. Geoderma, v.120, p.201-214, 2004.

DORAN, J.W. Soil health and global sustainability: translating science into practice. Agriculture, Ecosystems and Environment, v.88, p.119-127, 2002.

DRURY, C.F.; ZHANG, T.Q.; KAY, B.D. The non-limiting and least limiting water ranges for soil nitrogen mineralization. Soil Science Society of America Journal, v.27, p. 1388-1404, 2003.

EARL, R. Prediction of trafficability and workability from soil moisture deficit. Soil and Tillage Research, v.40, p.155-168, 1997.

EMPRESA BRASILEIRA DE PESQUISA AGROPECUÁRIA. Centro Nacional de Pesquisa de Solos. Sistema Brasileiro de Classificação de Solos. Brasília: Embrapa Produção de Informação, 1999. 412p.

ETANA, A.; COMIA, R.A.; HÅKANSSON, I. Effects of uniaxial stress on the physical properties of four Swedish soils. Soil and Tillage Research, v.44, p.13-21, 1997.

FINNEY, D.J. Probit analysis: a statistical treatment of the sigmoid response curve. Cambridge: University Press, 1952. 318p.

FRITTON, D.D. An improved empirical equation for uniaxial soil compression for a wide range of applied stresses. Soil Science Society of America Journal, v.65, p.678-684, 2001. 
GABRIELS, D.; HORN, R.; VILLAGRA, M.M.; HARTMAN, R. Assessment, prevention, and rehabilitation of soil structure caused by soil surface sealing, crusting, and compaction. In: LAL, R.; BLUM, W.H.; VALENTINE, C.; STEWART, B.A. (Ed.). Methods for assessment of soil degradation. Boca Raton: CRC Press, 1998. cap.7, p.129-166.

GALLANT, R.A. Nonlinear statistical models. New York: John Wiley, 1987. 610p.

GIOVANNI, J.R.; BONJORNO, J.R. Matemática, 3: geometria analítica, números complexos, polinômios, limites e derivadas, noções de estatística: $2^{\circ}$ grau. São Paulo: FTD, 1992. 352p.

GLANTZ, S.A.; SLINKER, B.K. Primer of applied regression and analysis of variance. New York: McGraw-Hill, 1990. 770p.

GODWIN, R.J.; SPOOR, G. Soil factors influencing work days. Agricultural Engineer, v.32, p.87-90, 1977.

GRABLE, A.R.; SIEMER, E.G. Effects of bulk density, aggregate size, and soil water suction on oxygen diffusion, redox potential and elongation of corn roots. Soil Science Society of America Journal, v. 32, n.2, p.180-186, 1968.

GRAVETTER, F.J.; WALLNAU, L.B. Essential statistics for the behavioral sciences. 2.ed. Minneapolis: West Publishing Company, 1995. 431p.

GROENEVELT, P.H.; KAY, B.D.; GRANT, C.D. Physical assessment of a soil with respect to rooting potential. Geoderma, v.34, p.101-114, 1984.

HAISE, H.R.; HAAS, H.J.; JENSEN, L.R. Soil moisture studies of some Great Plains soils. II. Field capacity as related to 1/3-atmosphere percentage, and minimum point as related to 15- and 26-atmosphere percentage. Soil Science Society of America Proceedings, v.19, p.20-25, 1955.

HAKANSSON, I.; LIPIEC, J. A review of the usefulness of relative bulk density values in studies of soil structure and compaction. Soil and Tillage Research, v.53, p.71$85,2000$.

HÅKANSSON, I.; VOORHEES, W.B. Soil compaction. In: LAL, R.; BLUM, W.H.; VALENTINE, C.; STEWART, B.A. (Ed.). Methods for assessment of soil degradation. Boca Raton: CRC Press, 1998. cap.8, p.167-180. 
HERRICK, J.E.; JONES, T.L. A dynamic cone penetrometer for measuring soil penetration resistance. Soil Science Society of America Journal, v.66, p.13201324, 2002.

HSU, J.C. Multiple comparisons: theory and methods. London: Chapman \& Hall, 1996. $277 \mathrm{p}$.

IMHOFF, S. Indicadores de qualidade estrutural e trafegabilidade de latossolos e argissolos vermelhos. Piracicaba, 2002. 94p. Tese (Doutorado) - Escola Superior de Agricultura "Luiz de Queiroz", Universidade de São Paulo.

IMHOFF, S.; SILVA, A.P.; FALLOW, D. Susceptibility to compaction, load support capacity, and soil compressibility of Hapludox. Soil Society of America Journal, v.68, p.17-24, 2004.

IMHOFF, S.; SILVA, A.P.; TORMENA, C.A. Aplicações da curva de resistência no controle da qualidade física de um solo sob pastagem. Pesquisa Agropecuária Brasileira, v.35, n.7, p.1493-1500, 2000a.

IMHOFF, S.; SILVA, A.P.; TORMENA, C.A. Spatial heterogeneity of soil properties in areas under elephant-grass short-duration grazing system. Plant and Soil, v.219, p.161-168, 2000b.

IMHOFF, S.; SILVA, A.P.; DIAS JUNIOR, M.S.; TORMENA, C.A. Quantificação das pressões críticas para o crescimento das plantas. Revista Brasileira de Ciência do Solo, v.25, p.11-18, 2001.

IWATA, S.; TABUCHI, T.; WARKENTIN, B.P. Soil-water interactions: mechanisms and applications. New York: Marcel Dekker, 1995. 440p.

JONES, C.A. Effects of soil texture on critical bulk density for root growth. Soil Science Society of America Journal, v.47, p.1208-1211， 1983.

KARLEN, D.L.; DITZLER, C.A.; ANDREWS, S.S. Soil quality: why and how? Geoderma, v.114, p.145-156, 2003.

KARLEN, D.L.; MAUSBACH, M.J.; DORAN, J.W.; CLINE, R.G.; HARRIS, R.F.; SCHUMAN, G.E. Soil quality: a concept, definition, and framework for evaluation. Soil Science Society of America Journal, v.61, p.4-10, 1997. 
KELLS, L.M. Calculus. 2.ed. New York: Prentice Hall, 1954. 508p.

KLUTE, A. Water retention: laboratory methods. In: KLUTE, A. (Ed.). Methods of soil analysis: physical and mineralogical methods. 2.ed. Madison: American Society of Agronomy, 1986. cap.26, p.635-660.

LAL, R. Physical management of soils of the tropics: priorities for the $21^{\text {st }}$ century. Soil Science, v.135, n.3, p.191-207. 2000.

LARSON, W.E.; GUPTA, S.C.; USECHE, R.A. Compression of agricultural soils from eight soil orders. Soil Science Society of America Journal, v.44, p.450-457, 1980.

LEÃO, T.P. Intervalo hídrico ótimo em diferentes sistemas de pastejo e manejo da pastagem. Piracicaba, 2002. 58p. Dissertação (Mestrado) - Escola Superior de Agricultura "Luiz de Queiroz", Universidade de São Paulo.

LEÃO, T.P.; SILVA, A.P. A Simplified Excel ${ }^{\circledR}$ Algorithm For Estimating the Least Limiting Water Range of Soils Using Nonlinear Regression. Scientia Agricola, v.61, p.649-654, 2004.

LEÃO, T.P.; SILVA, A.P.; MACEDO, M.C.M., IMHOFF, S.; EUCLIDES, V.P.B. Intervalo hídrico ótimo na avaliação de sistemas de pastejo contínuo e rotacionado. Revista Brasileira de Ciencia do Solo. v.28, p.1-8. 2004.

LETEY, J. Relationship between soil physical properties and crop production. Advances in Soil Science, v.1, p.277-294, 1985.

MATERECHERA, S.A.; DEXTER, A.R.; ALSTON, A.M. Penetration of very strong soils by seeding of different plant species. Plant and Soil, v.135 p. 31-41. 1991.

MATHSOFT INC. Mathcad professional reference manual. Cambridge, 2000.

McKENZIE, D.C.; McBRATNEY, A.B. Cotton root growth in a compacted Vertisol (Grey Vertosol): I. Predictions using strength measurements and limiting water ranges. Australian Journal of Soil Research, v.39, p.1157-1 168, 2001.

MCNABB, D.H.; BOERSMA, L. Evaluation of the relationship between compressibility and shear strength of andisols. Soil Science Society of America Journal, v.57, p.923-929, 1993. 
MCNABB, D.H.; BOERSMA, L. Nonlinear model for compressibility of partly saturated soils. Soil Science Society of America Journal, v.60, p.333-341, 1996.

MOSADDEGHI, M.R.; HEMMAT, A.; HAJABBASI, M.A.; ALEXANDROU, A. Precompression stress and its relation with the physical and mechanical properties of a structurally unstable soil in central Iran. Soil and Tillage Research. vol.70, p.5364, 2003.

NEARING, M.A.; WEST, L.T.; BRADFORD, J.M. Consolidation of an unsaturated illitic clay soil. Soil Science Society of America Journal, v.52, p.929-934, 1988.

NELSON, W.L.; MEHLICH, A.; WINTERS, E. The development evaluation and use of soil tests for phosphorus availability. In: PIERRE, W.H., NORMAN, A.G. (Ed.). Soil fertilizer phosphorus in crop nutrition. New York: Academic Press, 1953. p.153188.

NETER, J.; WASSERMAN, W.; KUTNER, M.H. Applied linear regression models. Illinois: Richard D. Irwin, 1983. 547p.

NORTCLIFF, S. Standardization of soil quality attributes. Agriculture, Ecosystems and Environment, v.88, p.161-168, 2002.

PERFECT, E.; GROENEVELT, P.H.; KAY, B.D.; GRANT, C.D. Spatial variability of soil penetrometer measurements at the mesoscopic scale. Soil and Tillage Research, v.16, p.257-271, 1990.

PERUMPRAL, J.V. Cone penetrometer applications - A review. Transactions of the ASAE, v.30, n.4, p.939-944, 1987.

PHENE, C.J.; BEALE, W. High-frequency irrigation for water nutrient management in humid regions. Soil Science Society of America Journal, v.40, p.430-436, 1976.

PINTO, C.S. Curso básico de mecânica dos solos. São Paulo: Oficina de textos, 2000. $247 p$.

PRESS, W.H.; TEULKOLSKY, S.A.; VETTERLING, W.T.; FLANNERY, B.P. Numerical recipes in $\mathbf{C}$ : the art of scientific computation. 2.ed. Cambridge: Cambridge University Press, 1994. 964p.

RATKOWSKY, D.A. Handbook of nonlinear regression models. New York: Marcel Dekker, 1990. 241p. 
REICHARDT, K. Dinâmica da matéria e da energia em ecossistemas. 2.ed. Piracicaba: ESALQ, Departamento de Física e Meteorologia, 1996. 505p.

REYNOLDS, W.D.; BOWMAN, B.T.; DRURY, C.F.; TAN, C.S.; LU, X. Indicators of good soil physical quality: density and storage parameters. Geoderma, v.110, p.131-146, 2002.

RICHARDS, L.A.; WEAVER, L.R. Fifteen atmosphere percentage as related to the permanent wilting point. Soil Science, v.56, p.331-339, 1944.

ROSS, P.J.; WILLIAMS, J.; BRISTOW, K.L. Equations for extending water-retention curves to dryness. Soil Science Society of America Journal, v.55, p.923-927, 1991.

SAS INSTITUTE. SAS/GRAPH software: reference, version 6. Cary, 1990.

SAS INSTITUTE. SAS/OR user's guide: mathematical programming, version 8. Cary, 1999a.

SAS INSTITUTE. SAS/STAT user's guide: version 8. Cary, $1999 \mathrm{~b}$.

SAS INSTITUTE. SAS/ETS user's guide, version 8. Cary, 2000a.

SAS INSTITUTE. SAS/GRAPH software: reference, version 8. Cary, 2000b

SCHOENHOLTZ, S.H.; VAN MIEGROET, H.; BURGER, J.A. A review of chemical and physical properties as indicators of forest soil quality: challenges and opportunities. Forest Ecology and Management, v.138, p.335-356, 2000.

SEBER, G.A.F.; WILD, C.J. Nonlinear regression. New York: John Wiley, 1989. 768p.

SHARMA, P.K.; BHUSHAN, L. Physical characterization of a soil amended with organic residues in a rice-wheat cropping system using a single value soil physical index. Soil and Tillage Research, v.60, p.143-152, 2001.

SILVA, A.P.; KAY, B.D. Estimating the least limiting water range of soils from properties and management. Soil Science Society of America Journal, v.61, p.877883, 1997.

SILVA, A.P.; KAY, B.D.; PERFECT, E. Characterization of the least limiting water range of soils. Soil Science Society of America Journal, v.58, p.1775-1781, 1994. 
SILVA, A.P.; KAY, B.D.; PERFECT, E. Management versus inherent soil properties effects on bulk density and relative compaction. Soil and Tillage Research, v. 44, p.81-93. 1997.

SILVA, A.P.; IMHOFF, S.C.; TORMENA, C.A.; LEÃO, T.P. Avaliação da compactação de solos florestais. In: GONÇALVES, J.L.M.; STAPE, J.L. (Ed.). Conservação e cultivo de solos para plantações florestais. Piracicaba: IPEF, 2002a. cap.10, p.351-372.

SILVA, A.P.; TORMENA, C.A.; IMHOFF, S. Intervalo hídrico ótimo. In: MORAES, M.H.; MÜLLER, M.M.L.; FOLONI, J.S.S. Qualidade física do solo: métodos de estudo-sistemas de preparo e manejo do solo. Jaboticabal: FUNEP, 2002b. p.1-18.

SIMUNEK, J.; HOPMANS, J.W. Parameter optimization and nonlinear fitting. In: DANE, J.H.; TOPP, G.C.(Ed.). Methods of soil analysis. Madison: SSSA, 2002. pt.1: Physical methods, cap. 17, p. 139-157.

SINGH, B.P.; SAINJU, U.M. Soil physical and morphological properties and root growth. Hortscience, v.33, p.966-971, 1998.

SOANE, B.D.; VAN OUWERKERK, C. Soil compaction problem in world agriculture. In: SOANE, B.D.; VAN OUWERKERK, C. (Ed.). Soil compaction in crop production. Amsterdan: Elsevier, 1994. p.1-21.

SOJKA, R.E.; BUSSCHER, W.J.; LEHRSCH, G.A. In situ strength, bulk density, and water content of a durinodic xeric haplocalcid soil. Soil and Tillage Research, v.166, n.8, p.520-529. 2001.

SOUZA, G.S. Introdução aos modelos de regressão linear e não-linear. Brasília: Embrapa Produção de Informação, 1998. 489p.

SPAROVEK, G.; DE MARIA, I.C. Multiperspective analysis of erosion tolerance. Scientia Agricola, v.60, p.409-416, 2003.

TAYLOR, D.W. Fundamentals of soil mechanics. New York: John Wiley, 1958. 700p. TAYLOR, H.M.; ROBERSON, G.M.; PARKER, J.J. Soil strength-root penetration relations to coarse textured materials. Soil Science, v.102, p.18-22, 1966.

TERZAGHI, K. Theoretical soil mechanics. New York: John Wiley, 1959. 510p. 
TERZAGHI, K.; PECK, R.B. Mecánica de suelos en la ingeniería practica. Buenos Aires: Ateneo, 1955.659p.

TIETJEN, G.L. A topical dictionary of statistics. New York : Chapman and Hall, 1986. $171 \mathrm{p}$.

TOPP, G.C.; REYNOLDS, W.D.; COOK, F.J.; KIRBY, J.M.; CARTER, M.R. Physical attributes of soil quality. In: GREGORICH, E.G.; CARTER, M.R. (Ed.). Soil quality for crop production and ecosystem health. Amsterdan: Elsevier, 1997. cap.1, p.21-58.

TORMENA, C.A.; SILVA, A.P.; LIBARDI, P.L. Caracterização do intervalo hídrico ótimo de um Latossolo Roxo sob plantio direto. Revista Brasileira de Ciência do Solo, v.22, p.573-581, 1998.

TORMENA, C.A.; SILVA, A.P.; LIBARDI, P.L. Soil physical quality of a Brazilian Oxisol under two tillage systems using the least limiting water range approach. Soil and Tillage Research, v.52, p.223-232, 1999.

UNIVERSIDADE FEDERAL DE VIÇOSA. Compressibilidade (nota de aula versão preliminar). Viçosa: UFV, Departamento de Engenharia Civil, 2003. 53p.

VAN GENUCHTEN, M.Th. A closed form equation for predicting the hydraulic conductivity of unsaturated soils. Soil Science Society of America Journal, v.44, p.892-898, 1980.

VARGAS, M. Introdução a mecanica dos solos. São Paulo: EDUSP; McGraw-Hill do Brasil, 1977. 509p.

VAZ, C.M.P.; BASSOI, L.H.; HOPMANS, J.W. Contribution of water content and bulk density to field soil penetration resistance as measured by a combined cone penetrometer-TDR probe. Soil and Tillage Research, v.60, p.35-42, 2001.

VEPRASKAS, M.J. Cone index of loamy sands as influenced by pore size distribution and effective stress. Soil Science Society of America Journal, v.48, p.1220-1225. 1984.

VILLAMIL, M.B.; AMIOTTI, N.M.; PEINEMANN, N. Soil degradation related to overgrazing in the semi-arid southern caldenal of Argentina. Soil Science, v.166, n.7, p.441-452. 
WEBSTER, R. Statistics to support soil research and their presentation. European Journal of Soil Science, v.52, p.331-340. 2001.

WRAIT, J.M.; OR, D. Nonlinear parameter estimation using spreadsheet software. Journal of Natural Resources and Life Sciences Education, v.27, p.13-19, 1998. WU, L.; FENG, G.; LETEY, J.; FERGUSON, L.; MITCHELL, J.; McCULLOUGHSANDEN, B.; MARKEGARD, G. Soil management effects on the nonlimiting water range. Geoderma, v.114, p.401-414, 2003.

ZOU, C.; SANDS, R.; BUCHAN, G.; HUDSON, I. Least limiting water range: a potential indicator of physical quality of forest soils. Australian Journal of Soil Research, v.38, p.947-958, 2000. 